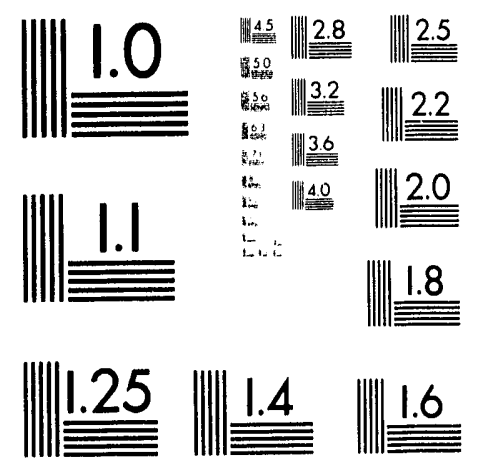



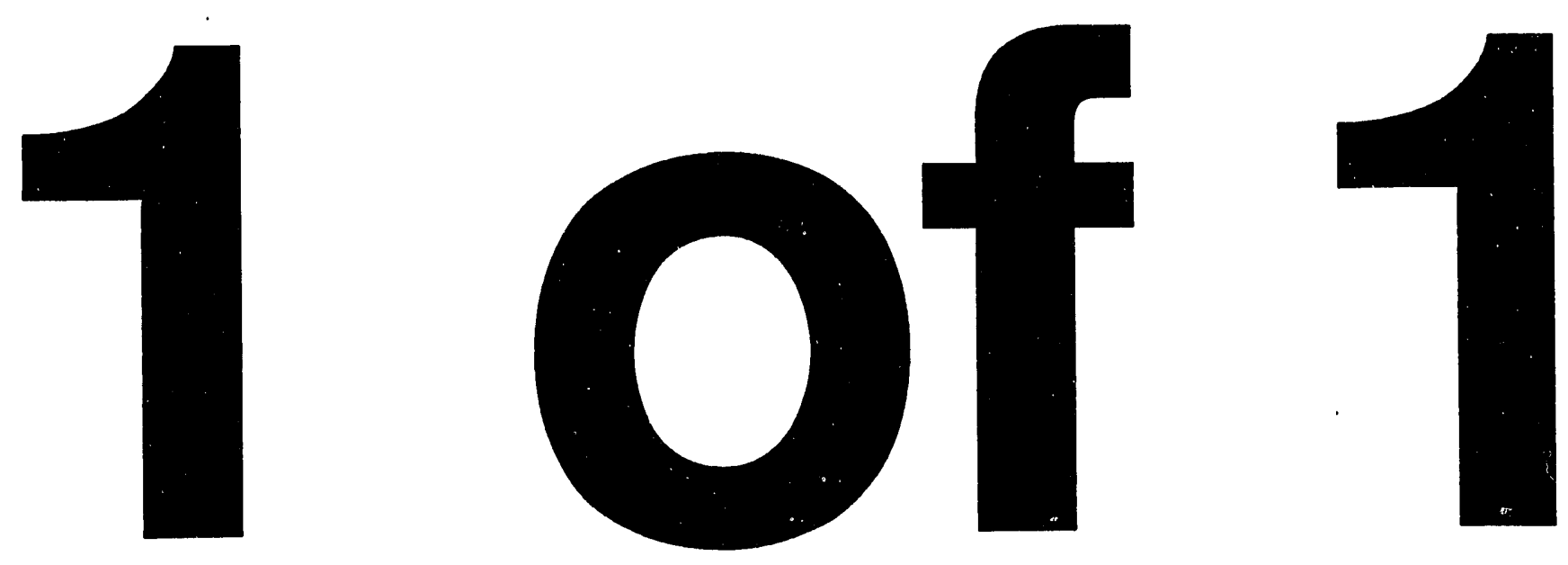
UCRL-ID-115135

\section{Test and Analysis of Canister-Frame Connections}

Ting-Yu Lo

Anthony M. Davito

August 31, 1993

This is an informal report intended primarily for internal or limited external distribution. The opinions and conclusions stated are those of the author and may or may not be those of the Laboratory.

Work performed under the auspices of the U.S. Department of Energy by the Lawrence Livermore National Laboratory under Contract W-7405-Eng-48. 


\section{ACKNOWLEDGEMENTS}

The authors wish to thank Jens Mahler, Hugh Watling, Alex Blake, Dave Trummer, and Tony Lee for their helpful comments. The authors also wish to thank the members of the pull-test team at EG\&G (Las Vegas Operations), especially Dennis Reid, Marc McDermott, and Bucky Claus for a smooth, fullscale pull test of the canister bolts.

This document was prepared as an account of work sponsored by an agency of the United States Government. Neither the United States Government nor the University of Califomia nor any of their employees, makes any warranty, express or implied, or assumes any legal liability or responsibility for the accuracy, completeness, or usefulness of any information, apparatus, product, or process disclosed, or represents that its use would not infringe privately owned rights. Reference herein to any specific commercial products, process, or service by trade name, trademark, manufacturer, or otherwise, does not necessarily constitute or imply its endorsement, recommendation, or favoring by the United States Government or the University of Califomia. The views and opinions of authors expressed herein do not necessarily state or reflect those of the United States Government or the University of Califomia, and shall not be used for advertising or product endorsement purposes.

This repon has been reproduced directly from the best available copy.

Available to DOE and DOE contractors from the Office of Scientific and Technical Information P.O. Box 62, Oak Ridge, TN 37831

Prices available from (615) 576-8401, FTS 626-8401

A vailable to the public from the National Technical Information Service

U.S. Department of Commerce 5285 Pon Royal Rd. Springfield, VA 22161 


\section{ABSTRALT}

A finite element analysis was performed for the structural connections of a downhole nuclear test emplacement assembly. The bolt loads as well as the stresses in the cable tray and end plates of the assembly were examined for a range of bolt preloads and applied external axial loads. The focus of this study was the effects of preload on the bolt load and the stresses in various parts of the assembly. The effects of bolt size and door strap were also examined. A full-scale pull test of the structural connections was performed. The results of the test validated not only the finite element analysis but also the computer code NIKE3D used in the analysis. 


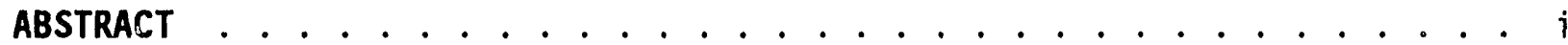

TABLE OF CONTENTS ....................... . . . . . . . .

LIST OF FIGURES . . . . . . . . . . . . . . . . . . . v v

LIST OF TABLES ........................ . . . . . . . . . . . .

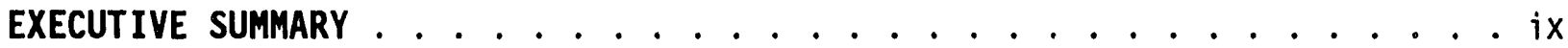

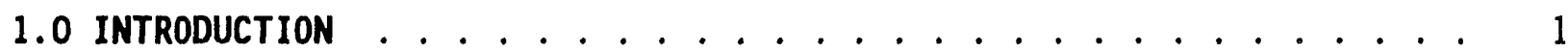

2.0 FINITE ElEMENT ANALYSIS MODELS . . . . . . . . . . . . . . . 4

3.1 Deformed Shape . . . . . . . . . . . . . . . . 13

3.2 Bolt Loads . . . . . . . . . . . . . . . . . . . . . . . . . . 14

3.3 Stresses in End plates and Cable Trays . . . . . . . . . . . . . 17

3.3.1 Definition of Stresses . . . . . . . . . . . . . . . . 17

3.3.2 Allowable Stresses . . . . . . . . . . . . . . . . . 20

3.3.3 Stresses in the End plates . . . . . . . . . . . . . . . 21

3.3.4 Stresses in Cable Trays .................. 22

3.3.5 Stresses in Welds. . . . . . . . . . . . . . . . . 26

4.0 FULL-SCALE PULL TEST OF CANISTER CONNECTIONS . . . . . . . . . . 60

5.0 SUMMARY AND CONCLUSIONS . . . . . . . . . . . . . . 71

6.0 REFERENCES . . . . . . . . . . . . . . . . . . 74

APPENDIX A Data Acquisition System - Full-Scale Pull Tests of
Canister Frame Connections . . . . . . . . . 75 


\section{LIST OF FIGURES}

Figure 1. A typical canister frame . . . . . . . . . . . . . . . 3

Figure 2. Assumed symmetry planes in the finite element analysis . . . 8

Figure 3a. Finite element analysis model - end plate . . . . . . . . . 9

Figure 3b. Finite element analysis model - cable tray . . . . . . . . 10

Figure 3c. Finite element analysis model - bolts . . . . . . . . . . . 10

Figure 4. A complete finite element analysis model . . . . . . . . . . 11

Figure 5. A finite element analysis model with a cut-out in the end plate..................... 12

Figure 6. Load curves used in the NIKE3D finite element analysis . . . . 31

Figure 7. Displacement of the bolt heads and the mid-points

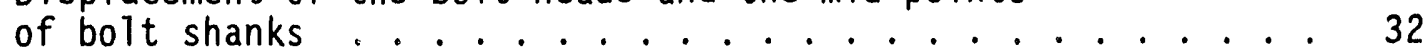

Figure 8. Exaggerated deformed shapes of a canister frame . . . . . . . 33

Figure 9. Effects of preload on the calculated bolt loads - 1-3/8 bolts................... 34

Figure 10. Effects of preload on the calculated bolt loads - 1-1/8 bolts.................. 35

Figure 11. Effects of door straps on the calculated bolt loads - 1-3/8 bolts.................. 36

Figure 12. Effects of door straps on the calculated bolt loads - 1-1/8 bolts.....................

Figure 13. Effects of bolt size on the calculated bolt loads

- inner bolts.................... 38

Figure 14. Effects of bolt size on the calculated bolt loads - outer bolts...................

Figure 15. Bending moment in the bolts about an axis parallel to the cable tray flanges .............. 40

Figure 16. Rotation of bolt heads . . . . . . . . . . . . . . . 41

Figure 17. Locations at which the stresses are of interest in design . . 42

Figure 18. Contours of effective stress in the end plate - top view . . 43 
Figure 19. Contours of effective stress in the end plate - bottom view

Figure 20. Effective stress in the most highly loaded elements in the

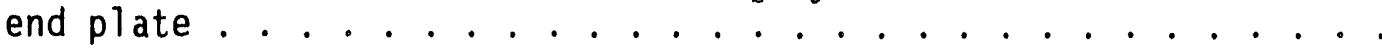

Figure 21. Peak effective stresses at Location $F$ in the end plate for cases involving 1-3/8" bolts ............. 46

Figure 22. Peak effective stresses at Location $F$ in the end plate for cases involving 1-1/8" bolts .............

Figure 23. Typical contours of moment resultant (Mxx) in the cable tray with door straps . . . . . . . . . . . . . .

Figure 24. Typical contours of axial membrane stress (z-stress) in the cable tray with door straps .............

Figure 25. Typical contours of effective stress in the cable tray with door straps ..................

Figure 26. Typical contours of maximum principal stress in the cable tray with door straps ...............

Figure 27. Typical contours of axial membrane stress (z-stress) in the cable tray without door straps . . . . . . . . . . .

Figure 28. Typical contours of effective stress in the cable tray without door straps ............... 53

Figure 29. Typical contours of maximum principal stress in the cable tray without door straps . . . . . . . . . . . .

Figure 30. Typical contours of effective surface stress in the cable tray with door straps ................

Figure 31. Effective stresses as functions of external load ("time") in the most highly loaded elements in the cable tray with door straps

Figure 32. Axial membrane stress (z-stress) as a function of external load ("time") in the most highly loaded elements in the cable tray with door straps

Figure 33. Maximum principal stresses as functions of external load ("time") in the most highly loaded elements in the cable tray with door straps ................. 58

Figure 34. Maximum effective surface stresses as functions of external load ("time") in the most highly loaded elements in the cable tray with door straps

Figure 35. Bolt loads obtained in the full-scale pull test . . . . . . 64 
Figure 36. Average inner and outer bolt loads............ . 65

Figure 37. Comparison of test and analysis results . . . . . . . . . . 66

Figure 38. Sum of all bolt loads as functions of the applied external axial load..................... 67

Figure 39. Bolt loads with adjustments in preload . . . . . . . . 68

Figure 40. Average inner and outer bolt loads with adjustments in preload . . . . . . . . . . . . . . . . . 69

Figure 41 . Comparison of test and analysis results (with adjustments in preload) .............. 70

\section{LIST OF TABLES}

Table 1. Finite element analysis cases . . . . . . . . . . . 27

Table 2. Categorization of normal stresses in various regions of a canister frame .. . . . . . . . . . . . . 28

Table 3. Allowable stresses in the NTED Design Guide and the ASME B\&PV Code. ................... 29

Table 4. The stresses in a cable tray ................ . 30

Table 5. Finite element models corresponding to the pull test cases . . 63 


\section{viii}




\section{EXECUTIVE SUMMARY}

A finite element analysis was performed for the structural connections of a downhole nuclear test emplacement assembly. The bolt loads as well as the stresses in the cable trays and end plates of the assembly were examined for a range of bolt preloads and applied external axial load.

The results of the finite element analysis indicated that the bolt load increases with the preload for any given external load. The results also showed that an uneven distribution of bolt loads exists between inner and outer bolts due to the eccentricity in the load path through the connections. The inner bolts carry more load than the outer bolts.

Preload generally does not improve the bolt loads and the cable tray stresses except in making the bolt loads between inner and outer bolts more equitable. The summation of all bolt loads at a canister interface is greater than the applied external axial load due to the combined effects of preload and prying. The prying is caused by the bolts being off-center from the cable tray. As a result of the bending in the end plates, some bending moment also exists in the bolts due to the rotation of bolt heads.

Because the end plates are thick, they experience only low levels of stresses except in the regions between cable tray flanges and the bolt holes. There are two regions of high stresses in the cable trays. One is in the curved region between the flange and the web of the cable tray just above the end plate. The other is on the cable tray flange below the cut-off point of the door strap. This latter region of high stresses does not exist if door straps are not used. However, without the door straps, the stresses in the former region will be higher. The door straps also have the advantage of causing more even distribution in bolt loads by shifting the neutral axis of the cable tray radially outward.

Stress information for bolts, cable trays, and end plates is documented in this report. For a specific design, stresses such as primary membrane, primary 
bending, local membrane, local bending, or the combination of these stresses can be obtained. An evaluation of the design can be made using the NTED Design Guide or the existing codes, such as the ASME Boiler and Pressure Vessel Code.

The analytical study documented in this report was based on the finite element method using NIKE3D code. A full-scale pull test of the canister frames was carried out by a team of EG\&G personnel at a DOE facility in Las Vegas, Nevada. Two canister frames having the same end plate geometry and cable tray thickness were bolted together with sixteen bolts. The four bolts around one of the four cable trays are load-sensing bolts. Three levels of preload were tested. The applied external axial load on the canister assembly and the bolt loads in these load-sensing bolts were monitored. There was a good agreement in bolt loads between the test and the finite element analysis. The agreement not only validated the analysis results presented in this report but also provided additional evidence about the validity of the LLNL computer code, NIKE3D.

The study documented in this report was for an 86-inch-diameter canister with cable tray thickness of 0.5 inches and end plate thickness of 2.25 inches. Although this study provided valuable insight on the behavior of other canisters with the same geometry but with different dimensional characteristics, these other canisters may have significantly different local stresses. Therefore, it is recommended that these dimensional effects be examined in future studies.

A couple of areas which were not included in this study but are important in the design of canister frames should be examined in the future. These areas are the weld integrity and the optimum type of canister-to-canister connection method. The current method of canister-to-canister connection produces high stresses in cable tray flanges and is not the optimum design. Other types of connections should be explored. Modifying current design, such as changing the locations and the number of bolts around the cable tray, provides a good starting point for this effort. 


\section{TEST AND ANALYSIS OF CANISTER-FRAME CONNECTIONS}

\subsection{INTRODUCTION}

The work documented in this report is a continuation of a sensitivity study started by Dave McCallen and Tony Davito in 1988 (Ref. 1). The objective of this sensitivity study is to examine the connections of a downhole nuclear test emplacement assembly in detail using the NIKE3D code (Ref. 2). The focus of the study is the effect of preload, bolt size, and door strap on bolt load and the stresses in various parts of the assembly except the welds.

A nuclear test assembly consists of several special purpose canister modules connected in series. The most severely loaded connection of the test assembly occurs at the upper-most module interface, which is between the streak camera module and the upper diagnostic canister module. A typical module of interest in this study is shown in Fig. 1. This module consists of three major components: four channels used as cable trays; ring-shaped plates used as the end plates of the module; and sixteen bolts used as the connecting elements of two modules. Cable trays and end plates are welded together to form a module. The bolts are used to connect the end plates of two modules; the bolts are placed on the side of channel flanges. There are two bolts for each flange of a cable tray channel. The material for the cable trays and the end plates is ASTM A-537. In some modules, $3 / 8$ " $\times 5$ " plates made of A-36 steel are welded to the free edges of the cable trays to serve as door straps for $3 / 8$ "-thick aluminum doors.

The external loading on the test assembly is mainly axial, and is due to the dead weight of the assembly, the stemming load, and the pull-test load. Of interest in this study are the bolt loads and the stress distributions in the cable trays and in the end plates under combined effects of the external load and the bolt preloads.

McCallen's finite element model was constructed of 8-node brick elements and beam (or truss) elements (Ref. 1). Shell elements were not used because they were not 
working properly at the time. Use of brick elements to model cable trays is cumbersome because more nodes are needed. Also, using only one brick layer through the thickness of a cable tray is not desirable in terms of analytical accuracy. The NIKE3D code has been significantly improved since McCallen's study was completed. The problem associated with the shell element was ironed out. Also, a beam or truss element with circular cross section was implemented in the code. This circular beam or truss element makes possible more precise modeling of the bolts.

An important finding in McCallen's study is that an eccentricity exists in the load path through the connections. The neutral axis of the cable tray parallel to the web of the channel is closer to the inner bolts than to the outer bolts; the line of action of the bolts is not collinear with the axial force transmitted by the cable tray. As a result, the inner bolt carries significantly more load than the outer bolt. This uneven distribution of bolt loads affects the stress distribution in the cable trays and in the end plates. The uneven distributior. of bolt loads will be examined further in this report.

The sensitivity study described in this report was made to examine the behavior of the connections under bolt preloads. The materials were assumed to be linear elastic to avoid the complications due to material yielding and strain hardening. The results of the study are presented in figures and tables such that important stress information can be extracted for any given external applied load and any prescribed bolt preload. The stresses are valid for canister frames with 2.25-inch-thick end plates and 0.5-in-thick cable trays. The nominal bolt diameters considered are $1-3 / 8$ and $1-1 / 8$ inches. 


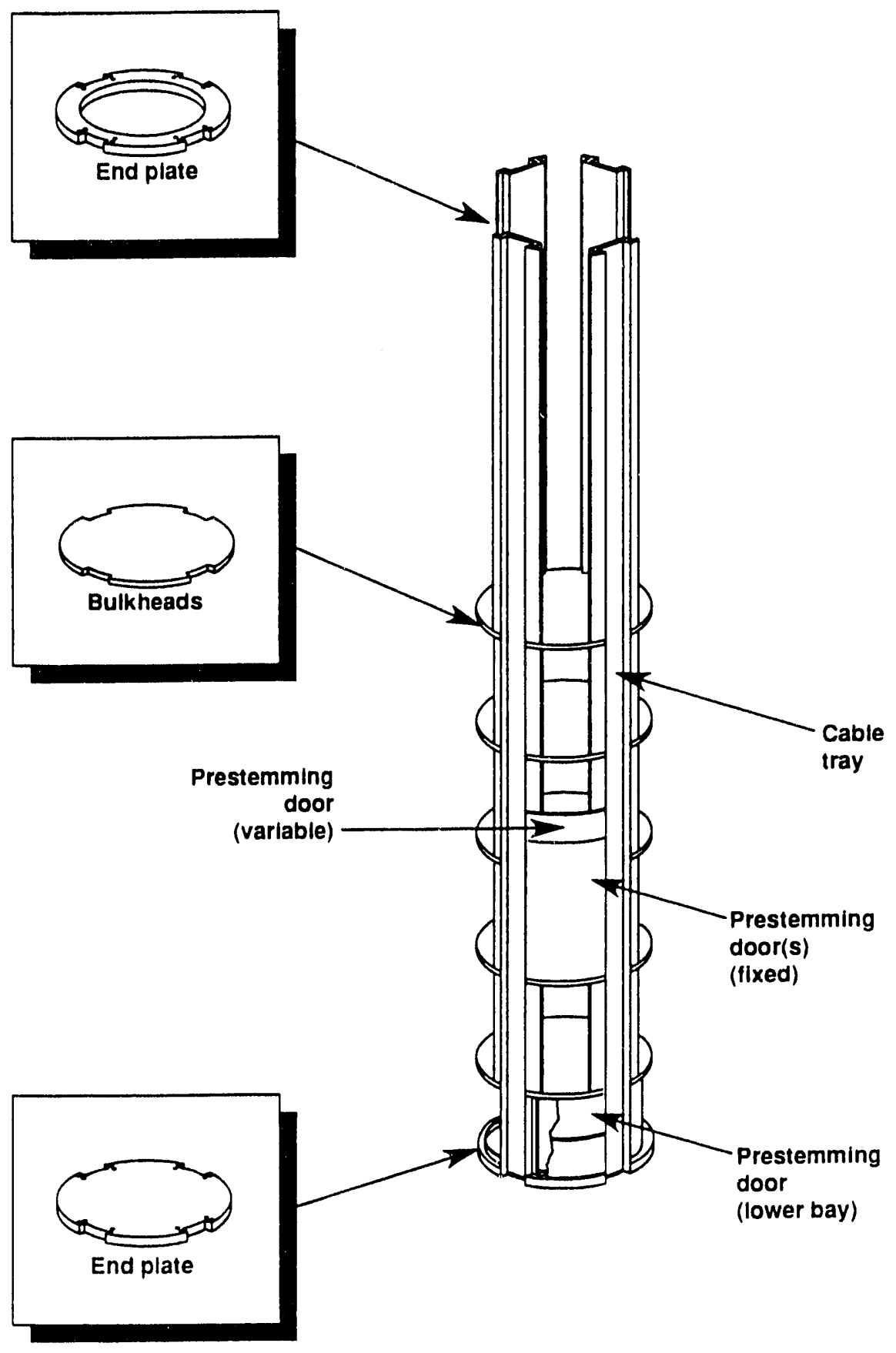

Figure 1. A typical canister frame. 


\subsection{FINITE ELEMENT ANALYSIS MODELS}

In this study, a typical 86-inch-diameter downhole assembly was analyzed. The cable tray is 0.5 -inch thick and the end plate is 2.25 inches thick. The bolts considered are SAE 1-3/8 - $6 \mathrm{Gr} .8$ and SAE 1-1/8 - $7 \mathrm{Gr}$. 8. These bolts have a yield strength of $120 \mathrm{ksi}$ and a tensile strength of $150 \mathrm{ksi}$. Finite element models were constructed using the mesh generator SLIC (Ref. 3), and they are based on several assumed symmetry conditions. These symmetry conditions are described in the following paragraphs, and they are graphically illustrated in Fig. 2 .

1. The streak camera module and the upper diagnostic canister frame were assumed to be identical in geometry. This assumption will not create any significant error in the results because the cable trays are very long. The advantage of this assumption is that the two modules become mirror images of each other. By using the stone wall feature of the NIKE3D code, only one module needs to be modeled. Please note that, for each bolt, only half of the shank length is modeled. The mid-point of the bolt shank is located on a plane coinciding with the stone wall.

2. It was assumed that each module has a plane of symmetry perpendicular to the axis of the test assembly located at the mid-point between the end plates of a module. This assumption reduces the model to one-half of a module.

3. The cable trays, end plates, and bolts were assumed to have two perpendicular planes of symmetry along the axis of the test assembly in both loading and geometry conditions. As a result of this assumption, only one quadrant of the structure needs to be modeled. This quadrant consists of a cable tray, a 90-degree sector of an end plate, and four bolts.

4. Each quadrant was assumed to consist of a plane of symmetry bisecting the cable tray and the end plate into two equal 45-degree segments of the structure. 
The above assumed symmetry planes are reasonable and are not expected to cause significant error in results. Due to the fact that only a small portion of the structure needs to be modeled, a refined finite element mesh in the regions of interest can be achieved. The shank of the bolts was modeled as a circular beam element. The bolt head was simulated by a group of rectangular beam elements which are connected to a group of surface nodes of the end plate. The area covered by these nodes and beams is the contact area between the bolt head and the end plate. The models thus constructed consist of a half segment of a cable tray, a one-eighth sector of an end plate, and two bolts. Various parts of a typical finite element model are shown in Figs. 3a, 3b, and 3c. A complete model with associated symmetry planes is shown in Fig. 4. Also shown in Fig. 4 is the coordinate system of the model. The origin of the coordinate system is at the center of the end plate on the stone wall. The $x$-axis is perpendicular to the web of the cable tray, and the z-axis is along the axis of the downhole assembly.

As stated in the previous section, the materials were assumed to be linearly elastic. However, the finite element analyses are nonlinear because of the stone wall, from which the end plates may become separated as the external load is applied. The external load representing the pull-test load, the dead weight, the emplaced load, and the stemmed load is applied to the centroid of the cable tray cross section at the model boundary $\mathrm{plane}$ of symmetry. The centroid shares the same axial (or vertical) degree of freedom with all nodes on this boundary plane of symmetry.

In the finite element analysis, the preload in a bolt can be applied by pulling the mid-point of the bolt for a predetermined amount of axial displacement. This displacement is equal to the sum of the anticipated bolt elongation under preload and the displacements of bolt heads due to the compression of the end plate in the thickness direction. The displacements of the bolt heads can be calculated with the following formulation.

$$
\left(\begin{array}{l}
d_{i} \\
d_{o}
\end{array}\right)=\left[\begin{array}{ll}
f_{i i} & f_{i o} \\
f_{o i} & f_{o 0}
\end{array}\right]\left(\begin{array}{l}
F_{i} \\
F_{o}
\end{array}\right)
$$


where $d, F$, and $f$ are the displacements of the bolt head in the direction of the bolt axis, the desired preloads, and the elements of a flexibility matrix representing the flexibility of the end plate at the bolt locations. The subscripts $i$ and 0 represent the inner and outer bolt locations, respectively. For example, $d_{i}$ and $F_{f}$ are the bolt head displacement and the desired preload of the inner bolt.

In Eq. (1), $f_{\text {or }}$ equals $f_{i 0}$ in accordance with the reciprocal theorem of elasticity. The terms $f_{\text {or }}$ and $f_{10}$ represent the interaction effects between the inner and outer bolts. The elements of the flexibility matrix were calculated by performing three finite element analyses, in which different loads were applied to the bolt heads while observing their displacements. Please note that in these finite element analyses, the bolt shanks were excluded from the model. For an end plate thickness of 2.25 inches and a nominal bolt diameter of $1-3 / 8$ inches, $f_{11}$, $f_{01}\left(\right.$ or $\left.f_{10}\right)$, and $f_{00}$ have values of $2.15 E-8,2.16 E-9$, and $2.59 E-8$ in./1b., respectively. The following formula (Refs. 4, 5, 6 and 7) was used to verify the flexibility values, $f_{11}$ and $f_{00}$.

$$
f=t /\left(E A_{c}\right)
$$

where

$$
\begin{aligned}
& A_{c}=3.14 *\left[\left(D_{b}+t / 10\right)^{2}-D_{h}^{2}\right] / 4 \\
& E=\text { modulus of elasticity (psi) } \\
& t=\text { total thickness of plates = grip length (in.) } \\
& D_{b}=\text { diameter of contact between the bolt head and } \\
& \quad \text { the plate. } \\
& D_{h}=\text { diameter of bolt hole. }
\end{aligned}
$$

Equation (2) is for a single-bolt connection with large inplane joint dimension (diameter greater than $3 D_{b}$, and with $t$ less than eight times the bolt nominal diameter). The hand calculation using Eq. (2) yields a flexibility value of $2.35 E-8$ in./1b, which is very close to the $f_{11}$ and $f_{00}$ values obtained in the finite element analysis described above. The $f_{o o}$ value is slightly larger than $f_{11}$ and the hand calculated value. It is larger because the outer bolt hole is near a free edge, therefore, the end plates are more flexible in the thickness direction at that location. 
In this study, the information of interest is the stresses, deformations, forces, and bending moments in the bolts, cable trays, and end plates. Effective stress (or von Mises stress) is used extensively in this study because it is an excellent gauge of material distortion under loads. Other stress information, such as the axial membrane stresses and the maximum principal stresses, were also calculated.

Another finite element model was also constructed in this study (Fig. 5). This model consists of a cut-out in the end plates. This cut-out was needed for the placement of a diagnostic instrument. As expected, this model yields information of interest deviating very little from that of the model shown in Fig. 4. The small deviation is due to the fact that the cut-out is not near the load path of the connection. Therefore, the results of the finite element model shown in Fig. 5 will not be presented in this report. 

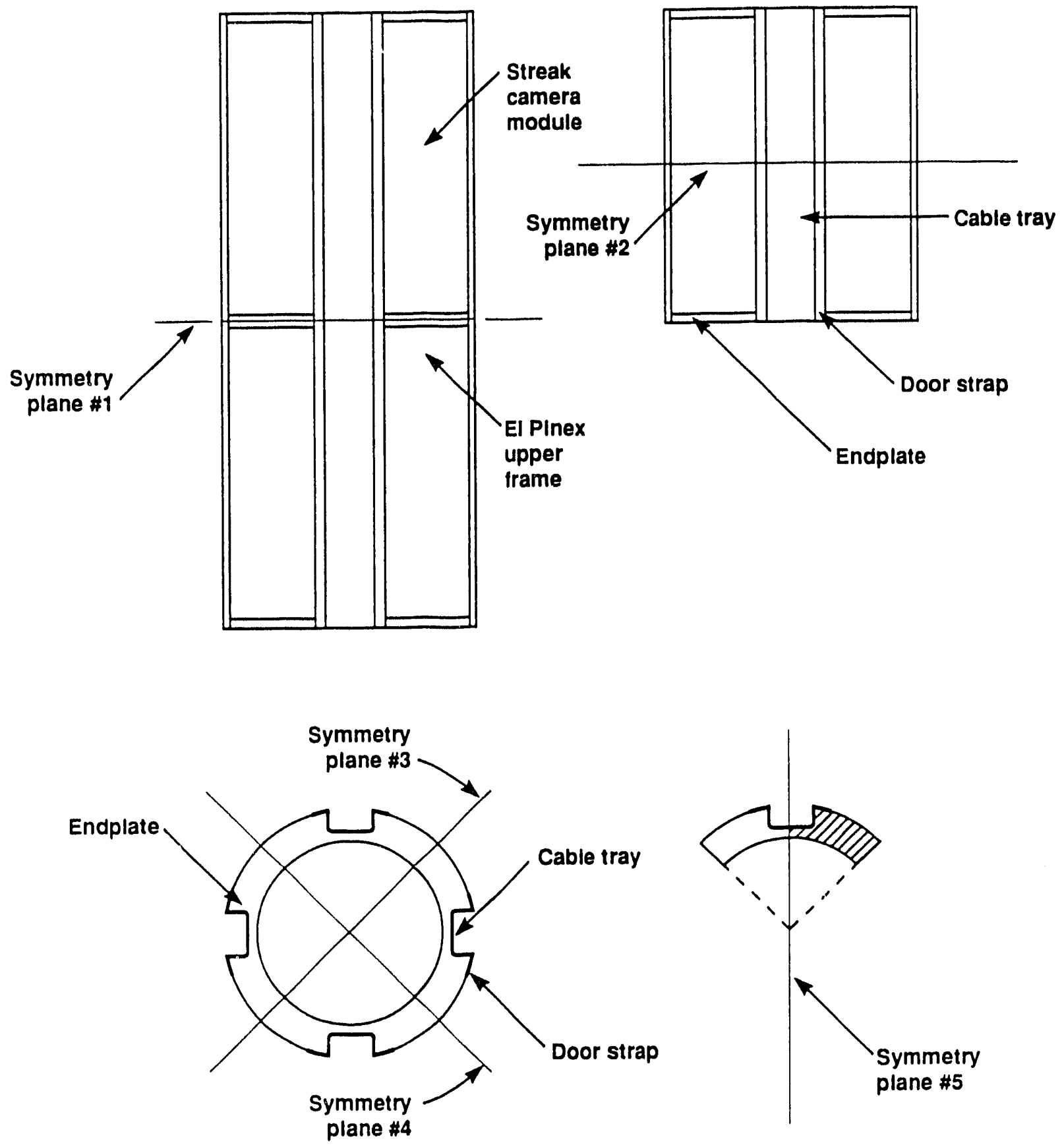

Figure 2. Assumed symmetry planes in the finite element analysis. 


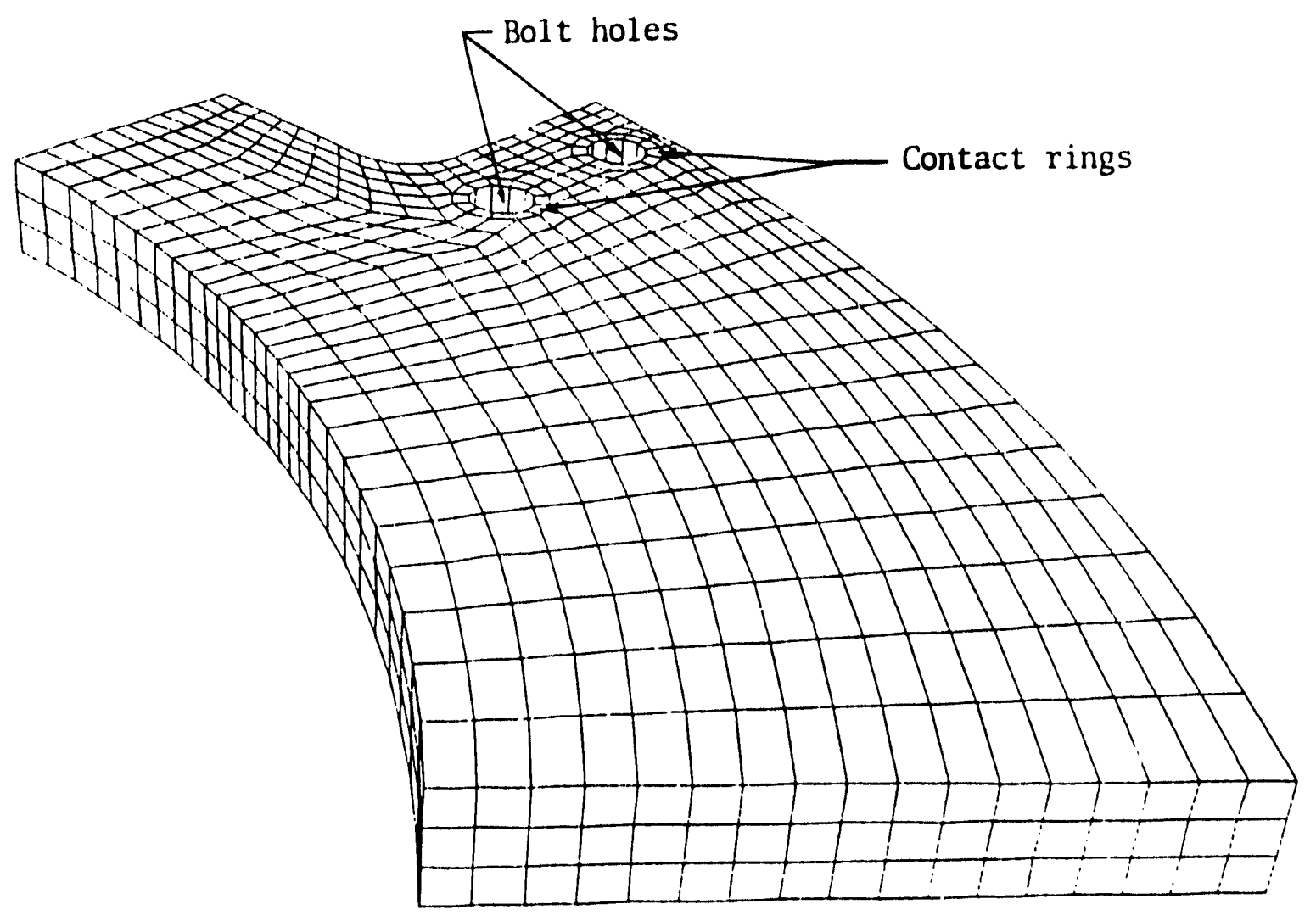

Figure 3a. Finite element analysis model - endplate. 

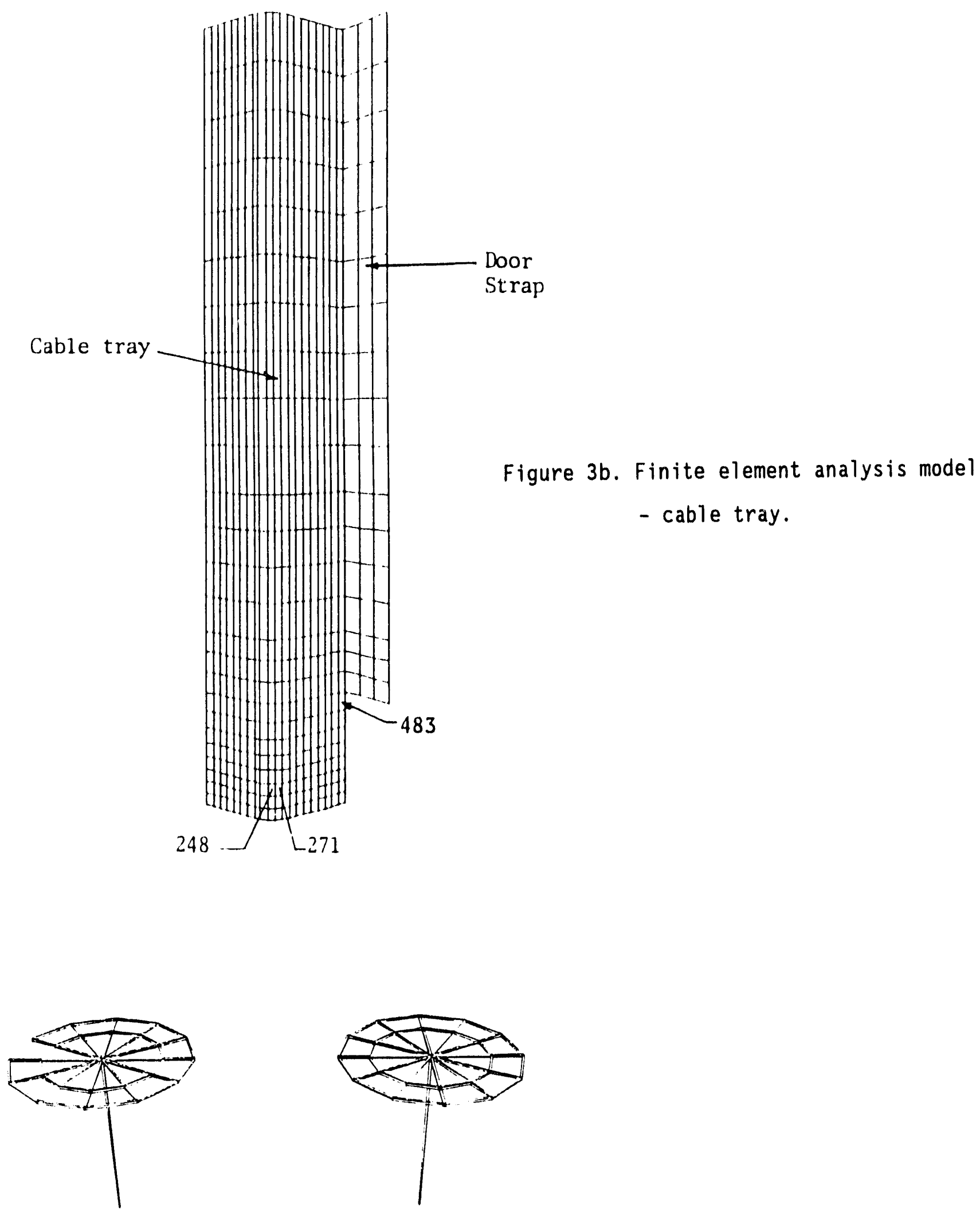

Figure 3c. Finite element analysis model - bolts. 


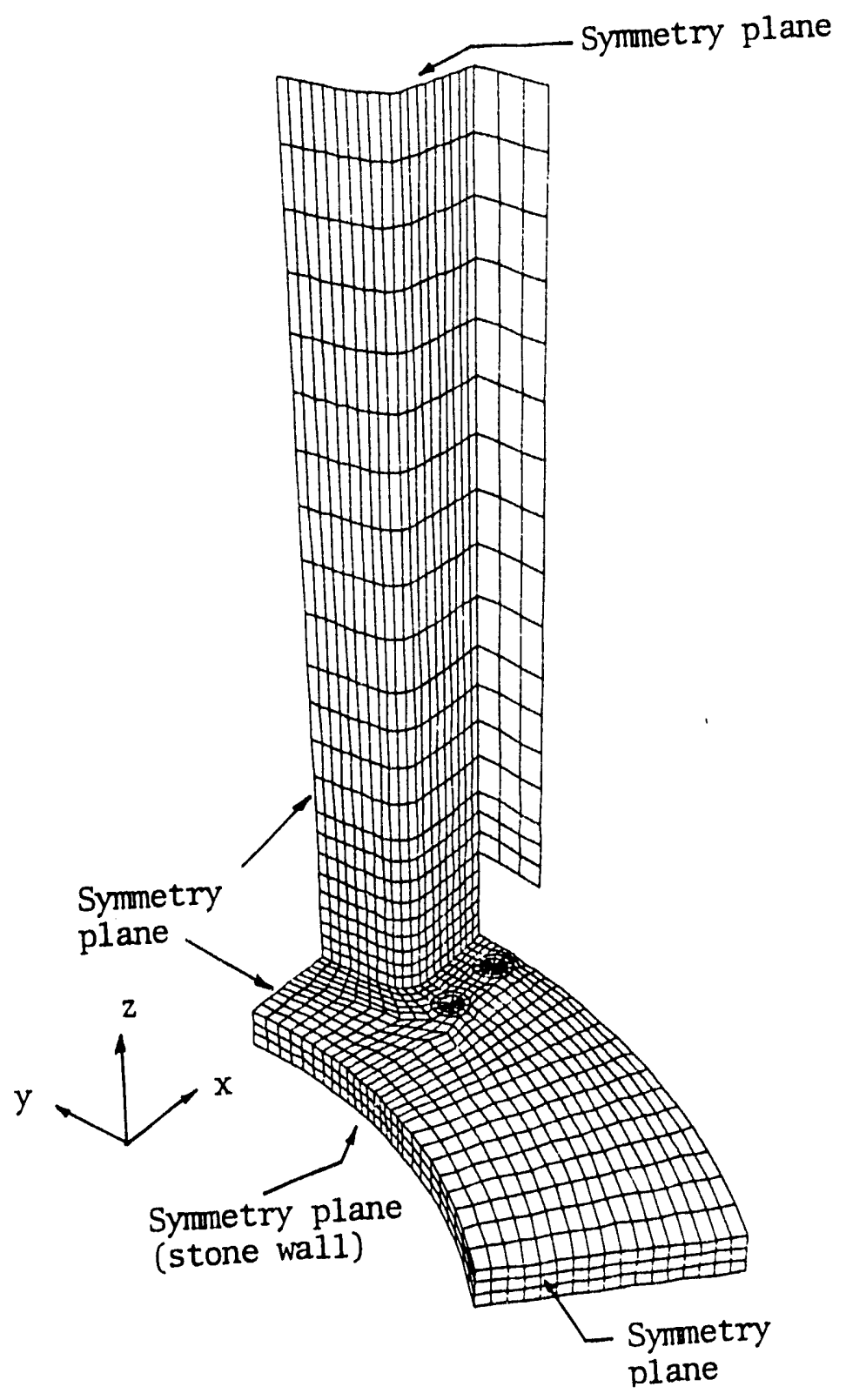

Figure 4. A complete finite element analysis model. 


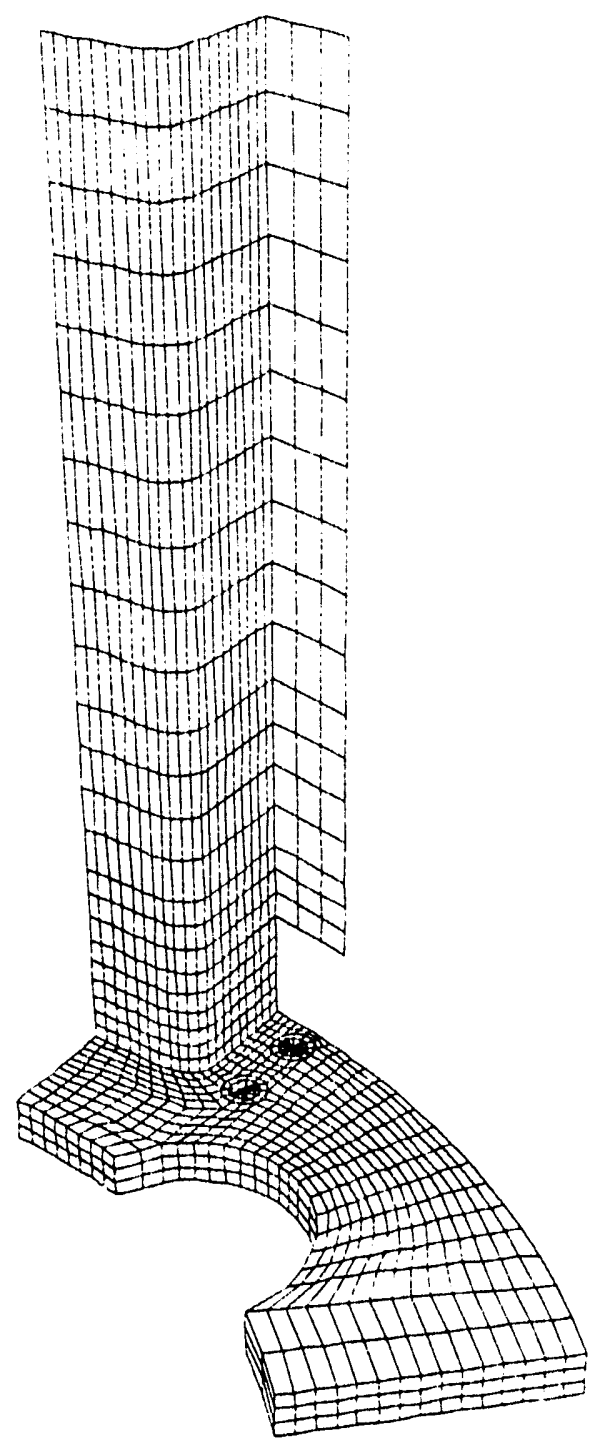

Figure 5. A finite element analysis model with a cut-out in the endplate. 


\subsection{ANALYSIS RESULTS}

By varying the bolt size and the bolt preload, and by either considering or not considering the door straps, eleven NIKE3D finite element analyses were performed. Preloads of $0,50,75,100$, and 125 kips per bolt were used. The inner and outer bolts were given the same amount of preload consistent with the field practice, although different values can be applied. Table 1 shows the relevant parameters of these analysis cases.

Typical load curves for the preload and the applied external load are shown in Fig. 6. In a NIKE3D static analysis, the "time" is only a fictitious parameter for applying the loads. As described earlier, the preload is applied by pulling the mid-point of a bolt to a predetermined displacement equal to the sum of the surface displacement of the end plate calculated in accordance with Eq. (1) and the expected elongation of the half-length of the bolt shank. In the finite element analysis, the applied displacement at the mid-point as a function of "time" is equal to the product of the load factor shown in Fig. 6 and this predetermined displacement. When the load factor reaches 1.0, the full amount of the predetermined displacement is applied and the desired preload is achieved. Thereafter, no further pulling of the bolt mid-point is administered by keeping the load factor at 1.0. Figure 7 shows a typical displacement plot of the bolt heads and the mid-points of the inner and the outer bolts. In Fig. 7, the displacements of bolt mid-points (nodes $B$ and $C$ ) are kept unchanged after the predetermined values are reached at "time" $=0.5$, while the bolt heads (nodes $A$ and D) are unconstrained and move upward as the external load is applied.

\subsection{Deformed Shape}

The deformed shape of the canister connections is generally consistent with McCallen's finding. Two exaggerated views of the deformed shape of a typical case are shown in Fig. 8, along with McCallen's plot of his model. As stated by McCallen, the end plates tend to pull apart at the location of the cable tray. 
The maximum separation is along symmetry plane \#5 (Fig. 2). The end plate deformation drops sharply beyond the location of the bolts. There is a prying action on the bolts as the load is transferred from the cable tray to the end plate, and then to the bolts. The flanges of the cable tray bend outward near the end plate, while the web bends inward. The axial elongation of the bolts is clearly visible in these plots.

\subsection{Bolt Loads}

Figure 9 shows the calculated axial bolt load (ordinate) as a function of the total applied external load or the average applied load on a bolt (abscissa). Figure 9 is for cases with 1-3/8-in. bolts and with door straps included (i.e., cases 1 through 4 ). The average applied load on a bolt is equal to the total applied external load divided by the number of bolts in a connection. For the typical connections considered in this study, the number of bolts is 16 . Also shown in Fig. 9 is a 45-degree line, which represents an imaginary case in which the effects of preload, prying, and uneven distribution between the inner and the outer bolts are nonexistent. Several observations can be made:

1. The bolt load increases with the preload. This applies to both the inner and outer bolts. The bolt loads start with the preloads when the external load is initially applied. The bolt loads converge gradually as the external load increases. The increase in bolt load beyond preload can be explained by the use of a joint diagram. Readers are referred to Section 3.1 of Ref. 8 and text books by Bickford (Ref. 4), Shigley and Mitchell (Ref. 9), and Juvinall (Ref. 10) for the details of the joint diagram.

2. There is an uneven distribution of bolt loads between the inner and outer bolts. The inner bolts carry more load than the outer bolts. The source of this difference is due to an eccentricity in the load path - the neutral axis of the cable tray is closer to the inner bolts than to the outer bolts.

3. The preload generally improves the uneven distribution described in Item 2. For any given external load, the difference between inner and outer bolt 
loads decreases as the preload is increased. However, the improvement is insignificant.

4. The summation of bolt loads is greater than the applied external load; i.e., the average of inner and outer bolt loads is above the 45-degree 1 ine. The excess bolt load is the combined effect of preload and prying. For the case without preload, prying is the only cause of higher total bolt load. If there were no prying effect, then one of the bolts would fall below the 45-degree line. Prying exists in these connections because the bolts are off-center from the cable tray flanges.

5. The occurrences of end plate separation are identified in Fig. 9. It is interesting to observe that the separations are close to being on a straight line through the origin. This applies to both inner and outer bolts. Another interesting observation of the cases with preloads is that, after end plates are fully separated from each other (or fully recovered from the deformation due to preload) at the bolt locations, the bolt loads are still higher than the case without preload for any given external load. This indicates that the prying effect is higher for cases with preloads than for the case without preloads.

The observations described above can also be applied to other bolt sizes. Figure 10 is an identical plot of Fig. 9, except that it is for a bolt size of 1-1/8 in. In general, the preload increases the bolt load. It is especially true when the external load is low as shown in Figs. 9 and 10. Preventing leakage in a pressure vessel and preventing vibration loosening are two of the most common reasons for applying bolt preloads. For the downhole emplacement assembly, the only benefit in prescribing the preload is to make inner and outer bolt loads more equitable because leakage and vibration loosening are unimportant in this case.

In the cases described above, door straps are included in the finite element models. Without the door straps, the neutral axis of the cable tray moves closer to the inner bolts. Therefore, it is expected that the uneven distribution in axial loads between the inner and the outer bolts will get worse. This larger 
difference between inner and outer bolt loads can be observed in Figs. 11 and 12, which are comparisons of bolt loads for cases with and without door straps for the two bolt sizes considered in this study.

Another comparison can be made on the effects of bolt size on the bolt load. This comparison is shown in Figs. 13 and 14, for the inner and the outer bolts, respectively. Larger bolts will result in slightly higher bolt loads. However, the effect of bolt size is really not significant considering the fact that there is a large increase of approximately $50 \%$ in stress area from $1-1 / 8$-in. bolts to 1-3/8-in. bolts. For a given preload, the difference is due solely to prying effects because there is no other identifiable source. This observation should not be interpreted as the bolt size being an unimportant factor in the design of downhole assembly. In fact, the bolt size should be selected based on appropriate stress requirements in accordance with the NTED Design Guide. The stress 1 imits for bolts in the NTED Design Guide are higher than those of the ASME Code because these bolts are subjected to much more stringent inspection criteria than the bolts designed in accordance with the ASME Code.

The above discussion is limited to the axial bolt loads. There is a small amount of bending in the bolts due to the bending of the end plates or, as a result of this bending, the rotation of bolt heads. Figure 15 shows the bending moments on the bolts about an axis parallel to the flange of the cable tray for a typical case (Case 7, Table 1). Corresponding to these bending moments, the bolt heads experience a small amount of angular rotations, which are shown in Fig. 16. The amount of angular rotations was verified by a hand calculation considering the effects of a bending moment and an axial load on the extreme end of a cantilever beam. The calculated bending moments in bolts can be considered as the upper bound values because, in reality, the bolt head may have a small amount of rotation relative to the end plate due to possible local plastic deformation of the end plate under the bolt heads. Please note that the bolts are usually made of higher strength material than the joint, or the end plates in this case. 


\subsection{Stresses in End plates and Cable Trays}

\subsubsection{Definition of Stresses}

The canister frames in a downhole assembly can be considered as mechanical components. It is therefore natural to classify the stresses in a canister frame in terms of ASME B\&PV Code stress definitions such as the normal, shear and bending stresses, and the primary and secondary stresses. The stress definitions included in the NTED Design Guide (Ref. 11) are corisistent with the ASME B\&PV Code. These stress definitions are presented in the following paragraphs along with examples applicable to the nuclear downhole emplacement assembly.

(1) Stress Intensity. Stress intensity is defined as twice the maximum shear stress. In other words, the stress intensity is the difference between the algebraically largest principal stress and the algebraically smallest principal stress at a given point. Tension stresses are considered positive, and compression stresses are considered as negative. For thin plates, e.g, the cable tray, the stress component normal to the surface of the plate is generally very small and can be assumed to be zero.

(2) Gross Structural Discontinuity. Gross structural discontinuity is a source of stress or strain intensification which affects a relatively large portion of a structure and has a significant effect on the overall stress or strain pattern or on the structure as a whole. Example of gross structural discontinuities are end plate-to-cable tray and cable tray-todoor strap junctions.

(3) Local Structural Discontinuity. Local structural discontinuity is a source of stress or strain intensification which affects a relatively small volume of material and does not have significant effects on the overall stress or strain pattern or on the structure as a whole. Examples are small attachments and partial penetration welds.

(4) Normal Stress. Normal stress is the component of stress normal to the plane of reference such as the stress normal to the cross section of a 
cable tray. Usually the distribution of normal stress is not uniform through the thickness of a part, so this stress is considered to be made up in turn of two components, one of which is uniformly distributed and equal to the average value of stress across thickness of the section under consideration, and the other of which varies with the location across the thickness.

(5) Shear Stress. Shear stress is the component of stress tangent to the plane of reference.

(6) Membrane Stress. Membrane stress is the component of normal stress which is uniformly distributed and equal to the average value of stress across the thickness of the section under consideration.

(7) Bending Stress. Bending stress is the variable component of normal stress described in (4) above.

(8) Primary Stress. Primary stress is a normal or shear stress developed by the imposed loading which is necessary to satisfy the laws of equilibrium of external and internal forces and moments. The basic characteristic of a primary stress is that it is not self-limiting. Primary stresses which considerably exceed the yield strength will result in failure, or at least, in gross distortion. A thermal stress is not classified as a primary stress because a slight distortion of the structure will result in significant reduction in this stress. A general primary membrane stress $P_{m}$, is one which is so distributed in the structure that no redistribution of load occurs as a result of yielding. An example of primary membrane stress is the normal stress averaged across the cable tray cross-sectional area due to the gravity load of the downhole emplacement assembly. Another type of primary stress is the primary bending stress, $P_{b}$. Primary bending stress is the bending portion of the normal stress at a location far away from structural discontinuities. An example of the primary bending stress in the downhole emplacement assembly is the bending stress at a cross section far away from the bolt holes and the cable trays. 
(9) Secondary Stress Q. Secondary stress is a normal stress or a shear stress developed by the constraint of adjacent parts or by self-constraint of a structure. The basic characteristic of a secondary stress is that it is self-limiting. Local yielding and minor distortions can satisfy the conditions which cause the stress to occur and failure from one application of the stress is not to be expected. Examples of secondary stress are the general thermal stress and the bending stress at a gross structural discontinuity.

(10) Local Primary Membrane Stress $P_{L}$. Cases arise in which a membrane stress produced by pressure or other mechanical loading and associated with a primary or discontinuity effect produces excessive distortion in the transfer of load to other portions of the structure. Conservatism requires that such a stress be classified as a local primary membrane stress even though it has some characteristics of a secondary stress.

(11) Peak Stress. The basic characteristic of a peak stress is that it does not cause any noticeable distortion and is objectionable only as a possible source of fatigue crack or a brittle fracture. Peak stress is generally not a problem for the down-hole system.

Following the stress definitions of the ASME B\&PV Code described above and the NTED Design Guide, the stresses in various locations of a canister frame can be classified (Table 2). These locations are shown in Fig. 17. In this figure, a total of seven locations (Locations $A$ through $G$ ) are identified to be of interest in the design of a canister frame. Because the ASME B\&PV Code applies mainly to pressure vessels, the stress definitions of the code cannot be followed strictly without some degree of engineering judgement for the end plates and cable trays of a canister frame. Therefore, the stress classifications included in Table 2 consider not only the definitions, but al so the structural deformation characteristics and the stress 1 imits with which the ASME B\&PV Code stress definitions are closely associated.

The ASME B\&PV Code uses stress intensity limits for vessel designs based on the maximum shear stress theory (or Tresca criterion). This theory is less accurate 
than the distortion energy theory (or Mises criterion) in which effective stress is used to predict significant structural distortion. Therefore, effective stresses based on the distortion theory can also be used in lieu of the stress intensities in determining the adequacy of a design. The effective stresses were calculated in this study and are the major stress information presented in this report.

\subsubsection{Allowable Stresses}

The allowable stresses, or the stress limits, for downhole emplacement assembly are documented in the NTED Design Guide (Ref. 11). These allowable stresses are defined in terms of stress categories (primary, local, and secondary stresses) and types of loading (emplaced, stemmed, and pull test loads) as stated in Section 3.3.1. These allowable stresses are shown in Table 3 . Table 3 also includes the corresponding stress limits of the ASME B\&PV Code Subsections NB and NF. Certain terininology associated with ASME B\&PV Code such as the Service Levels and stress intensity value $S_{m}$, are provided in the table. Subsection NB is for Class 1 pressure components and is used for all major safety-related components in nuclear power plant design. Subsection NF applies to component supports and is used here because, similar to the downhole emplacement assembly, the major loading is mechanical loads rather than pressure loads.

As described earlier in Section 3.3.1, the application of the ASME Code to the downhole emplacement assembly needs some degree of engineering judgement because the Code applies mainly to the design of pressure retaining components. Based on the definition of service levels, it seems that:

(1) The emplaced and stemmed loads can be categorized as loads associated with a Level A service condition.

(2) The pull test load can be categorized as a load associated with a Level B service condition.

Based on the above load categorization, it is shown in Table 3 that the stress limits of the NTED Design Guide are compatible with those of the ASME Code 
Section III, if the tensile strength of the material is less than two times the yield strength, which is usually true. The stress limits for stemmed loads are the same as those for the Level A service condition. The stress limits for pull test loads are slightly more conservative than those of the Service Level $B$. The emplaced load is unique for the downhole emplacement assembly and, according to the NTED Design Guide, has lower stress limits than the stemmed load.

\subsubsection{Stresses in the End plates}

Compared to the cable trays, end plates are very thick. There are little membrane stresses in the end plates; i.e., $P_{m}$ and $P_{L}$ are close to zero. The stresses in the end plates are mainly due to bending and are generally very low except in localized regions between the cable tray flanges and the bolt holes. As a result, no stress evaluation in the region represented by Location $D$ (or the regions far away from the cable tray and the connecting bolts) is necessary.

To illustrate the stress distributions in the region between bolt holes and flanges, the results of Case 7 are again presented. Figures 18 and 19 show the contours of effective stress on the surfaces of the end plate in the bolt hole region. Stress is higher at one edge of the bolt heads (Fig. 18) as the external load is transmitted from the cable tray to the end plate of one canister frame, to the bolts, and then to the end plate and cable tray of another canister frame. On the other surface of the end plate (Fig. 19), the peak effective stresses occur along the line connecting the centers of the two bolt holes. The bending moment along this line is the largest in the end plates. The primary bending stress, $P_{b}$, can be calculated based on the applied external load, the distance ( 2.22 in.) between a cable tray flange and the center line of the bolts next to this cable tray flange, and the area moment of inertia (12.34 $\mathrm{in}^{4}$ ) of the end plate cross section along the bolt center line. The extreme fiber stress, $P_{b}$, due to this primary bending moment is approximately equal to $25.3 \mathrm{ksi}$ per million pounds of total external applied axial load on a canister. Assuming the yield strength of the end plate material is $50 \mathrm{ksi}$, the normal stress, $P_{L}+P_{b}$, along the bolt center line is equal to $25.3 \mathrm{ksi}$ and is lower than the allowable stress of $37.5 \mathrm{ksi}\left(0.75 \mathrm{~S}_{y}\right)$ based on the NTED Design Guide and the ASME Code (Table 3 ) for an emplaced load of one million pounds. The local surface stresses in the region 
between bolt holes and cable tray flanges are secondary stresses due to local bending. In the downhole emplacement assembly, the region near the cable tray-end plate junction is vital to the integrity of the system. To prevent large deformation, it is therefore recommended that this local bending stress be upgraded to a primary bending stress, $P_{b}$, except at Location $E$ where strain hardening is usually allowed for seating of the bolt head and at Location $F$ at the edge of the bolt hole.

Figure 20 shows the effective stresses at two of the most severely loaded locations (Locations $E$ and $F$ ) as functions of "time" (or the external load, Fig. 6). Clearly, the stresses in the end plates are dependent on both the preload and the applied external load. The high stress at Location $E$ is the result of contact force between the bolt head and the end plate; and the high stress at Location $F$ is due to bending occurring at a gross structural discontinuity - the bolt hole. The stresses in these regions are of no major importance in the canister frame design because stress concentration in these regions is usually relieved by the slight strain hardening in the end plate material unless the bolt holes are significantly larger than those commonly required in codes and standards. In addition, the stresses at Location $E$ are mainly compressive stresses, which are less detrimental compared to tensile stresses. The stresses at these locations are secondary stresses. The ASME B\&PV Code places limits on the secondary stresses to avoid large plastic deformation. The effective stresses at Location $F$ are presented in Figs. 21 and 22 for the two bolt sizes included in this study. An evaluation of the stresses at locations $E$ and $\mathrm{F}$ can be made using the stress limits for secondary stresses in accordance with the ASME B\&PV Code and/or the NTED Design Guide.

\subsubsection{Stresses in Cable Trays}

Contrary to the end $\mathrm{plates,} \mathrm{the} \mathrm{cable} \mathrm{trays} \mathrm{experience} \mathrm{mainly} \mathrm{inplane} \mathrm{or} \mathrm{membrane}$ stress instead of bending stress as the external load is applied. Figure 23 clearly shows that the bending moment is small except in regions close to gross structural discontinuities. That is the primary bending stress $P_{b}$ is close to zero. For example, the bending stress at Location $C$ shown in Fig. 17 is a primary bending stress. 
The membrane stress is mainly along the axis of the cable tray. As a result, the contours of mid-plane z-stress (or membrane stress in the axial or z direction), effective stress, and maximum principal stress are not much different from one another. This is shown in Figs. 24, 25, and 26.

Stress peaks occur in the cable tray at two locations marked as Location $A$ and Location $B$ in Fig. 25. Location $A$ is just above the end plate and is located on the curved region between the $f l$ ange and the web of the cable tray. Location $B$ is on the cable tray flange below the cut-off point of the door strap. Without door straps, Location $B$ does not exist because the gross structural discontinuity caused by the door strap is eliminated. Figures 27,28 , and 29 show the same plots as Figs. 24, 25, and 26, except that the door straps are not included in the model. By excluding the door straps, the peak stresses at Location $A$ are increased.

Besides their main function, the door strans produce a more equitable distribution of bolt loads (Figs. 11 and 12) and smaller peak cable tray stresses (Table 4). The disadvantage is that they create a second location of high stresses (Fig. 30) in the cable tray due to the effect of bending (Fig. 23) at Location $B$.

Unlike the stresses in the end plate, the stresses in the cable tray are mainly dependent on the external load. These stresses are close to being linearly proportional to the applied external load as shown in Figs. 31 through 34 . The insensitivity of the cable tray to the preload is understandable because the preload affects mainly the bolt loads and the stresses in the localized region around the bolt holes in the end plates.

Because the stresses in the cable tray are close to being linearly proportional to the applied external load, these stresses can be expressed as follows:

$$
S_{1}=C_{1} F \text {, }
$$

where $S_{i}$ represents a stress component of interest in the cable tray; $F$ is the total applied external axial load; and $C_{1}$ is a proportional constant. The 
subscript $i$ identifies the component. For example, in Table 4 , the values of $C_{\text {me }}$, $C_{1 .}, C_{m z}$, and $C_{m p}$ are associated with the maximum effective membrane stress $S_{m e}$, maximum effective surface stress $S_{3 . e}$, maximum membrane $z$-stress $S_{m z}$, and maximum principal membrane stress $S_{m p}$, respectively.

The results shown in Table 4 clearly indicate that both the preload and the bolt size do not significantly affect the $C_{1}$ values. There is no significant difference between the maximum and the minimum values among the cases with different preloads. The difference in these $C_{1}$ values is also small between the two bolt sizes studied. The door straps have some effect on the $c_{i}$ values. However, the difference in stresses between the cases with and without door straps are still less than 20 percent for all the preloads and the bolt sizes considered in this study.

The average membrane stress, $S_{z}$ or $C_{2} F$, in the axial direction (total external axial load, F, divided by the cross-sectional area, A, of the cable tray) is a general primary membrane stress $\left(P_{m}\right)$ and is equal to $21.3 \mathrm{ksi}$ per million pounds of external force $F$. This general primary membrane stress is applicable to any cross section of the cable tray including the region near the cable tray-end plate junction (a gross structural discontinuity). A large safety margin should be maintained for general primary membrane stress. The ratios of maximum local primary membrane stresses, $P_{L}$, and the average axial membrane stress (i.e., $\operatorname{Max} / C_{2}$ values in Table 4 for $C_{m e}, C_{m z}$, and $C_{m p}$ ) are slightly less than 2 for cases with door straps and are close to or slightly over 2 for cases without door straps. There is little primary bending stress in localized regions; i.e., $P_{b}$ equals zero. Therefore, the ratio of $P_{m}$ and $\left(P_{L}+P_{b}\right)$ is around $1: 2$. The ratio of peak effective surface stress, $C_{\text {se }} F$, (or peak effective extreme fiber stress) and the average axial membrane stress, $C_{2} F$, is around 3 for the case with door straps and is slightly over 3 for the case without door straps. The surface stresses at Locations $A$ and $B$ are the combinations of local primary membrane $\left(P_{L}\right)$ and local bending stresses $(Q)$, and are secondary stresses, i.e., $P_{L}+P_{b}+Q$. Therefore, the ratio of $P_{m},\left(P_{L}+P_{b}\right)$, and $\left(P_{L}+P_{b}+Q\right)$ is approximately equal to $1: 2: 3$.

Based on the limited cases studied, the local stress criteria $\left(P_{L}\right.$ and $\left.P_{L}+P_{b}\right)$ seems to govern the design of cable trays because the ratio of stress limits 
$P_{m}:\left(P_{L}+P_{b}\right):\left(P_{L}+P_{b}+Q\right)$ in accordance with either the NTED Design Guide or the ASME B\&PV Code Section III is $1.0: 1.5: 3.0$; i.e.,

NTED Design Guide: General : Local : Secondary $=1: 1.5: 3.0$
ASME Stress Limits: $\quad \mathrm{P}_{\mathrm{m}}: \mathrm{P}_{\mathrm{L}}+\mathrm{P}_{\mathrm{b}}: \mathrm{P}_{\mathrm{L}}+\mathrm{P}_{\mathrm{b}}+\mathrm{Q}$
$\quad=\mathrm{S}_{\mathrm{m}}: 1.5 \mathrm{~S}_{\mathrm{m}}: 3.0 \mathrm{~S}_{\mathrm{m}}$

Approximate ratio of maximum stresses in a cable tray:

$$
P_{m}: P_{L}+P_{b}: P_{L}+P_{b}+Q=1: 2: 3
$$

$S_{m}$ is the design stress intensity factor defined in Appendix III of the ASME B\&PV Code Section III. For the design of canister frames, $S_{m}$ is the smaller of $2 S_{y} / 3$ and $S_{u} / 3, S_{y}$ and $S_{u}$ are the minimum yield and tensile strengths of the cable tray material at room temperature.

The above assessment was based on classifying the bending stress at Location $A$ as the local bending stress (i.e., a secondary stress, Q). In the downhole emplacement assembly, the region near the cable tray/end plate junction is vital to the integrity of the system as described in Section 3.3.3. It is therefore recommended that this local bending stress be upgraded to primary bending stress $P_{b}$ as shown in Table 2 to prevent large deformation. Following this stress reclassification, the maximum value of $P_{L}+P_{b}+Q$ occurs at Location $B$ and is less than the maximum surface stress in Location $A$. We, thus, have the following:

Approximate ratio of maximum stresses in a cable tray:

$$
P_{m}: P_{L}+P_{b}: P_{L}+P_{b}+Q=1: 3: \text { (less than 3) }
$$

The local stress criterion is again governing the design of the downhole emplacement assembly after the reclassification of the bending stress near the cable tray/end plate junction, because the ratio of maximum primary to maximum local stresses is $1: 3$ compared to the allowable stress ratio of $1.0: 1.5$. In short, the surface stress at Location A governs the design, and there is no need to evaluate the stresses at other Locations. It is the authors' opinion that the application of local stress criterion at Location A should not be strictly 
enforced in accordance with either the NTED Design Guide or the ASME Code if the exceedance at Location $A$ is not significant, because the bending stress at the cable tray/end plate junction is, afterall, a secondary stress. The amount of relaxation should be evaluated on a case-by-case basis using engineering judgement.

\subsubsection{Stresses in Welds.}

The stresses in welds were not examined in this study. It is not practical to perform a finite element analysis each time welding of two pieces of metals are involved. The weld requirements of existing civil structure codes, such as the AISC Code, have the advantage of being simple. However, because the welds between the cable trays and the end plates are vital in the performance of canister frames, a larger margin of safety is required compared to regular civil structures.

While it is not practical to perform finite element analysis of welds in the design of canister frames, it seems to be a good investment to perform a finite element analysis of limited scope with the objective of examining the stress distribution in the welds between the cable trays and the end plates. 
Table 1. Finite element analysis cases.

\begin{tabular}{|c|c|c|c|c|c|c||}
\hline $\begin{array}{c}\text { Case } \\
\text { Number }\end{array}$ & $\begin{array}{c}\text { Model } \\
\text { Number }\end{array}$ & $\begin{array}{c}\text { Bolt } \\
\text { Size } \\
\text { in.) }\end{array}$ & $\begin{array}{c}\text { Cable Tray } \\
\text { Thickness } \\
\text { in.) }\end{array}$ & $\begin{array}{c}\text { End plate } \\
\text { Thickness } \\
\text { in.) }\end{array}$ & $\begin{array}{c}\text { Preload } \\
\text { (kips) }\end{array}$ & $\begin{array}{c}\text { Include } \\
\text { Door } \\
\text { Straps? }\end{array}$ \\
\hline \hline 1 & 300 & 1.375 & 0.500 & 2.25 & 0 & yes \\
\hline 2 & 301 & 1.375 & 0.500 & 2.25 & 75 & yes \\
\hline 3 & 302 & 1.375 & 0.500 & 2.25 & 100 & yes \\
\hline 4 & 303 & 1.375 & 0.500 & 2.25 & 125 & yes \\
\hline \hline 5 & 400 & 1.125 & 0.500 & 2.25 & 0 & yes \\
\hline 6 & 401 & 1.125 & 0.500 & 2.25 & 50 & yes \\
\hline 7 & 402 & 1.125 & 0.500 & 2.25 & 75 & yes \\
\hline 8 & 403 & 1.125 & 0.500 & 2.25 & 100 & yes \\
\hline \hline 9 & 310 & 1.375 & 0.500 & 2.25 & 0 & no \\
\hline 10 & 311 & 1.375 & 0.500 & 2.25 & 75 & no \\
\hline 11 & 312 & 1.375 & 0.500 & 2.25 & 100 & no \\
\hline \hline 12 & 410 & 1.125 & 0.500 & 2.25 & 0 & no \\
\hline 13 & 411 & 1.125 & 0.500 & 2.25 & 50 & no \\
\hline 14 & 412 & 1.125 & 0.500 & 2.25 & 75 & no \\
\hline
\end{tabular}


Table 2. Categorization of normal stresses in various regions of a canister frame.

\begin{tabular}{|c|c|c|}
\hline Location & $\begin{array}{l}\text { Type of Normal } \\
\text { Stresses }\end{array}$ & Stress Category \\
\hline$A$ & $\begin{array}{l}\text { Membrane } \\
\text { Bending }\end{array}$ & $\begin{array}{l}\text { Local primary membrane stress, } P_{L} \\
\text { Primary bending stress } P_{b} \text { (NoTE: It is, in reality, a } \\
\text { local bending stress; i.e. a secondary stress, } Q \text {. Due to the } \\
\text { importance of this region in the dowhole assembly, it is appro- } \\
\text { priate to treat it as a primary bending stress) }\end{array}$ \\
\hline B & $\begin{array}{l}\text { Membrane } \\
\text { Bending }\end{array}$ & $\begin{array}{l}\text { Local primary membrane stress, } P_{L} \\
\text { Local bending stress (a secondary stress), } Q\end{array}$ \\
\hline C & $\begin{array}{l}\text { Membrane } \\
\text { Bending }\end{array}$ & $\begin{array}{l}\text { General primary membrane stress, } P_{m} \\
\text { Primary bending stress, } P_{b}\end{array}$ \\
\hline$D$ & $\begin{array}{l}\text { Membrane } \\
\text { Bending }\end{array}$ & $\begin{array}{l}\text { General primary membrane stress, } P_{m} \\
\text { Primary bending stress, } P_{b}\end{array}$ \\
\hline$E$ & $\begin{array}{l}\text { Membrane } \\
\text { Bending }\end{array}$ & $\begin{array}{l}\text { Local primary membrane stress, } P_{L} \\
\text { Local bending stress (a secondary stress), } Q \\
\text { Yielding is generally allowed for seating of } \\
\text { bolt head. }\end{array}$ \\
\hline$F$ & $\begin{array}{l}\text { Membrane } \\
\text { Bending }\end{array}$ & $\begin{array}{l}\text { Local primary membrane stress, } P_{L} \\
\text { Local bending stress (a secondary stress), Q }\end{array}$ \\
\hline G & $\begin{array}{l}\text { Membrane } \\
\text { Bending }\end{array}$ & $\begin{array}{l}\text { Local primary membrane stress, } P_{L} \\
\text { Local bending stress (a secondary stress), } Q\end{array}$ \\
\hline
\end{tabular}

NOTE: General primary membrane stress and primary bending stress exist at at locations including locations at or near gross structural discontinuities. See Sec. 3.3.4, Sec. 3.3.3, and Table 4 for details.

A - Curved region of a cable tray near the end plate. It is at a gross structural discontinuity.

$B$ - A region on the flange of a cable tray beneath the door strap cut-off. It is at a gross structural discontinuity.

C - Regions on the cable tray and door strap: (1) far away from structural discontinuities, (2) near a gross structural discontinuity; but the stresses are calculated based on a large cross-sectional area. Example: $P_{m}$ described in section 3.3.4, or $C_{2}$ in rable 4. This stress is applicable to regions far away as well as near the cable tray-end plate junction.

D - Regions on the end plate: (1) far away from bolt holes and cable trays, and (2) near a gross structural discontinuity; but the stresses are calculated based on a large cross-sectional area. Example: $P_{b}$ described in Section 3.3.3.

$E$ - The contact region between the bolt head and the end plate.

$F$ - Underside of the end $p l$ ate near the outer bolt hole.

$G$ - Welds and the regions adjacent to the welds. A gross structural discontinuity. 
Table 3. Allowable stresses in the NTED Design Guide and the ASME B\&PV Code.

NTED Design Guide

\begin{tabular}{|c|c|c|c|}
\hline & $\begin{array}{r}\text { General } \\
\text { Primary }\end{array}$ & \multirow{2}{*}{$\begin{array}{l}\begin{array}{l}\text { Local } \\
\text { Primary }\end{array} \\
P_{L}+P_{b} \\
\end{array}$} & \multirow{2}{*}{$\begin{array}{l}\text { Secondary } \\
P_{1}+P_{6}+Q\end{array}$} \\
\hline & $P_{m}, P_{b}$, or $P_{m}+P_{b}$ & & \\
\hline Emplaced Load & $0.500 \mathrm{~S}_{\mathrm{v}}$ & $0.750 \mathrm{~S}_{\mathrm{v}}$ & $1.500 \mathrm{~S}_{\gamma}$ \\
\hline Stemmed Load & $0.667 \mathrm{~S}_{v}$ & $1.000 \mathrm{~S}_{y}$ & $2.000 \mathrm{~S}_{y}$ \\
\hline Pull Test Load & $0.750 \mathrm{~S}_{\mathrm{v}}$ & $1.125 S_{v}$ & $2.250 \mathrm{~S}_{y}$ \\
\hline \multicolumn{4}{|c|}{$\begin{array}{l}\text { Maximum allowable limit for general membrane } P_{m} \text {, bending } P_{b} \text {, and general } \\
\text { membrane plus bending stresses }\left(P_{m}+P_{b}\right) \text {. } \\
\text { Maximum allowable limit for local membrane } P_{L} \text { and local membrane plus } \\
\text { bending stresses }\left(P_{L}+P_{b}\right) \text {. } \\
\text { Maximum allowable limit for sum of membrane } P_{L} \text { plus primary bending, } P_{b} \text {, } \\
\text { plus secondary stresses }(Q) \text {. } \\
\text { Material yield strength. }\end{array}$} \\
\hline
\end{tabular}

Stress Limits in Subsections NB and NF of ASME B\&PV Code Section III

\begin{tabular}{||c|c|c|c|}
\hline & $P_{m}$ & $P_{L}$ or $P_{L}+P_{b}$ & $P_{f}+P_{b}+Q$ \\
\hline \hline Design Loads & $S_{m}\left(0.67 S_{v}\right)$ & $1.5 S_{m}\left(S_{v}\right)$ & $3.0 S_{m}\left(2 S_{v}\right)$ \\
\hline Service Leve1 A & $S_{m}\left(0.67 S_{v}\right)$ & $1.5 S_{m}\left(S_{v}\right)$ & $3.0 S_{m}\left(2 S_{v}\right)$ \\
\hline Service Leve1 B & $1.150 S_{m}\left(0.77 S_{v}\right)$ & $1.725 S_{m}\left(1.15 S_{v}\right)$ & $3.450 S_{m}\left(2.30 S_{v}\right)$ \\
\hline $\begin{array}{l}\text { Testing Condition } \\
- \text { Pressure test }\end{array}$ & $\begin{array}{c}P_{m}<0.9 S_{y} \\
P_{m}+P_{b}<1.35 S_{v}\end{array}$ & & \\
\hline
\end{tabular}

$S_{m}$ is the smaller of $2 S_{y} / 3$ and $S_{u} / 3$, where $S_{y}$ and $S_{u}$ are the yield strength and tensile strength at room temperature. The number in parenthesis is obtained assuming that $2 S_{y} / 3<S_{u} / 3$.

Service Level $A$ is associated with loads for which the components may be subjected to in the performance of its specified service function.

Service Level B is associated with loads for which the component must withstand so that no damage requiring repair will occur. 
Table 4. The stresses in a cable tray.

$S=C F=$ Stress

$F=$ Total applied external axial load on a canister

$C=S / F=$ Stress per $10^{6}$ of $F$

$C_{\text {me }}=$ Peak effective membrane stress (ksi) per $10^{6} 1 \mathrm{~b}$ of $\mathrm{F}$

$C_{\text {se }}=$ Peak effective surface stress (ksi) per $10^{6} 1 \mathrm{~b}$ of $\mathrm{F}$

$C_{m z}=$ Peak axial membrane stress (ksi) per $10^{6} 1 \mathrm{~b}$ of $\mathrm{F}$

$C_{z}=$ Average axial membrane stress per $10^{6}$ lb of $F=F / 4 A\left(C_{z}=21.3 \mathrm{ksi}\right)$

$\left(A=\right.$ Cross sectional area of the cable tray $\left.=11.7 \mathrm{in}^{2}\right)$

$C_{m p}=$ Peak principal membrane stress (ksi) per $10^{6} 1 \mathrm{~b}$ of $\mathrm{F}$

$C_{z}$ is a general primary membrane stress.

$C_{m e}, C_{m z}$, and $C_{m p}$ are local primary membrane stresses.

$C_{\text {se }}$ is a surface stress which includes both local primary membrane and local bending stresses. $C_{\text {se }}$ is a secondary stress.

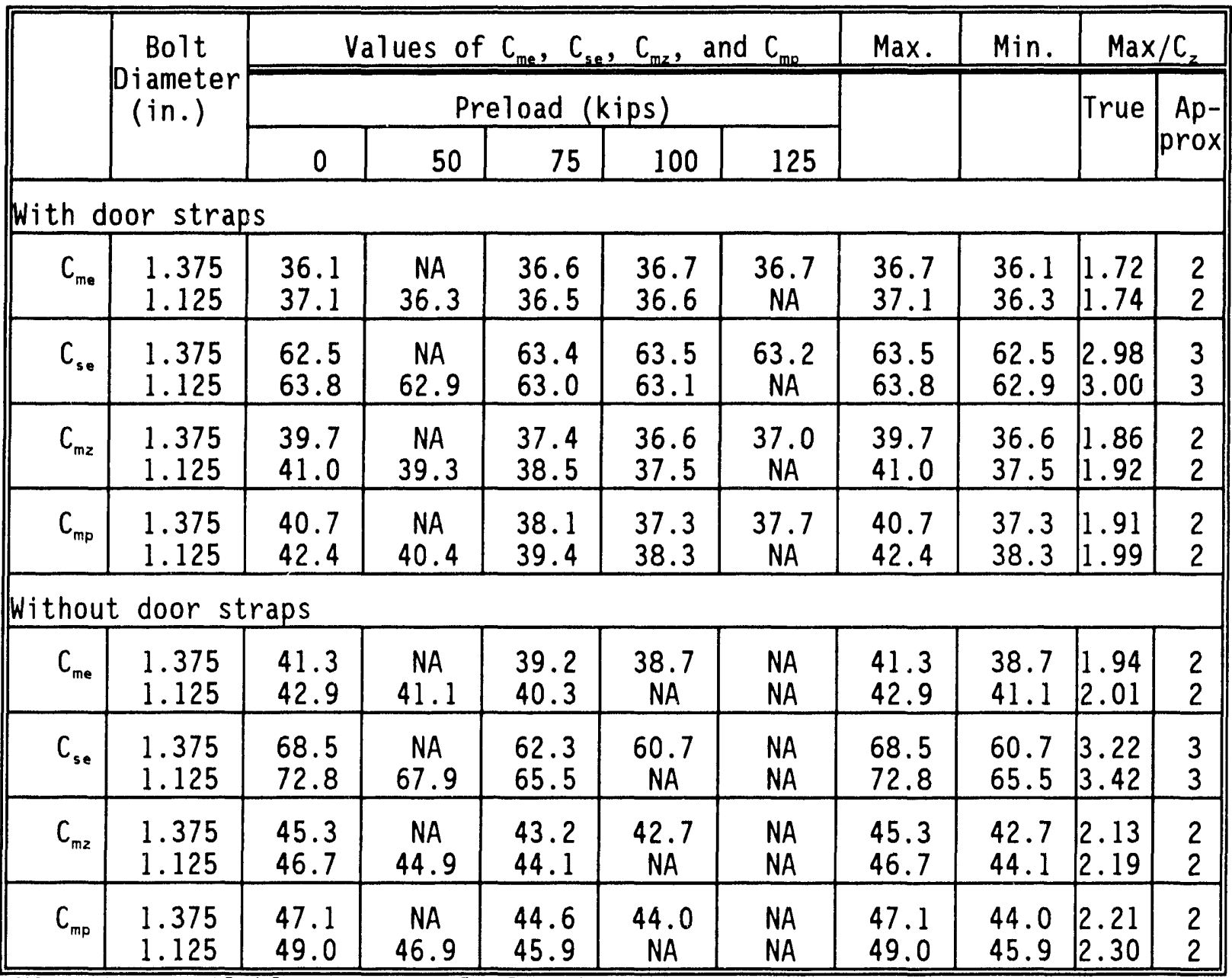

NA $=$ Not available or not calculated. NTED Design Guide:

NOTE: The values given in the last column are for calculating approximate stress ratios as described in Section 3.3.4. 

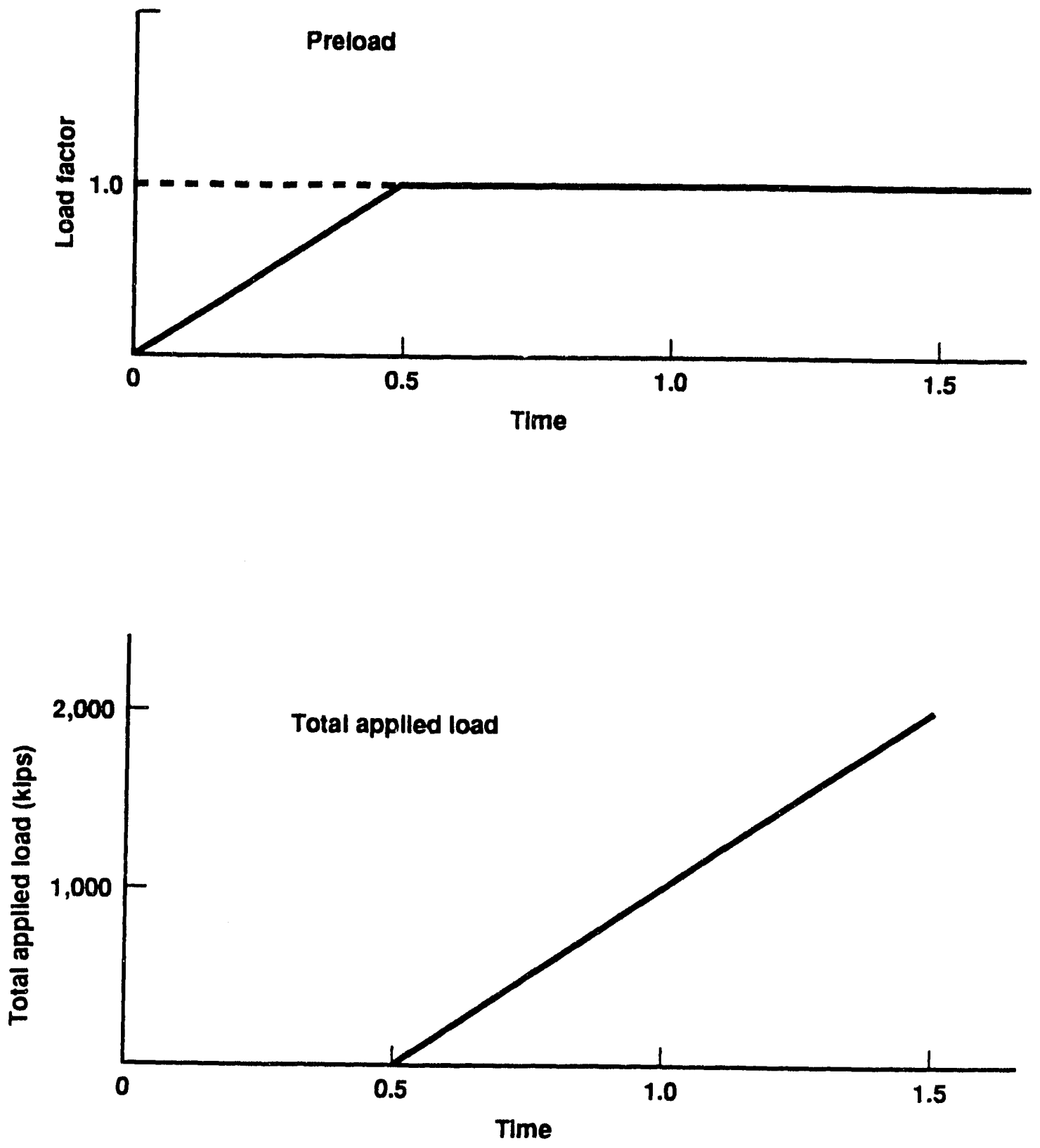

Figure 6. Load curves used in the NIKE3D finite element analysis. 


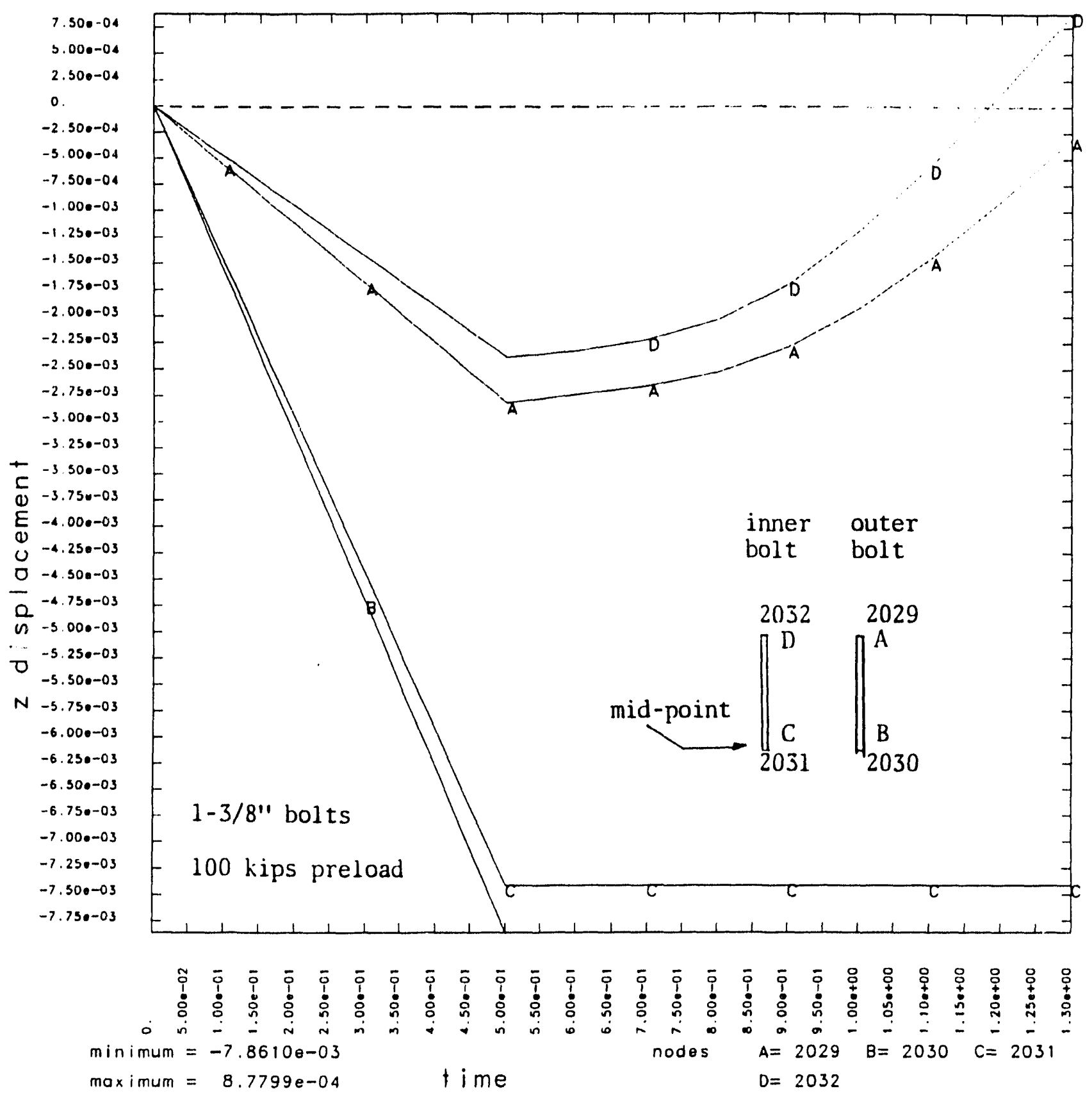

Figure 7. Displacement of the bolt heads and the mid-points of bolt shanks. 

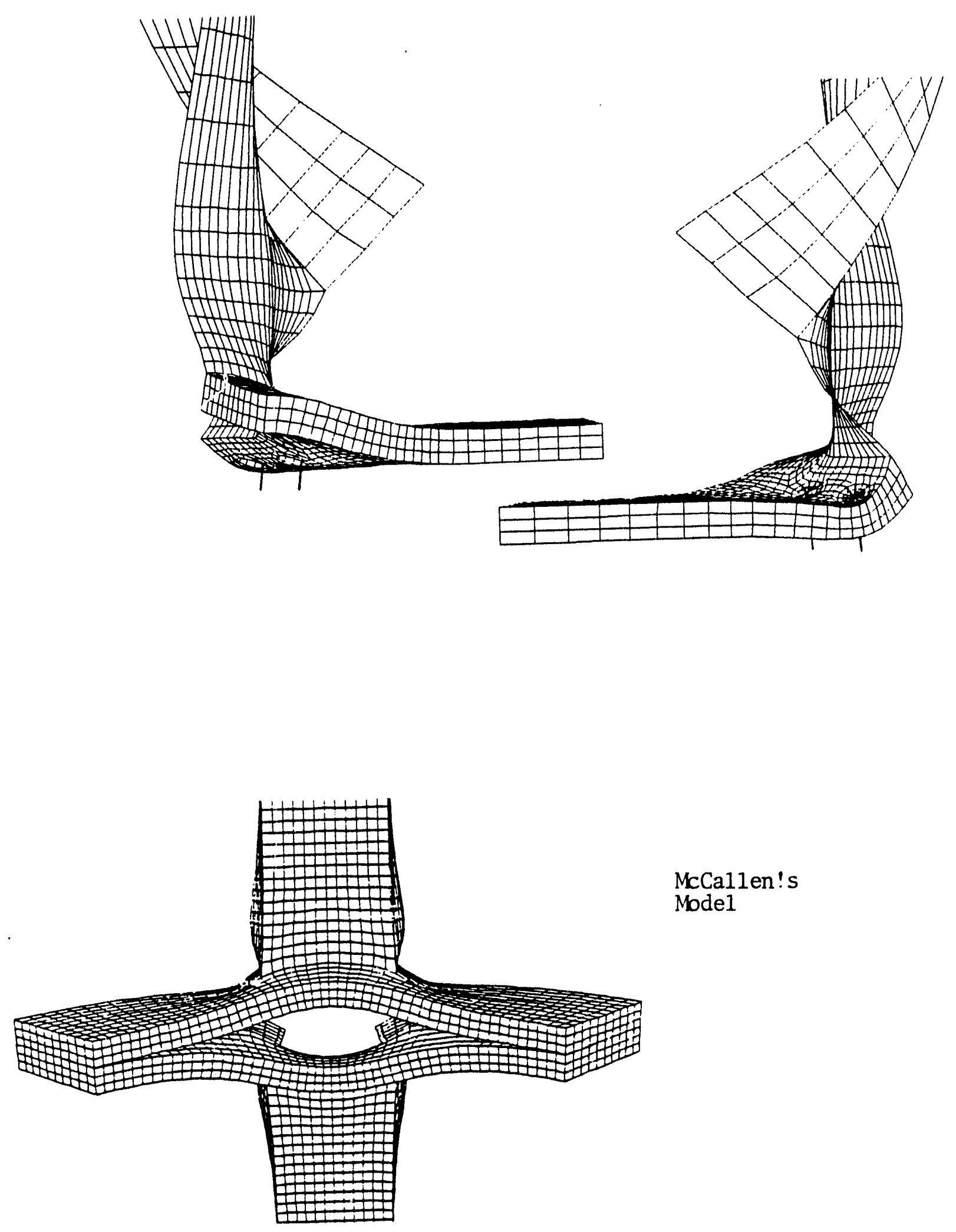

Figure 8. Exaggerated deformed shapes of a canister frame. 
Total applled load (klps)

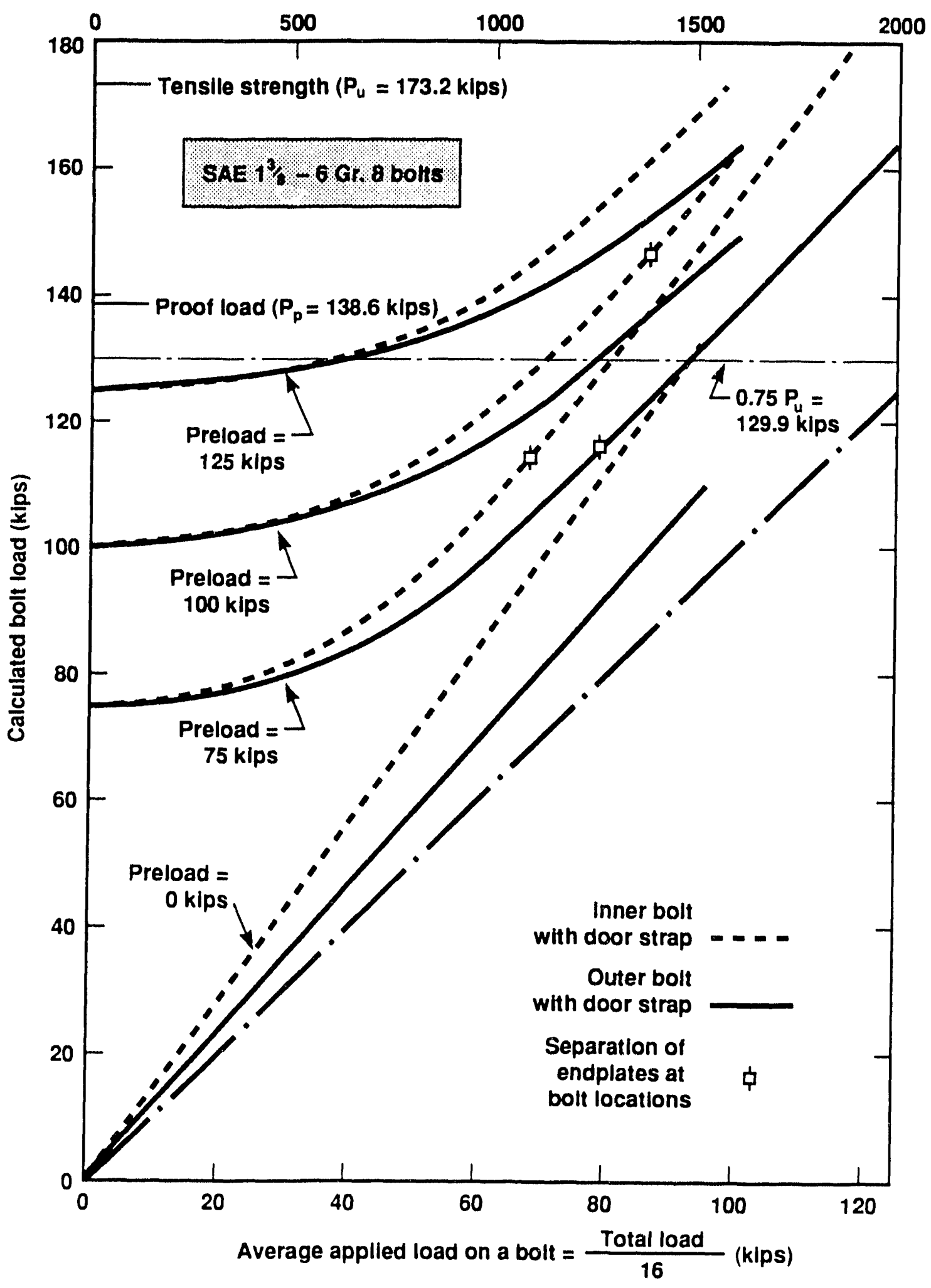

Figure 9. Effects of preload on the calculated bolt loads - 1-3/8 bolts. 
Total applled load (klps)

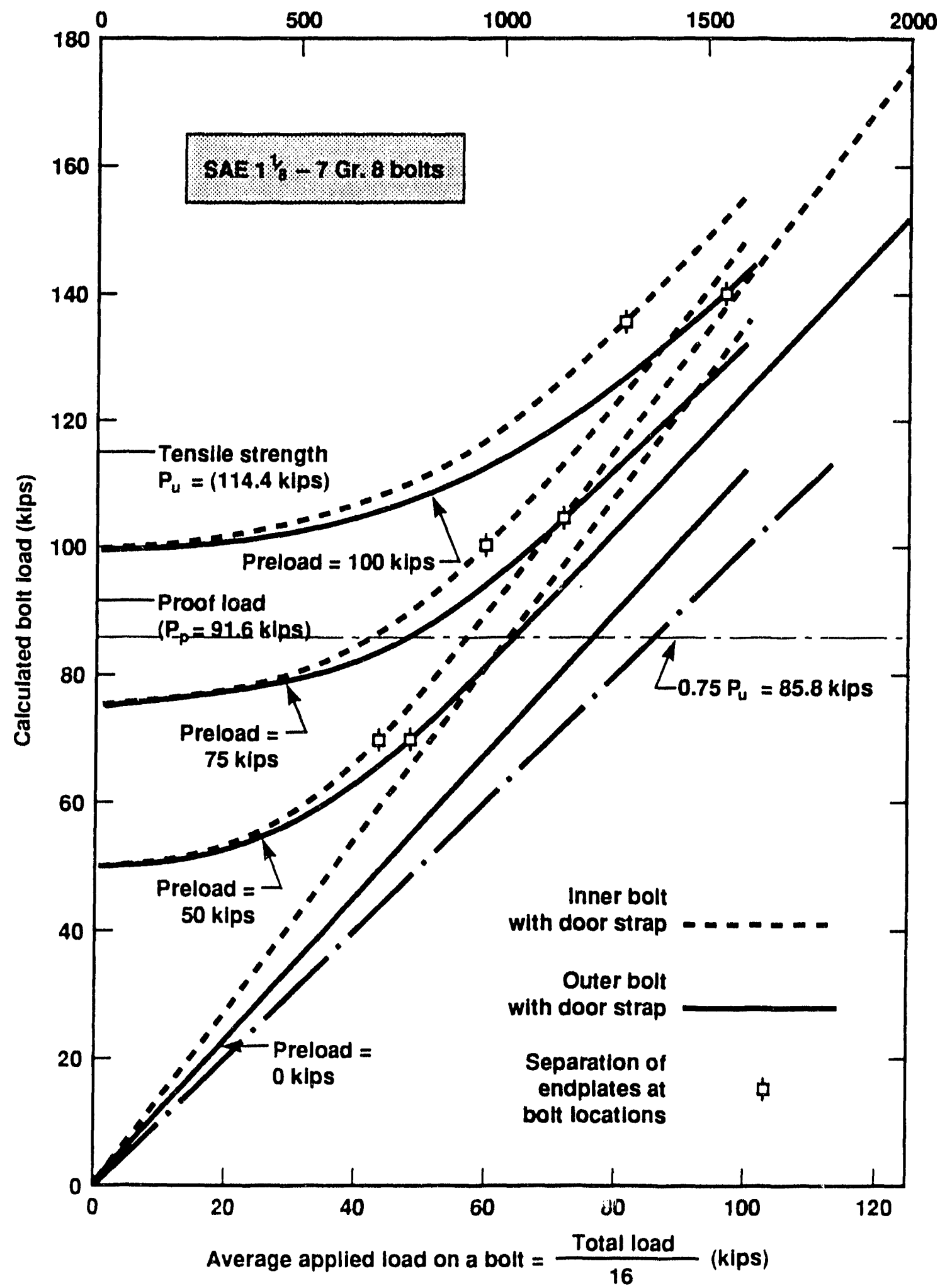

Figure 10. Effects of preload on the calculated bolt loads - 1-1/8 bolts. 
Total applled load (klps)

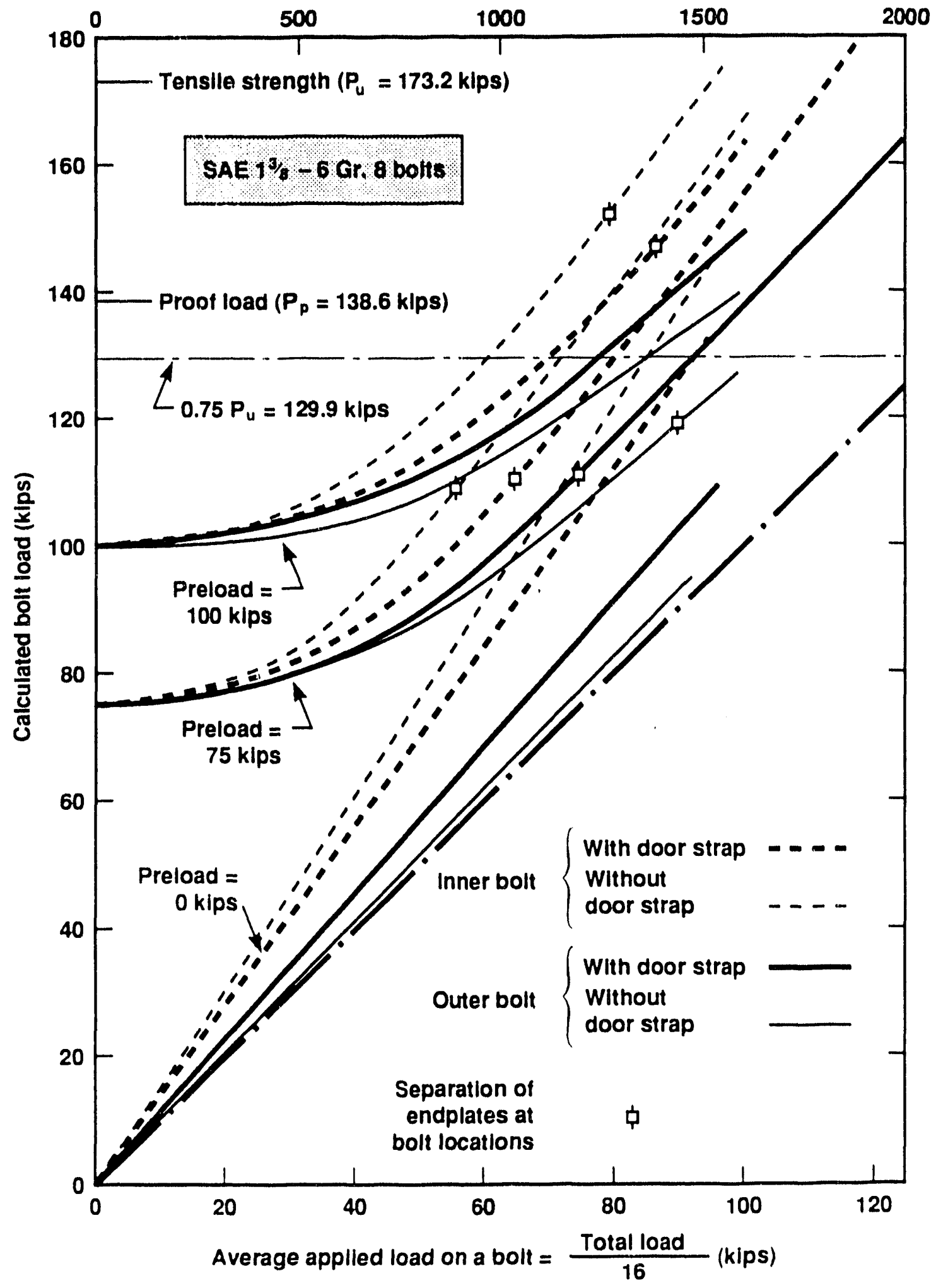

Figure 11. Effects of door straps on the calculated bolt loads $-1-3 / 3$ bolts. 
Total applled load (k/ps)

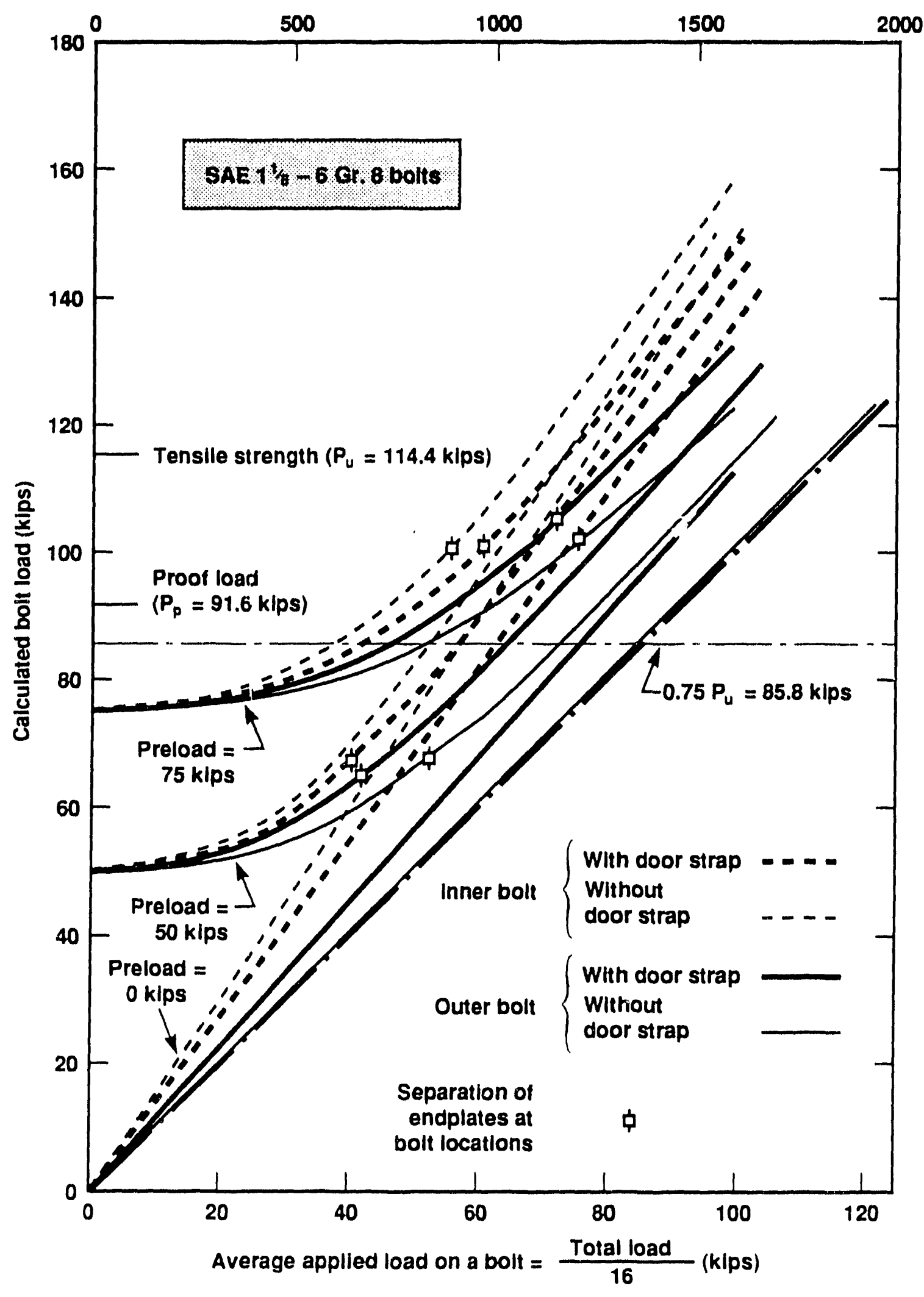

Figure 12. Effects of door straps on the calculated bolt loads $-1-1 / 8$ bolts, 


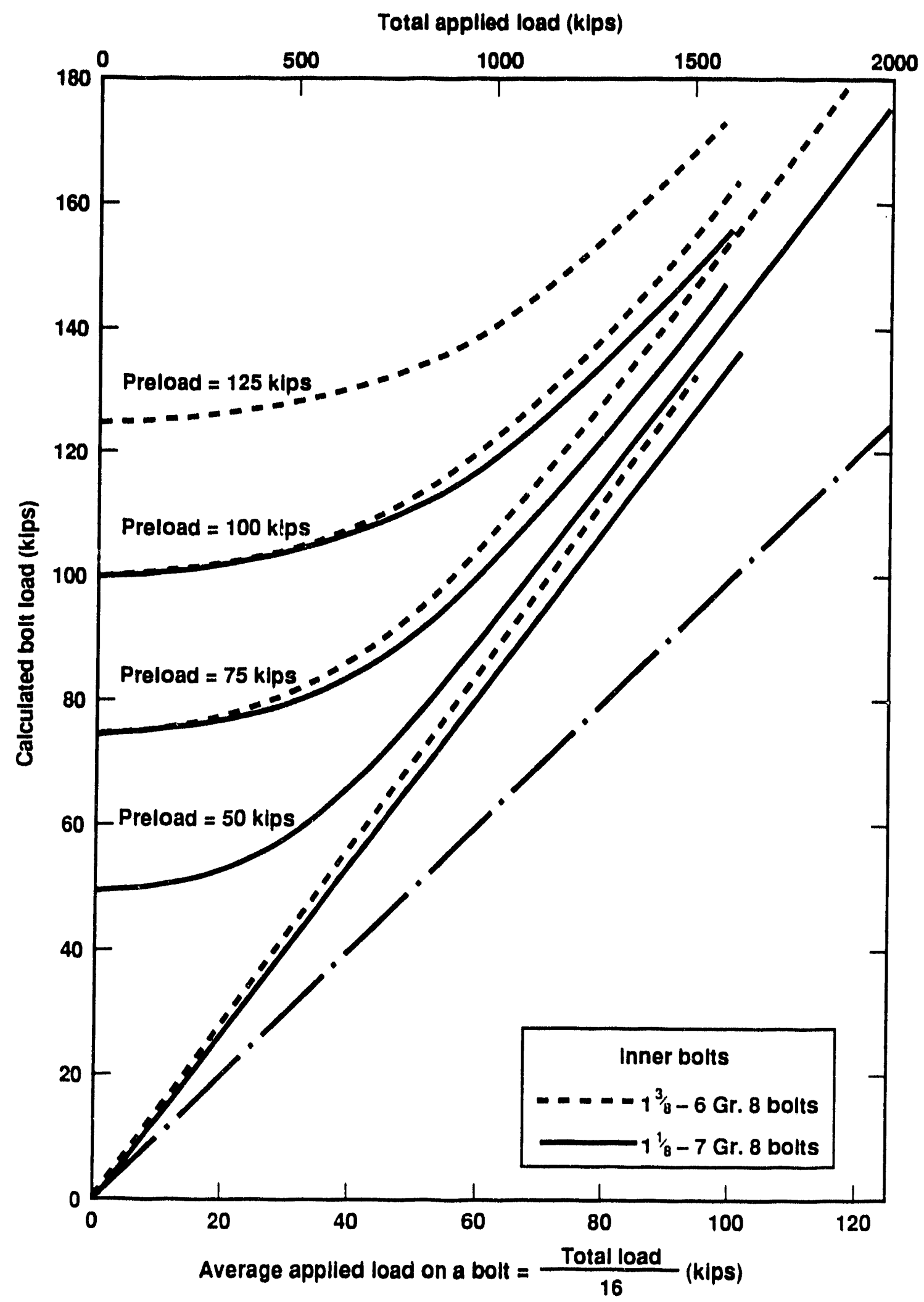

Figure 13. Effects of bolt size on the calculated bolt loads - inner bolts. 


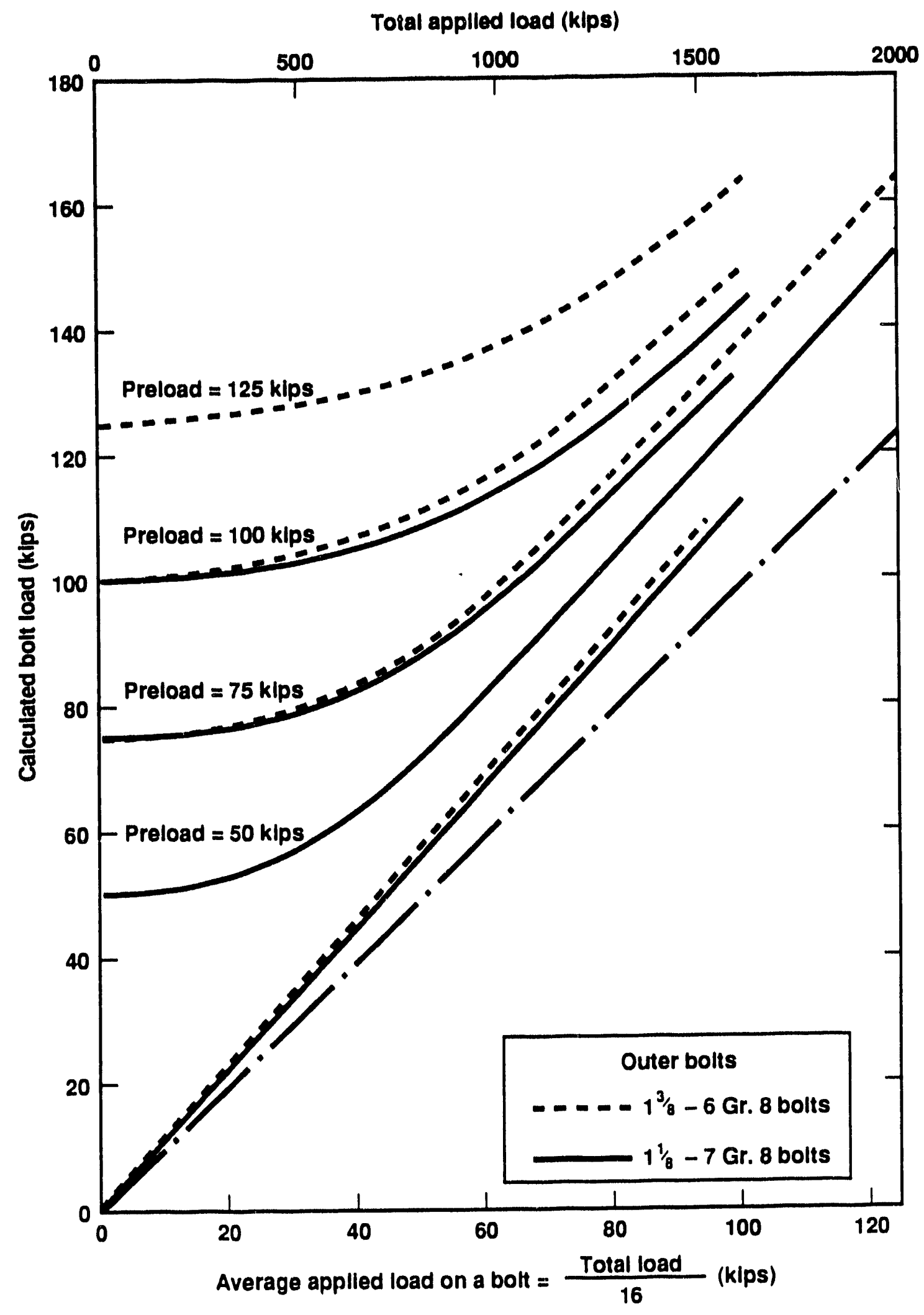

Figure 14. Effects of bolt size on the calculated bolt loads - outer bolts. 


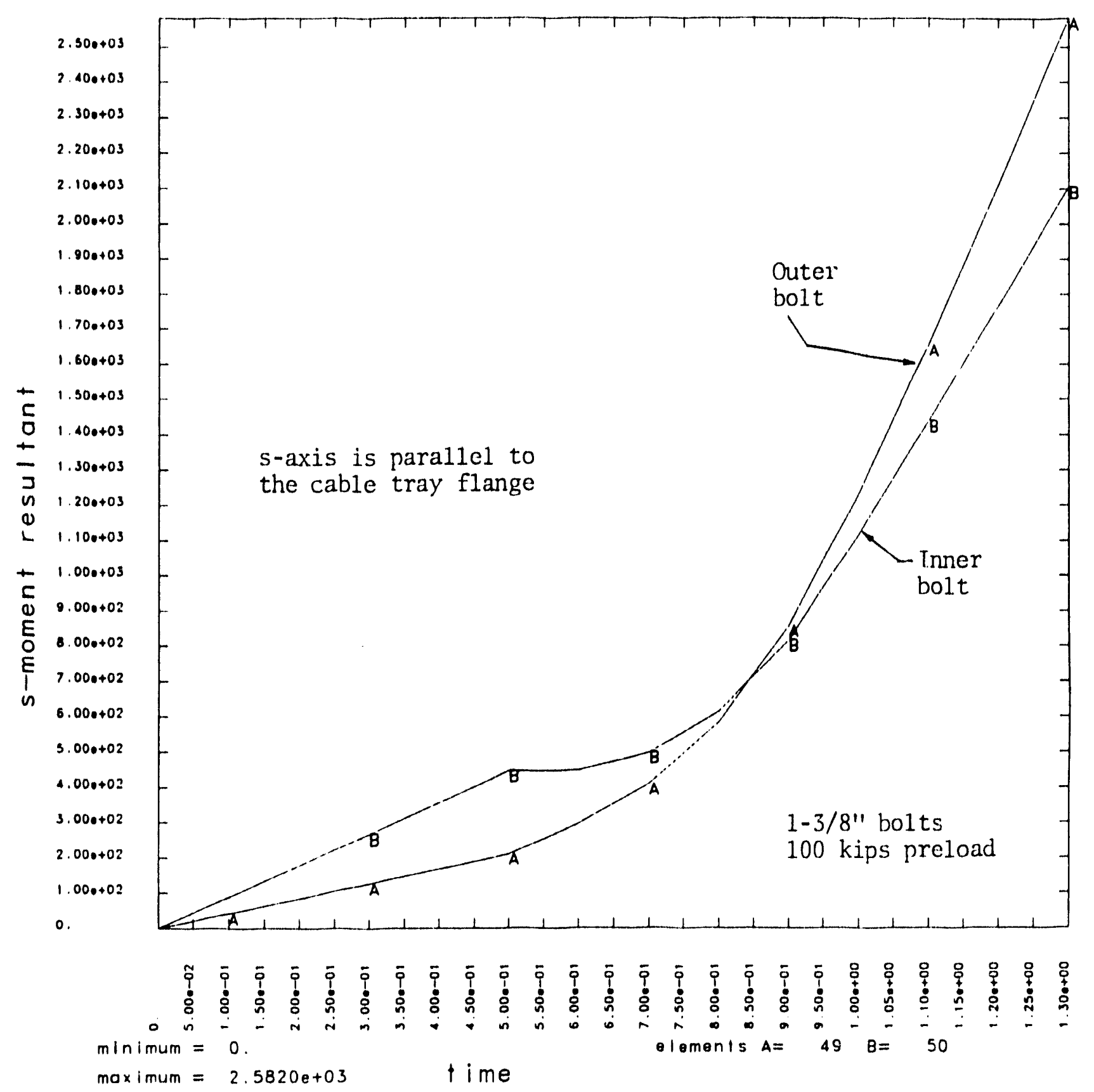

Figure 15. Bending moment in the bolts about an axis parallel to the cable tray flanges. 


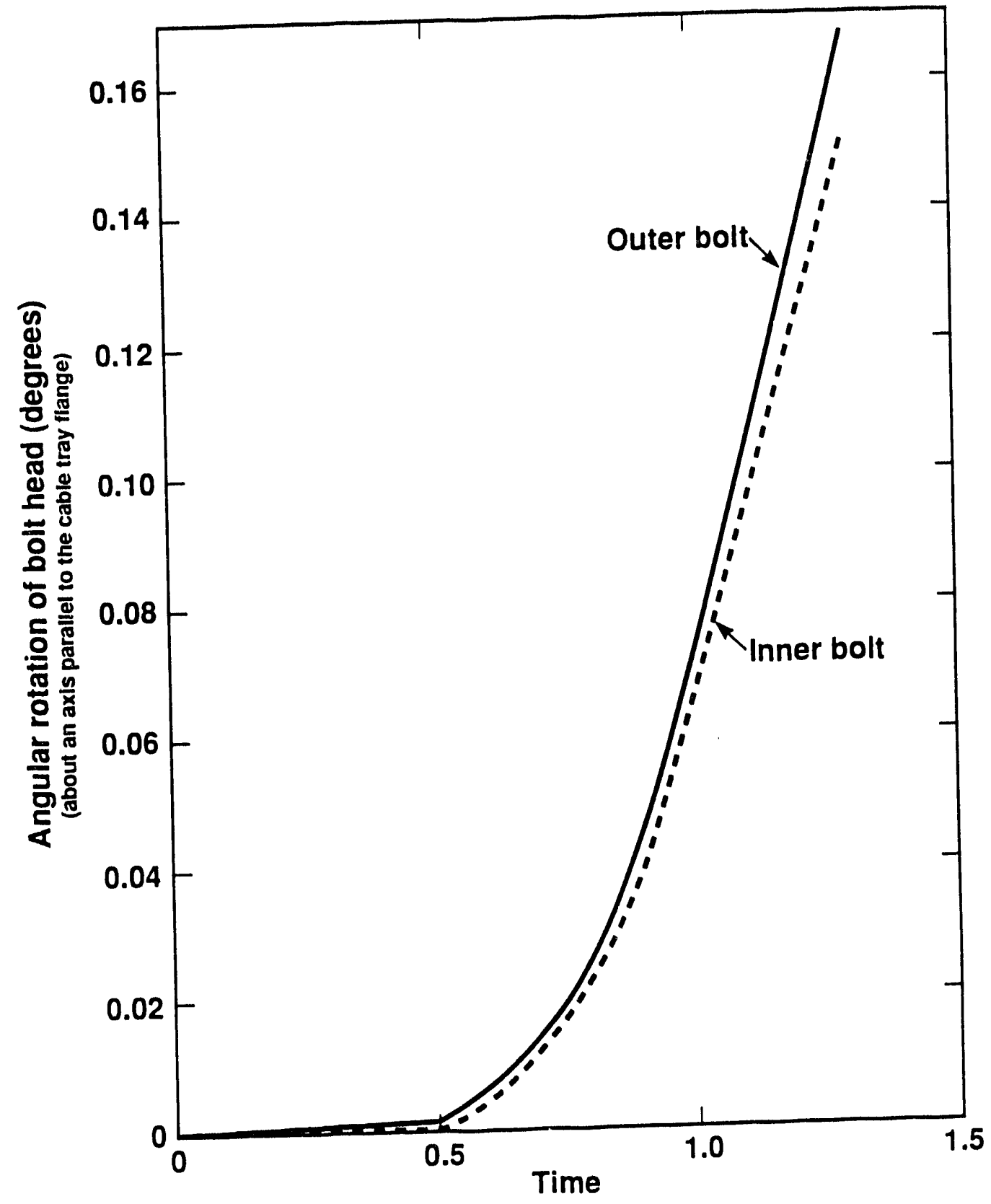

Figure 16. Rotation of bolt heads. 

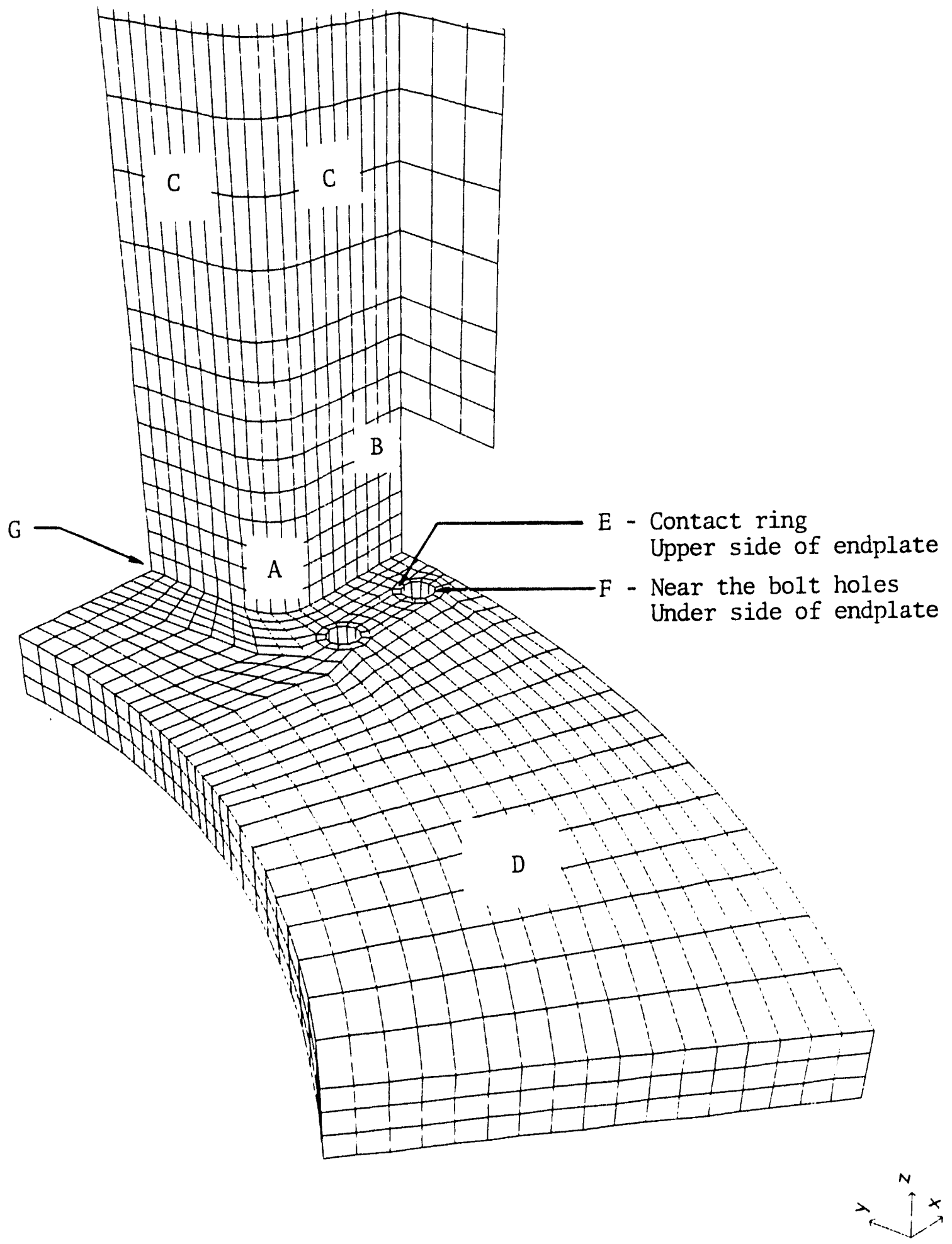

Figure 17. Locations at which the stresses are of interest in design. 


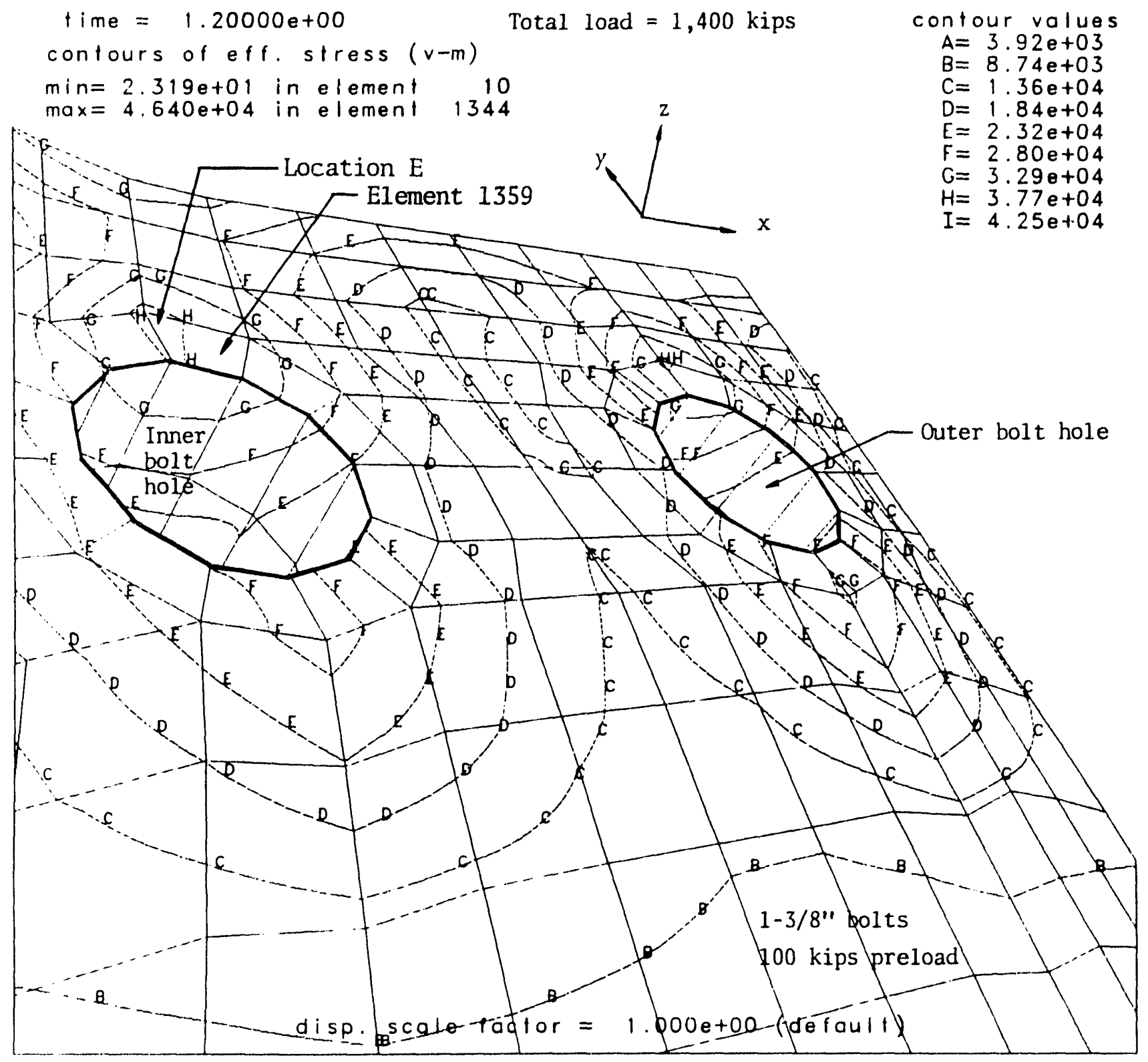

Figure 18. Contours of effective stress in the endplate - top view. 
Total load $=1,400 \mathrm{kips}$
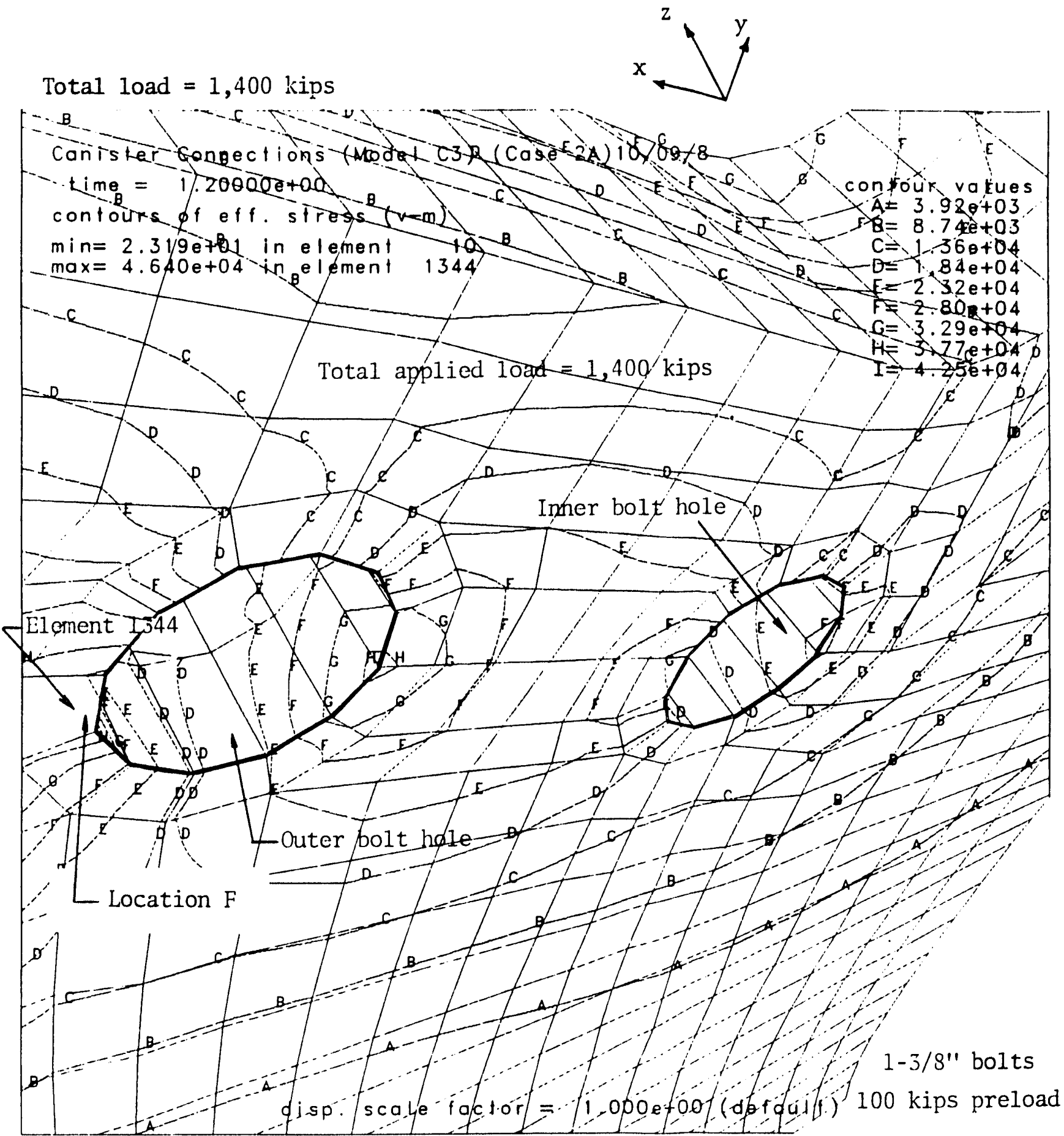

Figure 19. Contours of effective stress in the endplate - bottom view. 


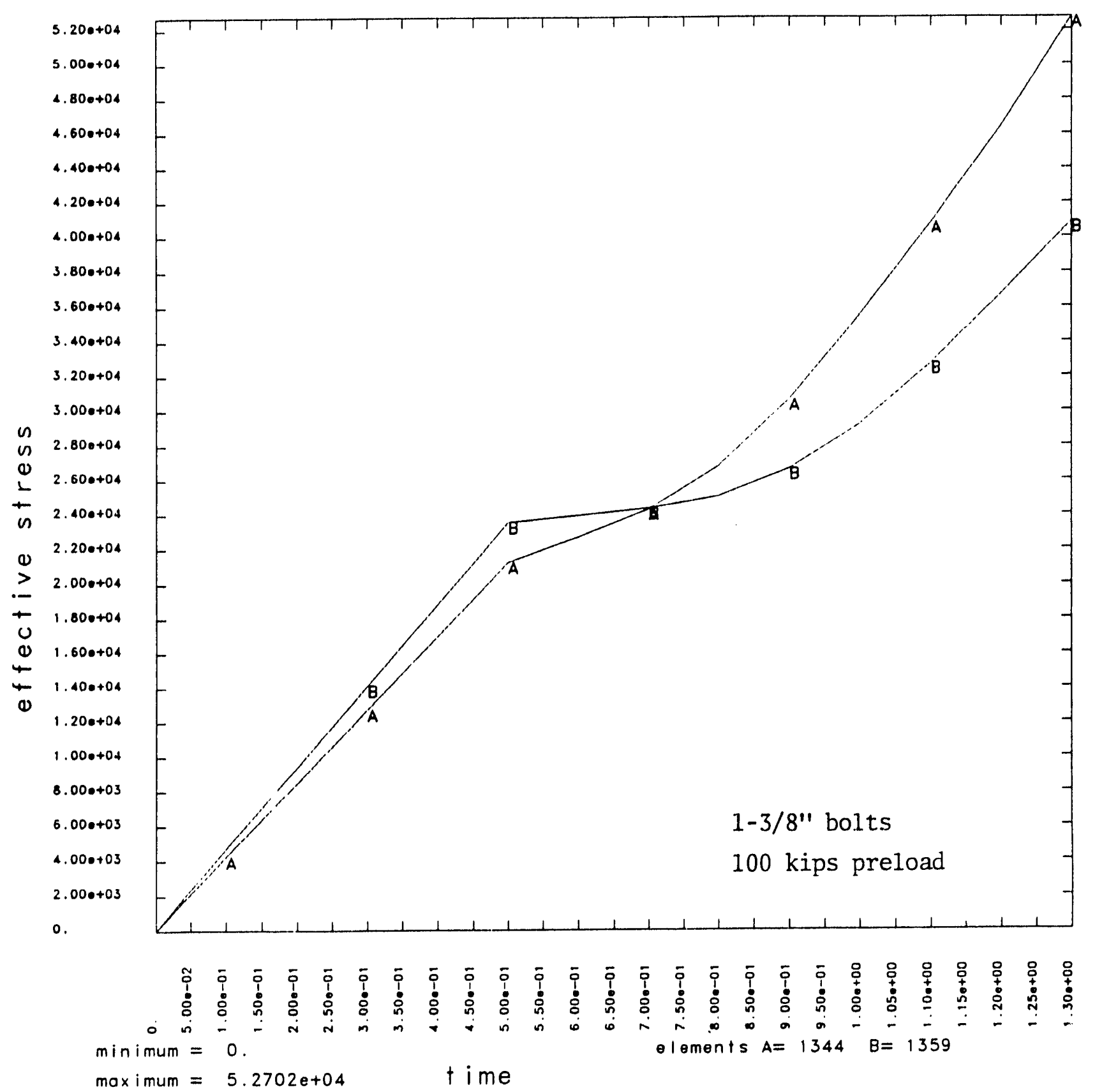

Figure 20. Effective stress in the most highly loaded elements in the endplate. 


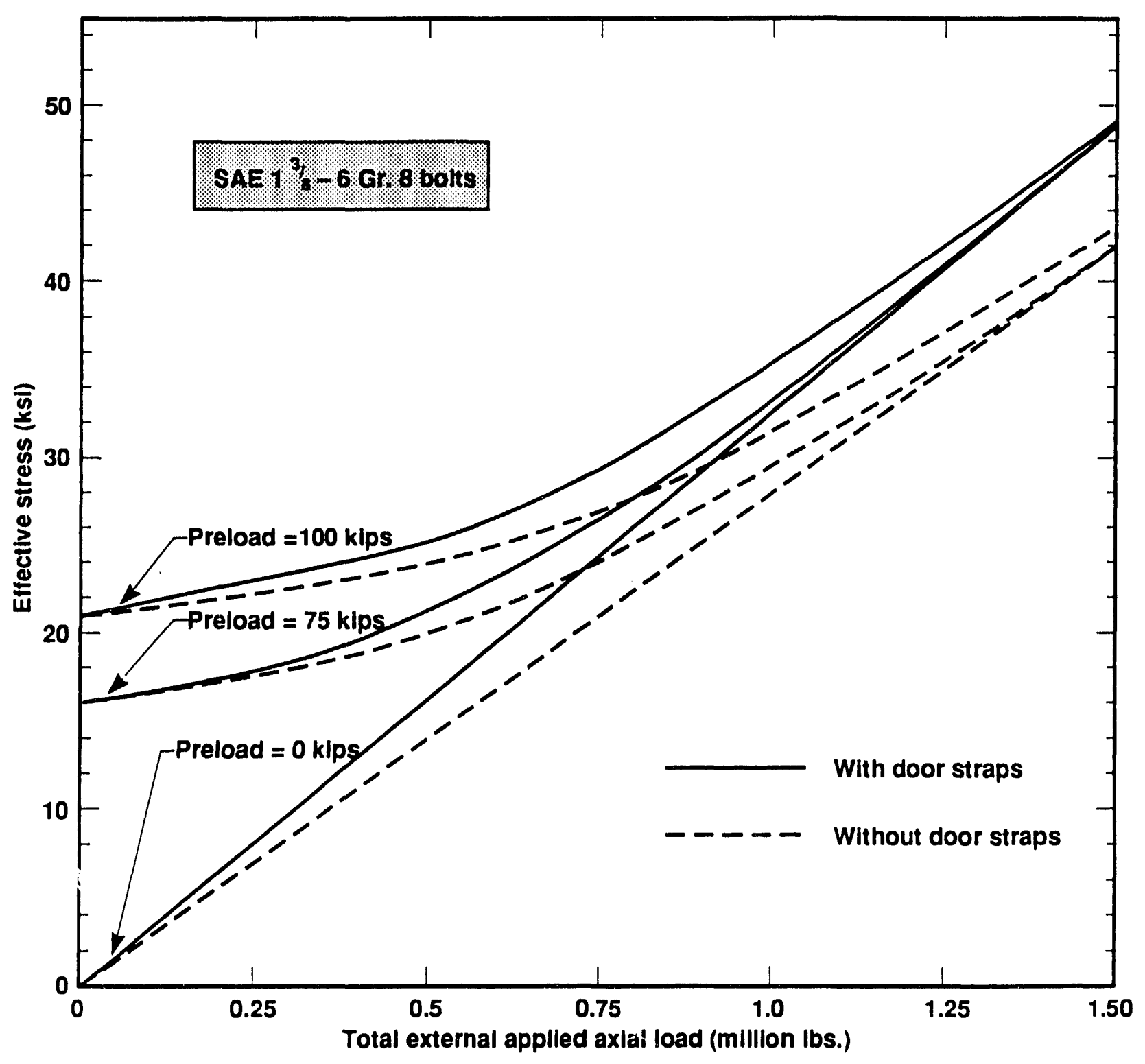

Figure 21. Peak effective stresses at Location $F$ in the endplate for cases involving $1-3 / 8$ " bolts. 


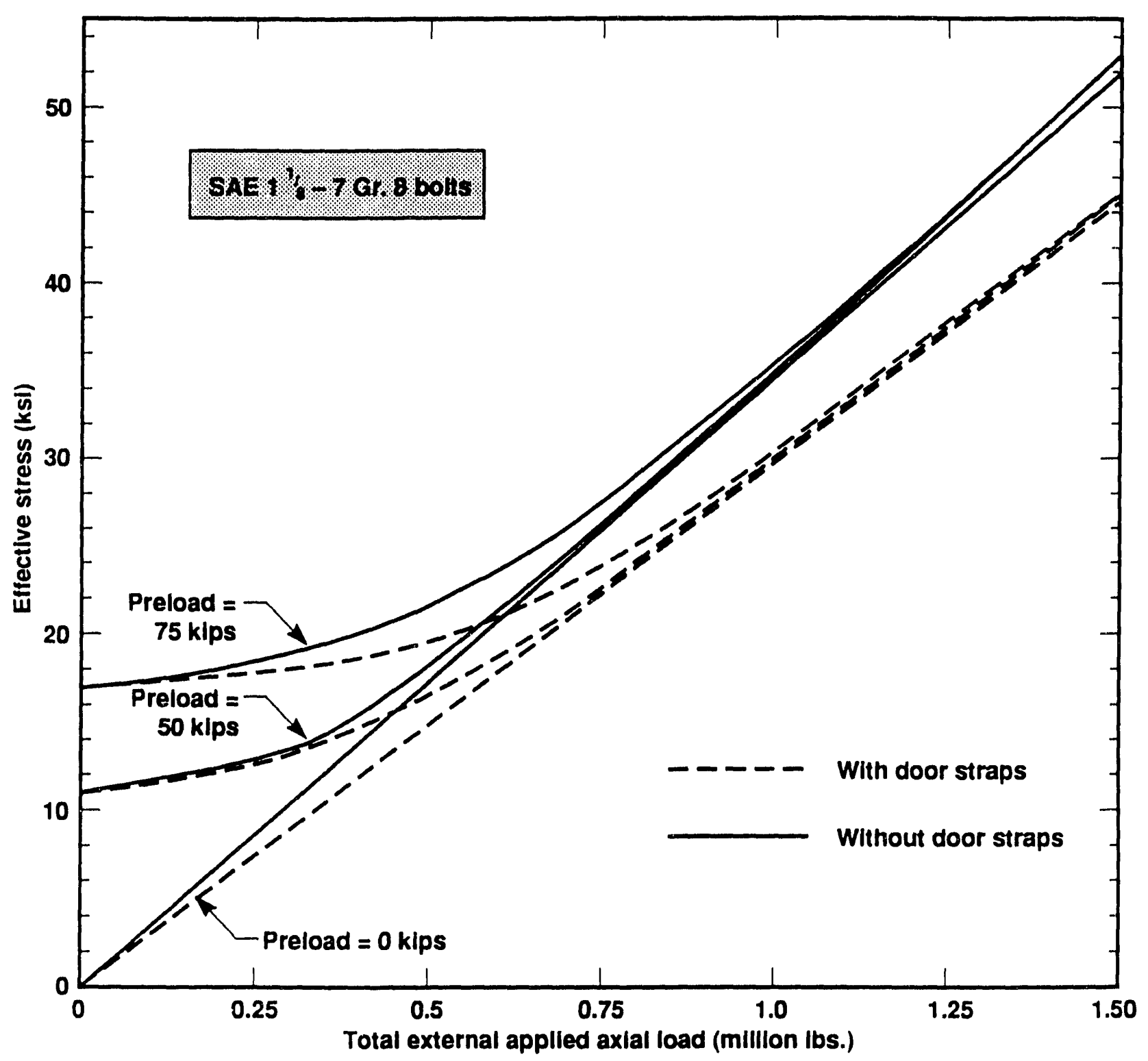

Figure 22. Peak effective stresses at Location $F$ in the endplate for cases involving 1-1/8" bolts. 


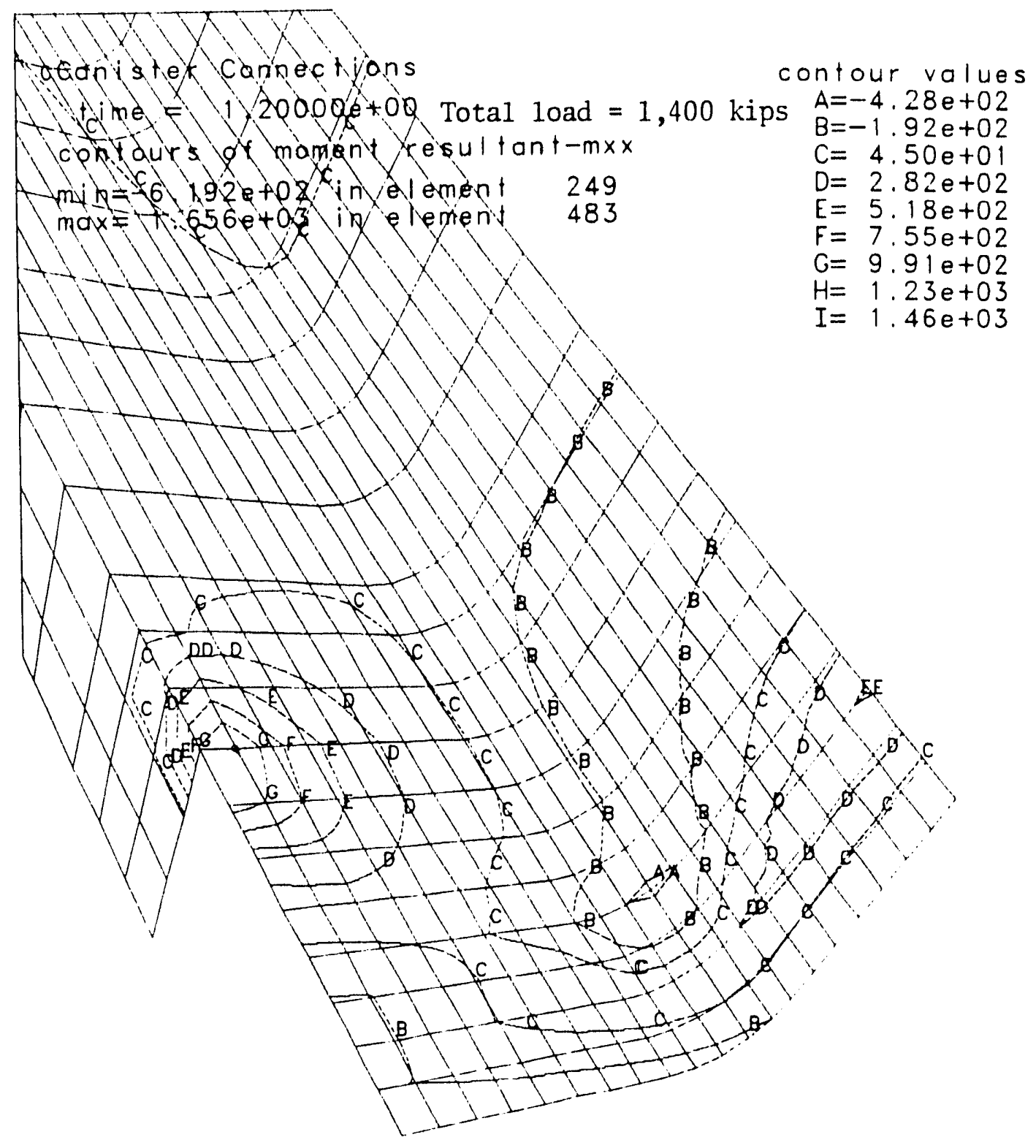

Figure 23. Typical contours of moment resultant $(M x x)$ in the cable tray with door straps. 


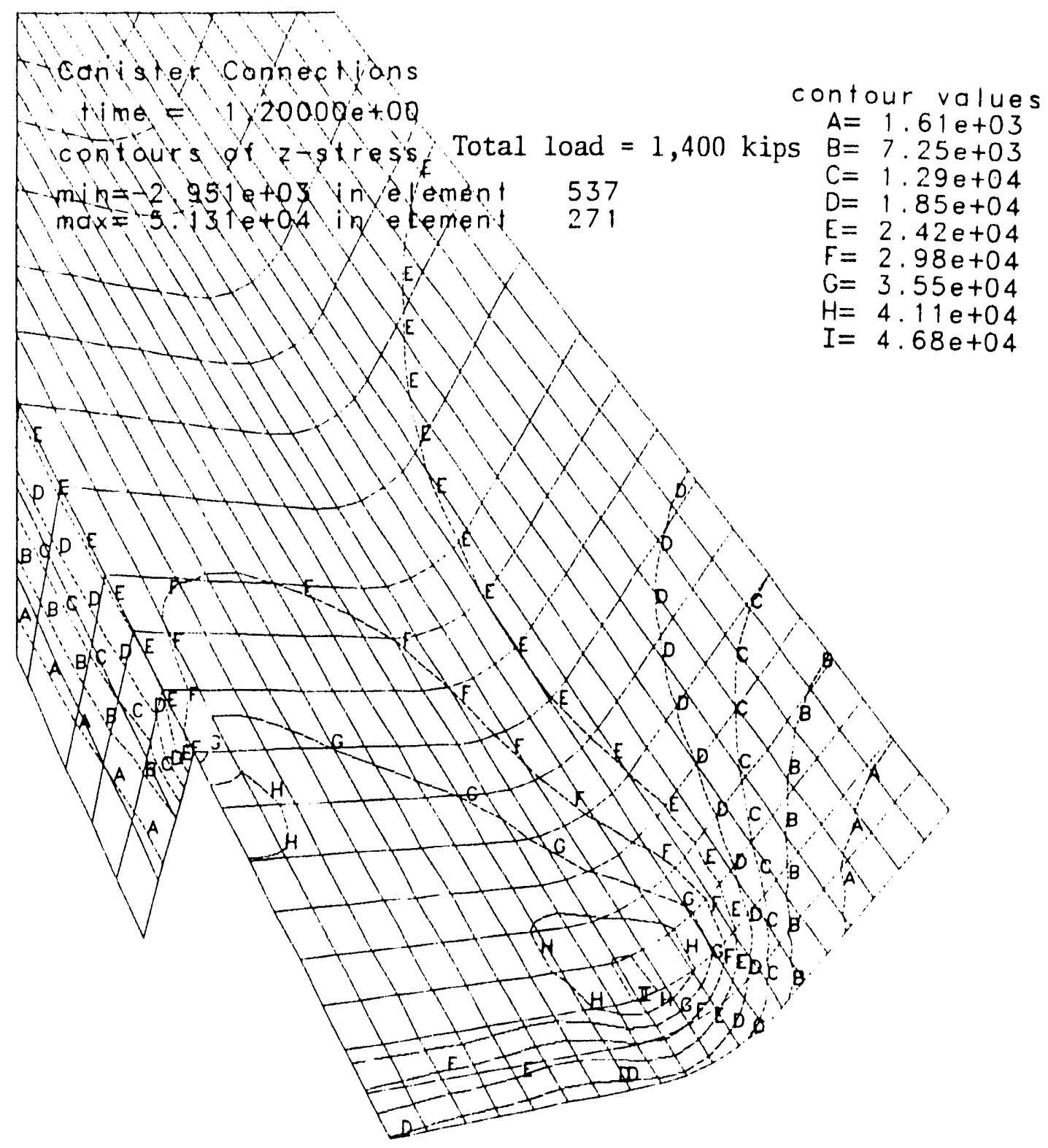

Figure 24. Typical contours of axial membrane stress (z-stress) in the cable tray with door straps. 


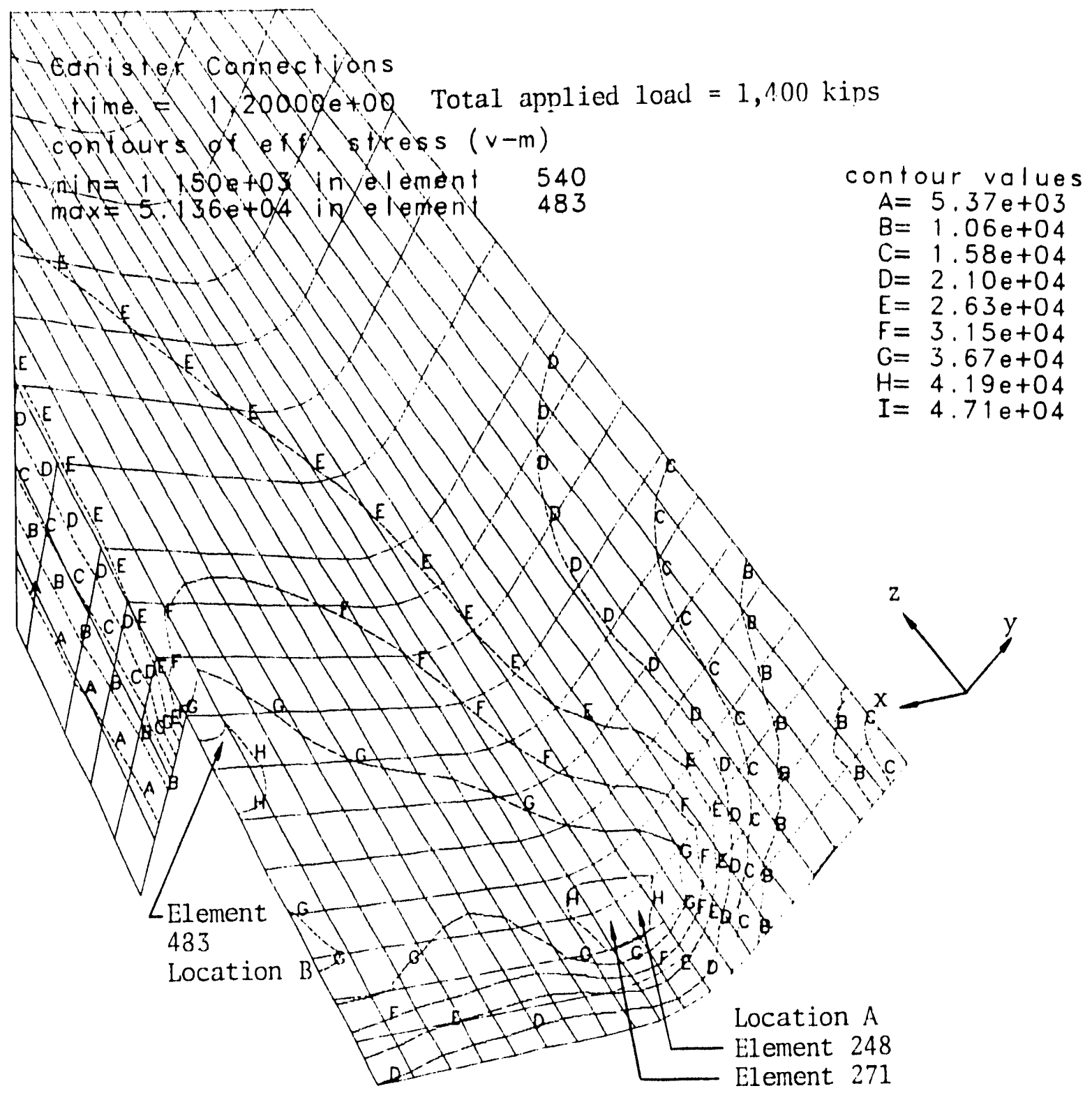

$1-3 / 8$ " bolts

100 kips preload

Figure 25. Typical contours of effective stress in the cable tray with door straps. 


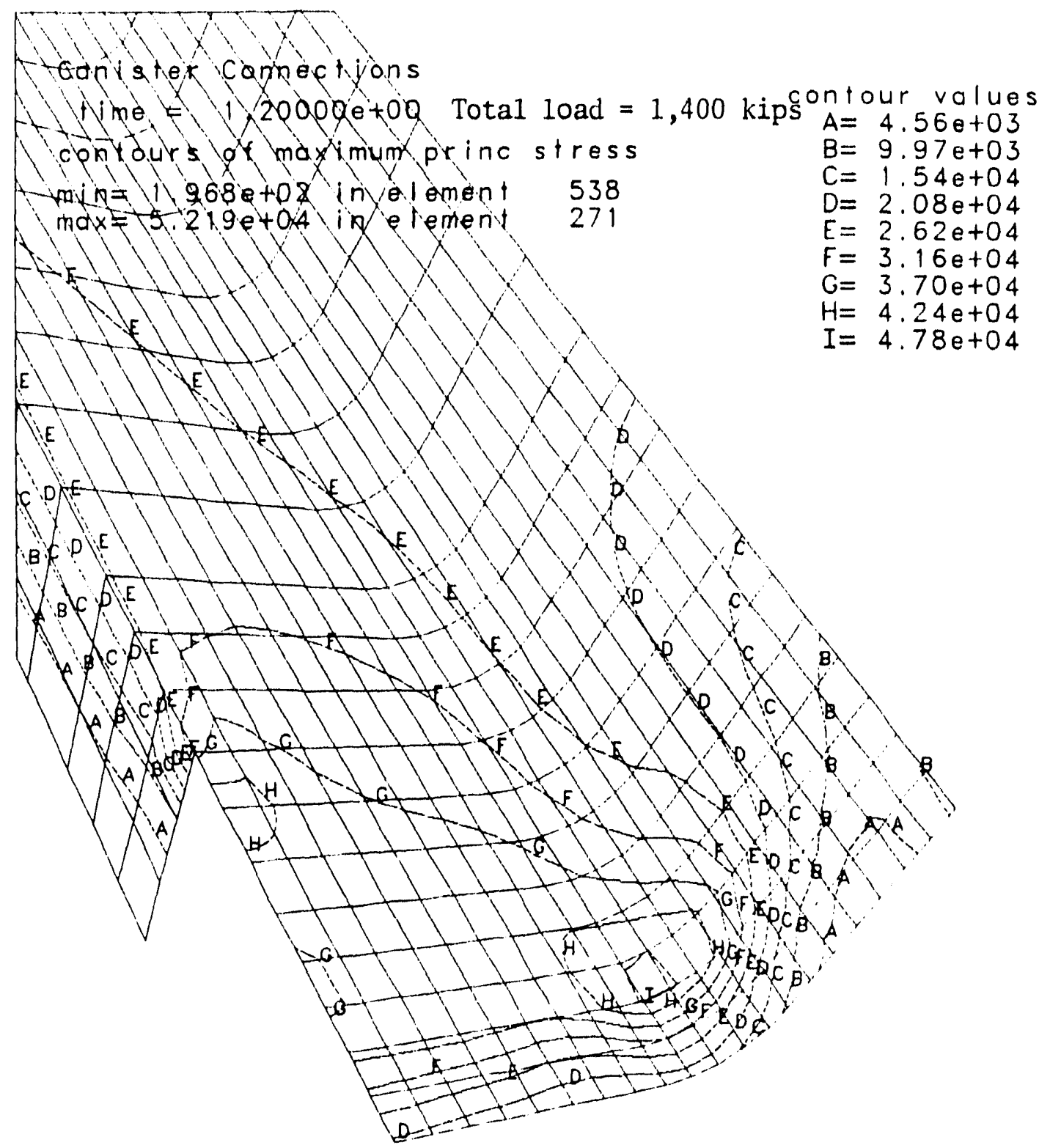

Figure 26. Typical contours of maximum principal stress in the cable tray with door straps. 


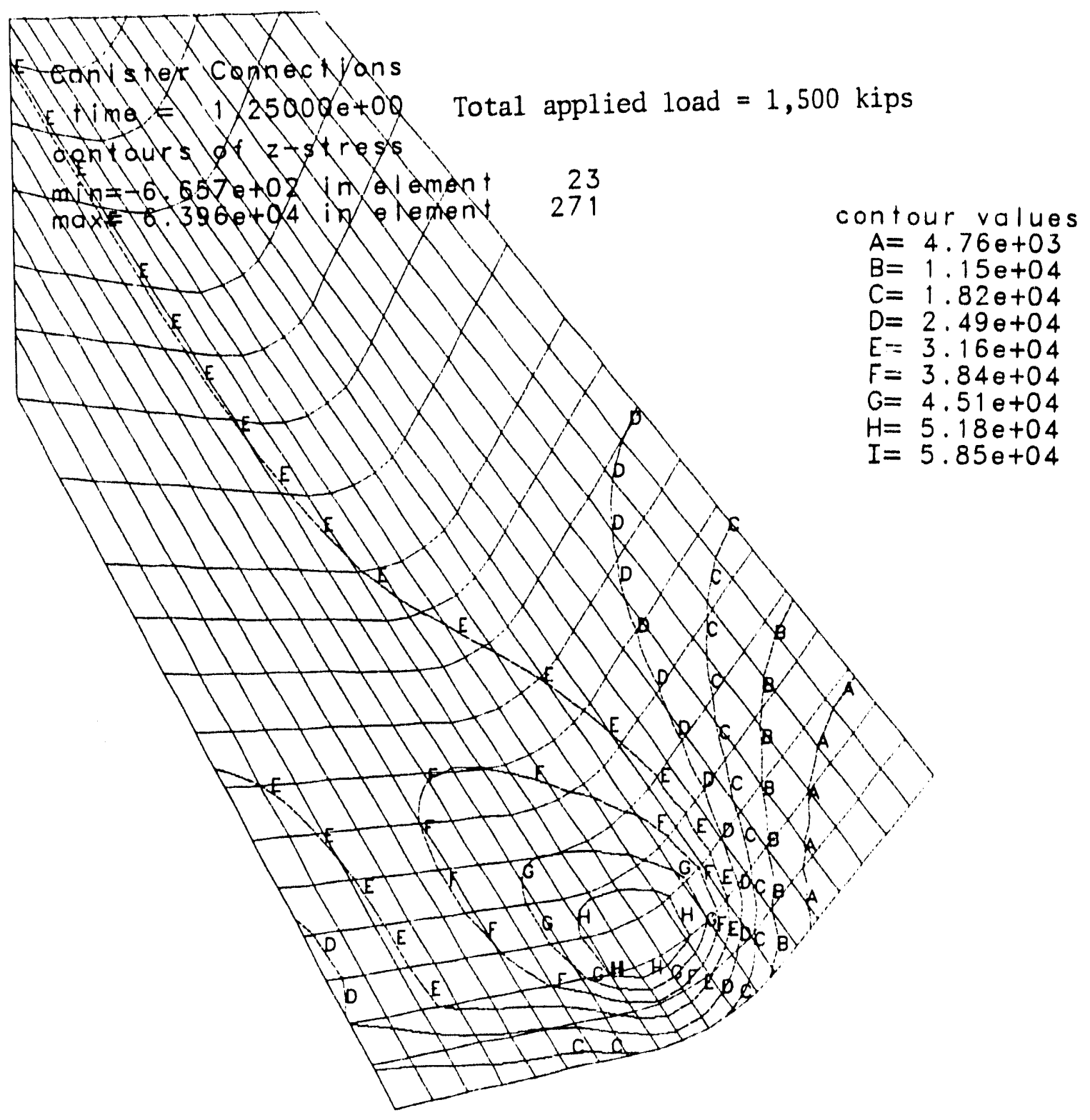

Figure 27. Typical contours of axial membrane stress (z-stress) in the cable tray without door straps. 


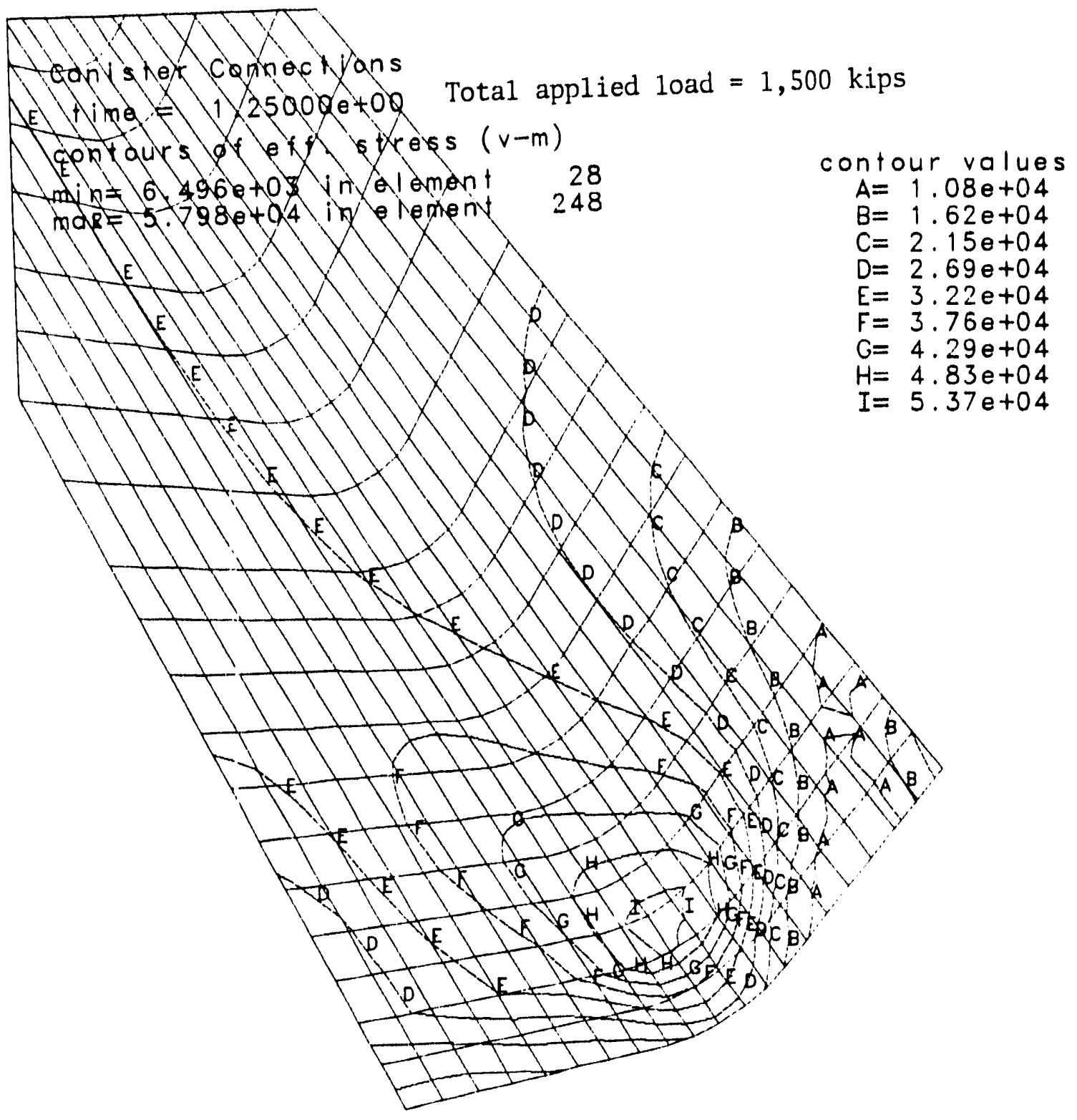

Figure 28. Typical contours of effective stress in the cable tray without door straps. 


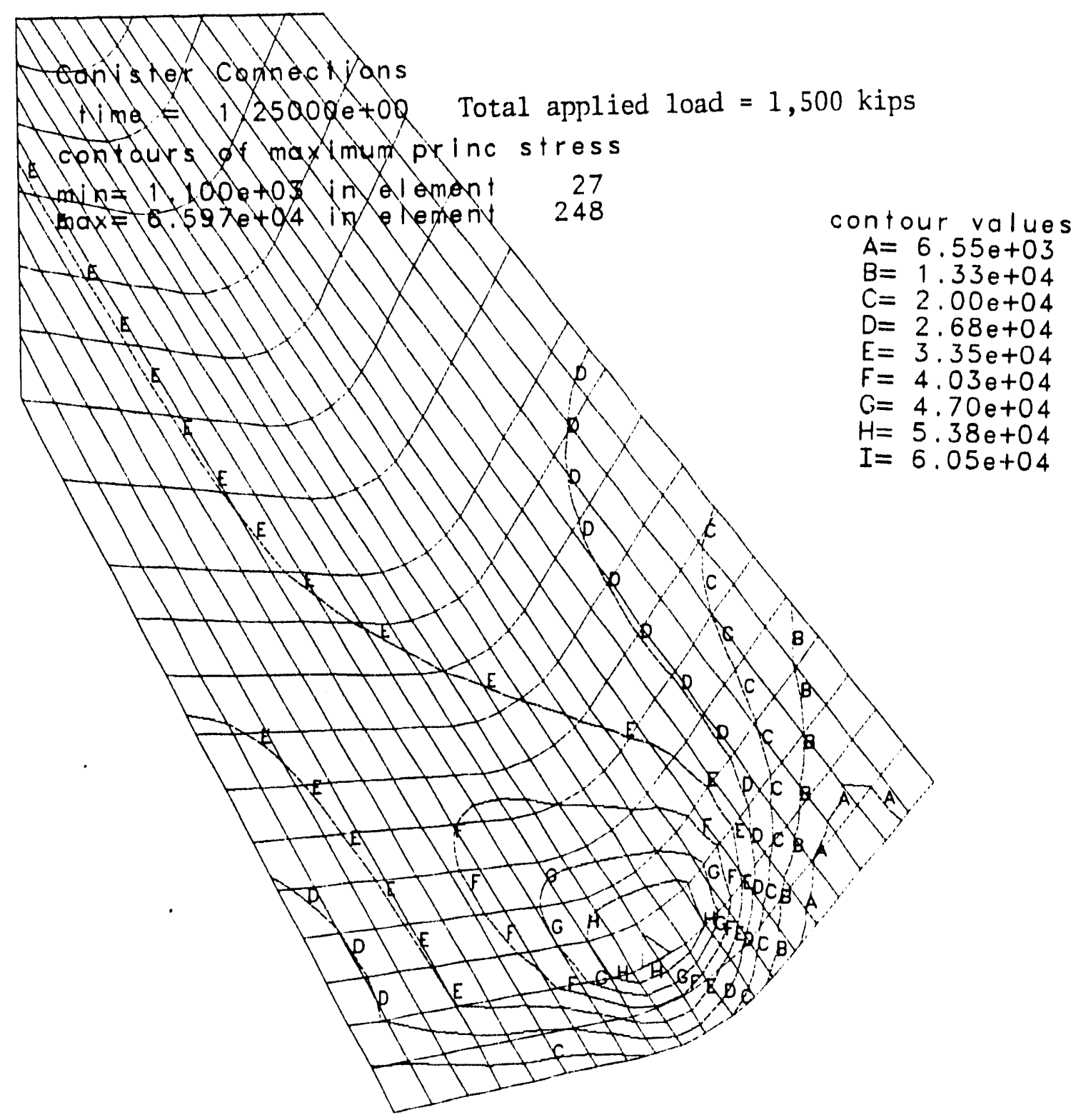

Figure 29. Typical contours of maximum principal stress in the cable tray without door straps. 


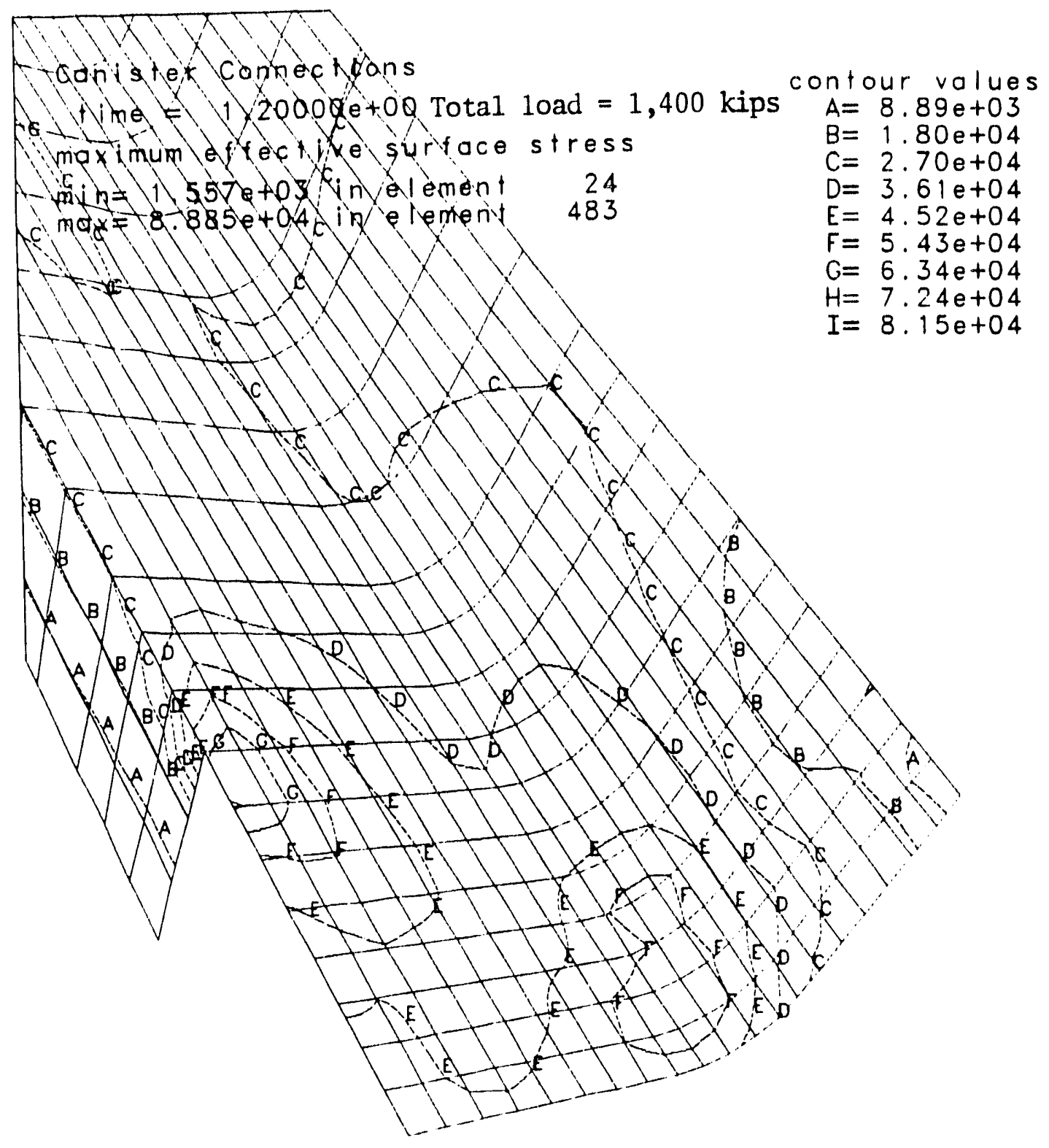

Figure 30. Typical contours of effective surface stress in the cable tray with door straps. 


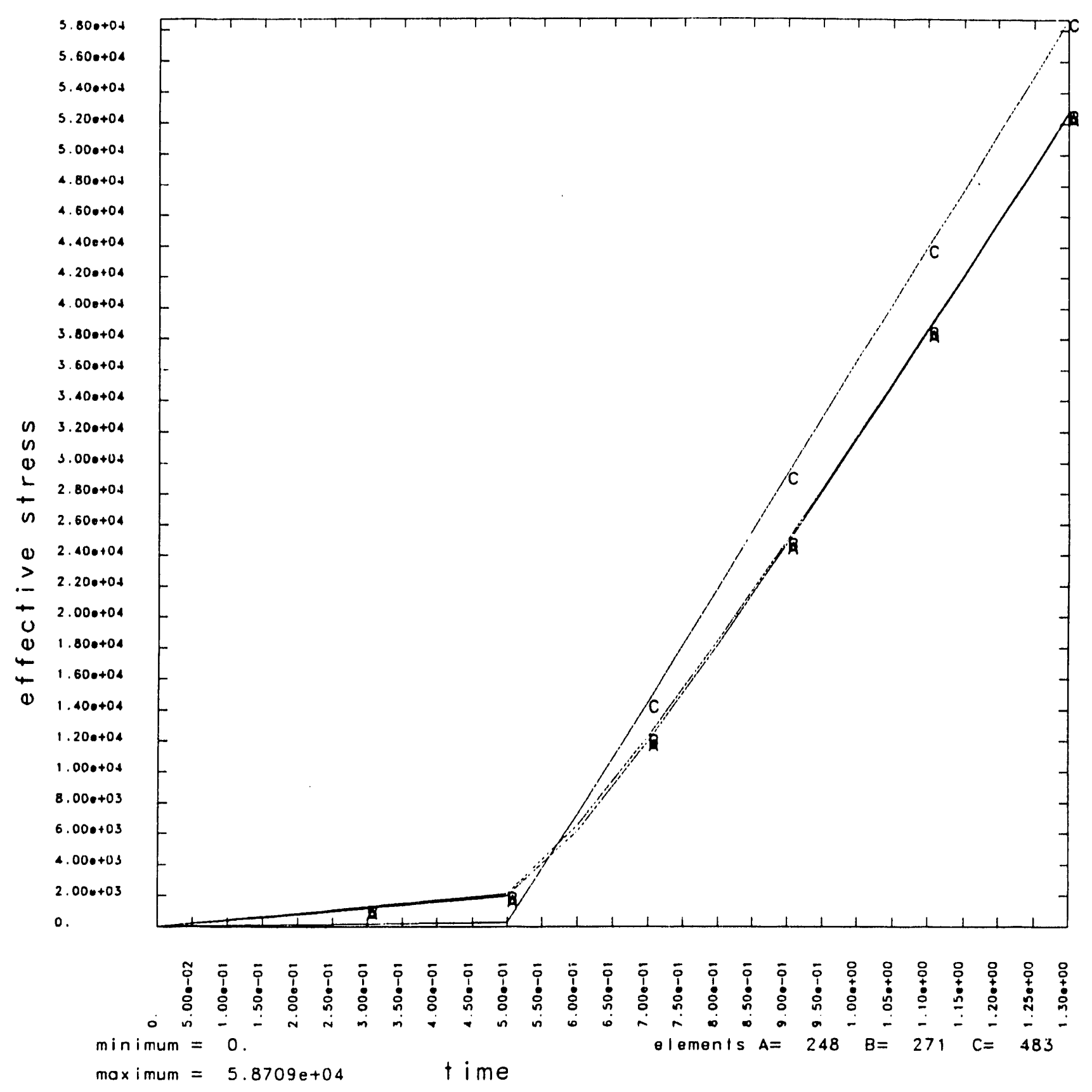

Figure 31. Effective stresses as functions of external load ("time") in the most highly loaded elements in the cable tray with door straps. 


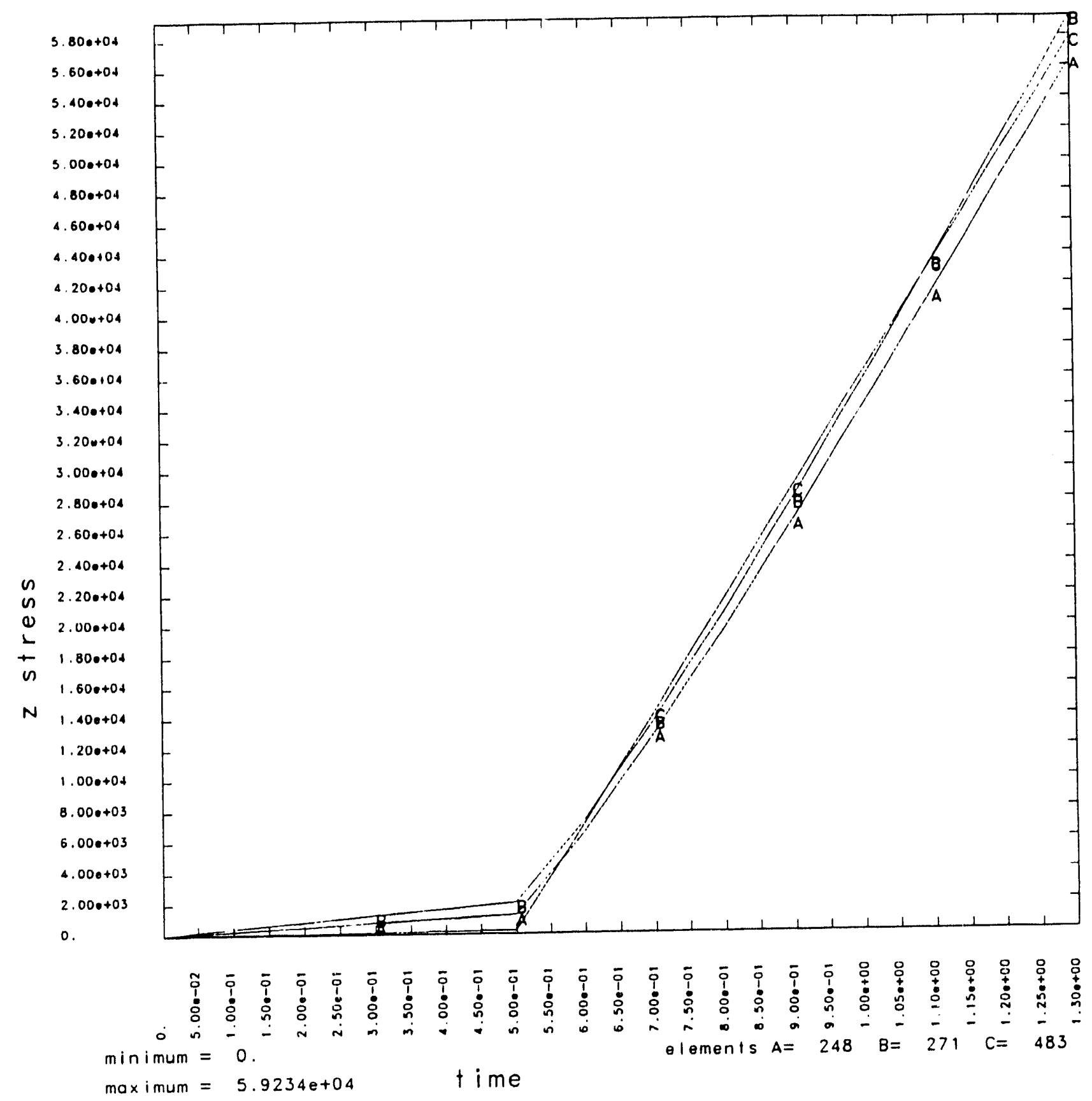

Figure 32. Axial membrane stress (z-stress) as a function of external load ("time") in the most highly loaded elements in the cable tray with door straps. 


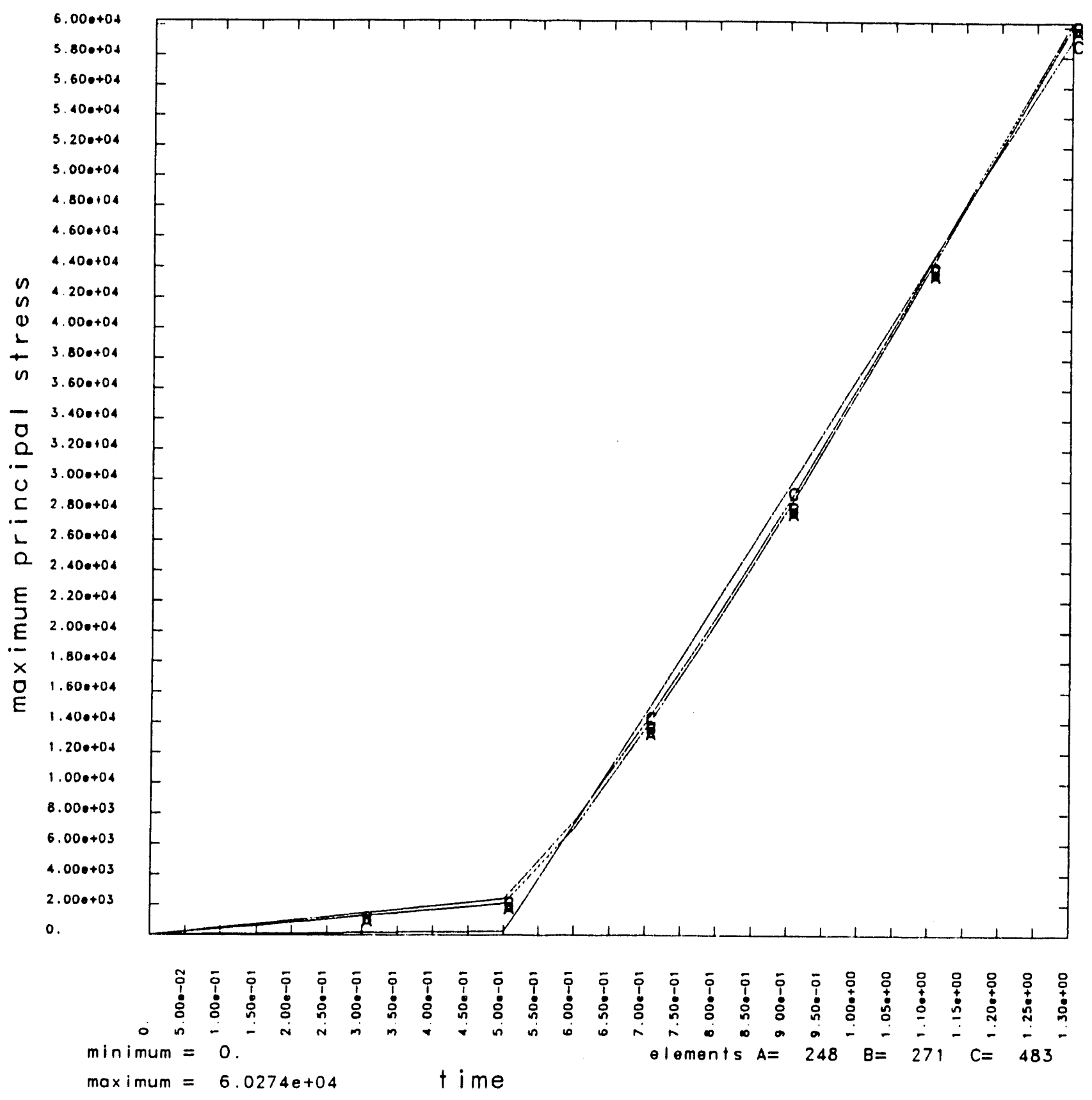

Figure 33. Maximum principal stresses as functions of external load ("time") in the most highly loaded elements in the cable tray with door straps. 


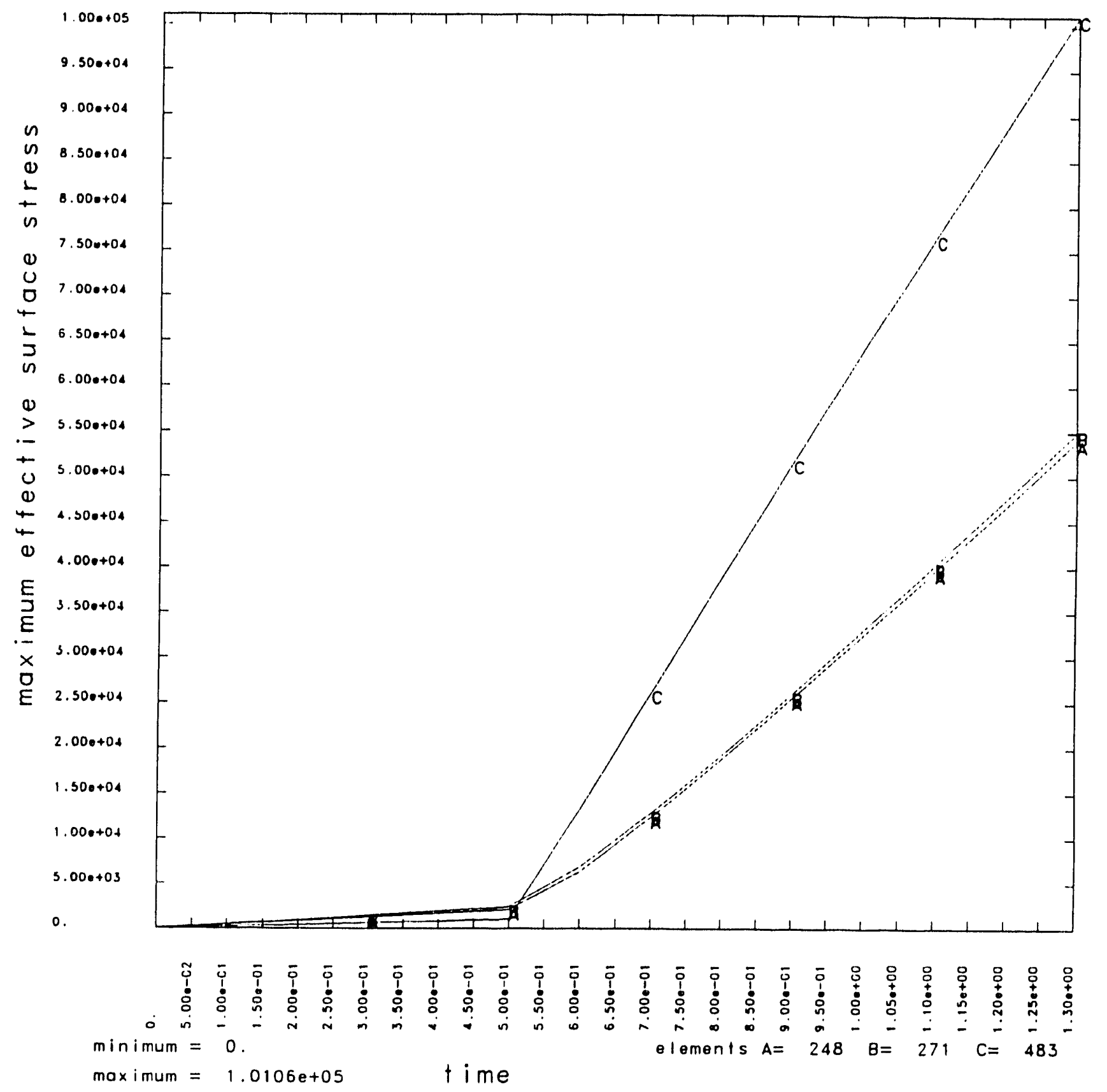

Figure 34. Maximum effective surface stresses as functions of external load ("time") in the most highly loaded elements in the cable tray with door straps. 


\subsection{FULL-SCALE PULL TEST OF CANISTER CONNECTIONS}

To validate the analysis presented in the previous sections, a full-scale pull test of canister frame bolts was conducted by a team of EG\&G personnel at a DOE horizontal load test facility (HLTF) in Las Vegas, Nevada. HLTF is described in Ref. 11. Two canister frames were bolted together back-to-back with sixteen SAE 1-3/8 - $6 \mathrm{Gr} .8$ bolts in a horizontal position. These canister frames have the same dimensions except for the length of the cable trays and the geometry of the end structures at two extreme ends of the assembly. From our experience in analyzing canister frames, these differences have little effect on the bolt loads. The thicknesses of the cable trays and the end plates are 0.50 and 2.25 inches, respectively.

A torque wrench, which was calibrated periodically in the shop, was used to preload the bolts. This test assembly was pulled at the two extreme ends in the opposite axial directions. The bolt loads due to the bending effect of the dead weight of the assembly is minimal and was neglected. Of the sixteen bolts, four bolts around a single cable tray were load-sensing bolts. These load-sensing bolts were designated as bolts \#23, \#24, \#25, and \#26. Bolts \#23 and \#26 are outer bolts; bolts \#24 and \#25 are inner bolts. Also, bolts \#23 and \#24 are on one side of the cable tray, while \#25 and \#26 are on the other side. The loads in these bolts were monitored during preload and during pull test.

Three levels of preload (approximately 75, 50, and 25 kips) were tested in sequence in descending order of magnitude. Each load-sensing bolt was loaded 25 kips above the desired preload before dropping back to the desired leve1. The objective of this exercise was to reduce the short-term preload relaxation generally observed in bolts. For each preload level, two to three pull tests were performed. In each pull test, the loading and unloading of the test assembly were done slowly to avoid dynamic effects. The load capacity of the load-sensing bolts is 100 kips. Unloading was manually set to start when the load in any of these load-sensing bolts reached this limit. The raw data of these tests was recorded as bolt load versus applied external axial load to the assembly for each of the 
load-sensing bolts. The data acquisition system used in this pull test is described in Appendix $A$ of this report.

The bolts follow clearly different load paths in the loading and unloading phases of the first pull test at each preload level. Some preload is apparently lost during this loading/unloading cycle. The first pull test seems to have gotten rid of most of the remaining short-term preload relaxation after the bolts were preloaded because the deviation of the unloading path from the loading path is very small for the second and the third pull tests. Three pull tests each were performed for 75- and 50-kip preloads. There is little difference in results between the second and the third pull tests. Repeatability was clearly achieved after the first pull test. Therefore, the third pull test was not performed for the case involving 25-kip preload. The results of the last pull test at each preload level are used in comparing test and analysis in this report. Because of the loss of preload in the first pull test, the preloads in these load-sensing bolts are slightly less than the prescribed value.

Figure 35 shows the results of the last pull tests for all three levels of preloads. The inner bolts carry a larger portion of the external load than the outer bolts as predicted in the analysis ( $\mathrm{Sec} .3)$. There is a slight difference in bolt loads on two sides of the cable tray because these canister frames are not perfect structures. Average inner and outer bolt loads were calculated for the corresponding bolts on either side of the cable tray and are presented in Fig. 36. Figure 37 shows a comparison of these averaged bolt loads from the test and the calculated bolt loads from the corresponding NIKE3D finite element analyses. Relevant parameters for the three finite element analyses are presented in Table 5. There is a good agreement between the test and analysis results. The maximum deviation of the calculated bolt load from the bolt loads obtained in the tests is less than $10 \%$ for all three preload levels and at all levels of applied external axial load.

The test results show less spread between the inner and the outer bolt loads than those obtained in the calculation. The difference between test and analysis results may be due to a slight deviation in the inner radius of the end plates considered in the analysis from that which actually existed in the test 
canisters. The end plate inner radius is 33 inches in the test canisters. It is 30 inches in the analysis.

As described in Sec. 3.2, there is no great incentive to prescribe high preload in component and vessel design except for the purpose of leak prevention and avoiding vibration loosening. This argument is also true for the design of canisters and is substantiated by Fig. 38 . Figure 38 is a plot of the total load in the 16 bolts as a function of the applied external axial load. This plot assumes that each cable tray carries one quarter of the applied external axial load. The total bolt load is always greater than the applied external load if there is preload in the bolts. The total bolt load is higher for higher preload.

To eliminate the slight difference in preloads between the test and analysis results, adjustments were made by shifting the curves shown in Fig. 35 up or down to the preloads used in the analysis. This adjustment would have been perfectly valid if these bolts were loaded separately in an axisymmetric situation without prying. For the bolts used in the canister frames, it is not a bad adjustment because the amount of shift in preload is minimum and the error introduced will not be significant. With this adjustment, Figs. 35, 36, and 37 are replotted and are shown in Figs. 39,40 and 41 , respectively. These new figures generally retain their original characteristics and the observations described earlier are still valid.

In summary, the pull tests validated the analysis presented in the previous sections because there is a good agreement between the test and analysis results. These pull tests also provided additional validation for the computer code NIKE3D, which has been used extensively in the past both inside and outside of LLNL. 
Table 5. Finite element models corresponding to the pull test cases.

\begin{tabular}{|c|c|c|c|c|c|c||}
\hline $\begin{array}{c}\text { Case } \\
\text { Number }\end{array}$ & $\begin{array}{c}\text { Model } \\
\text { Number }\end{array}$ & $\begin{array}{c}\text { Bolt } \\
\text { Size } \\
\text { (in.) }\end{array}$ & $\begin{array}{c}\text { Cable Tray } \\
\text { Thickness } \\
\text { (in.) }\end{array}$ & $\begin{array}{c}\text { End plate } \\
\text { Thickness } \\
\text { (in.) }\end{array}$ & $\begin{array}{c}\text { Preload } \\
\text { (kips) }\end{array}$ & $\begin{array}{c}\text { Include } \\
\text { Door } \\
\text { Straps? }\end{array}$ \\
\hline $15^{*}$ & 311 & 1.375 & 0.500 & 2.25 & 75 & no \\
\hline 16 & 313 & 1.375 & 0.500 & 2.25 & 50 & no \\
\hline 17 & 314 & 1.375 & 0.500 & 2.25 & 25 & no \\
\hline
\end{tabular}

* Same as Case 10 (Table 1) 


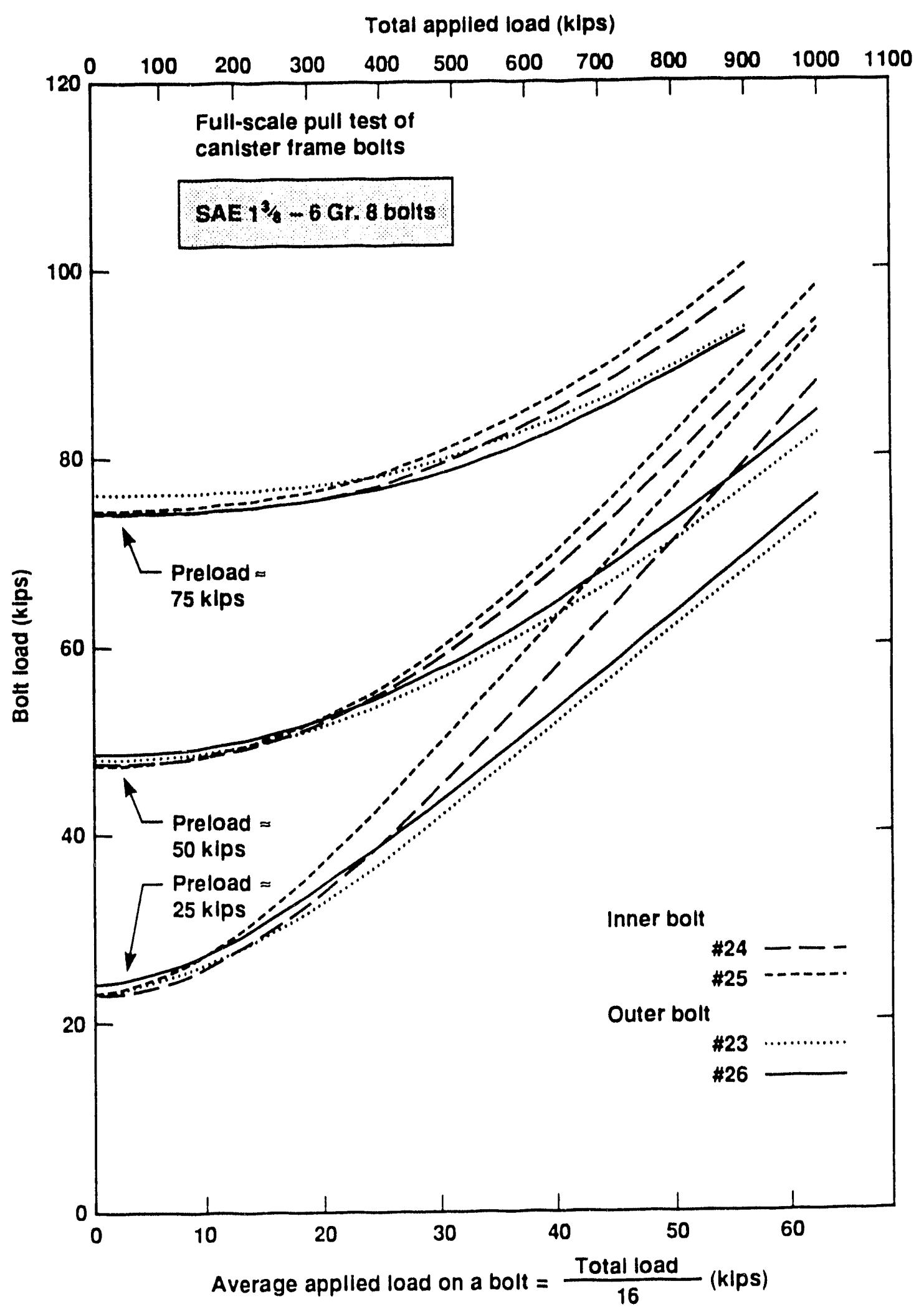

Figure 35. Bolt loads obtained in the full-scale pull test. 


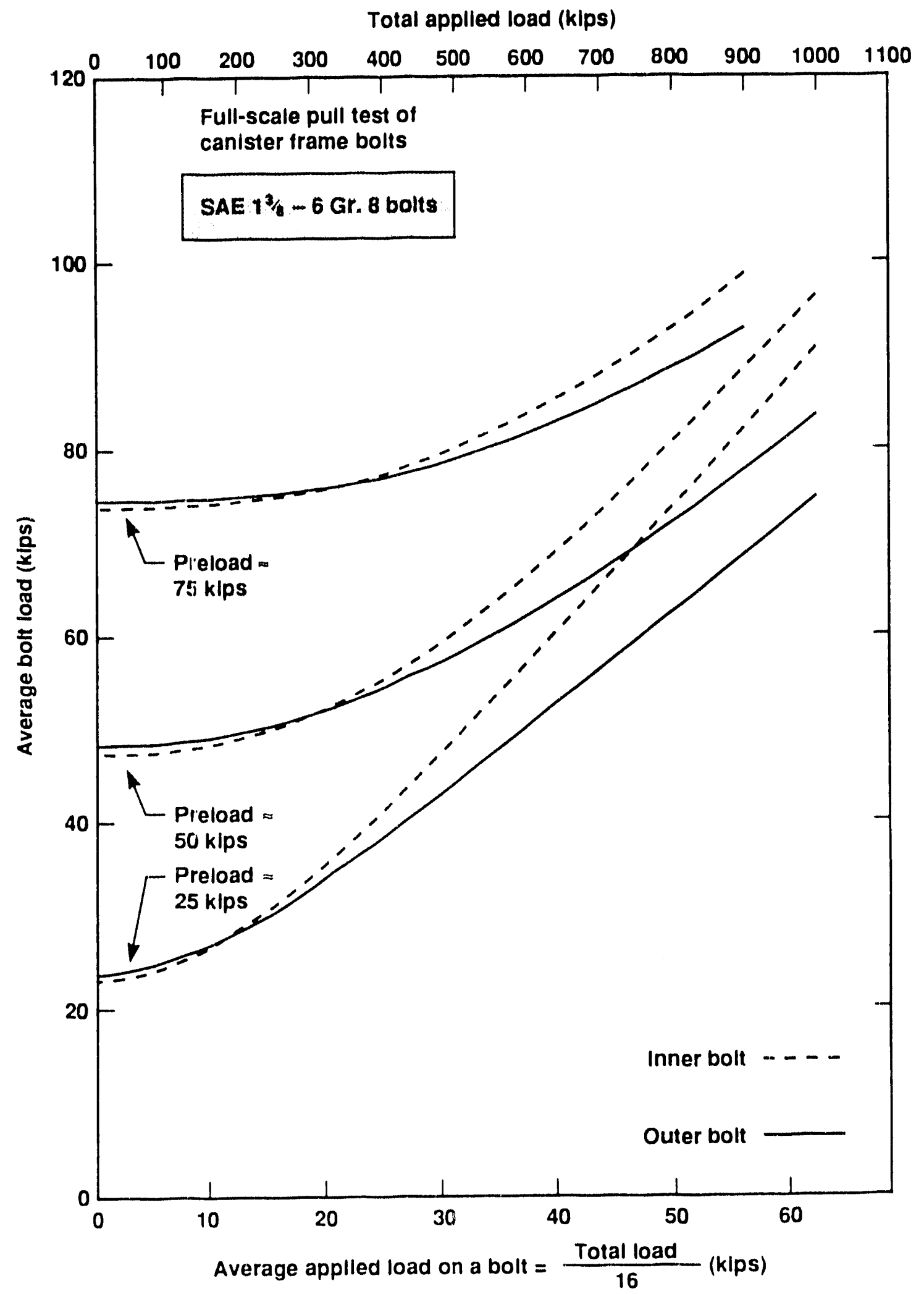

Figure 36. Average inner and outer bolt loads. 


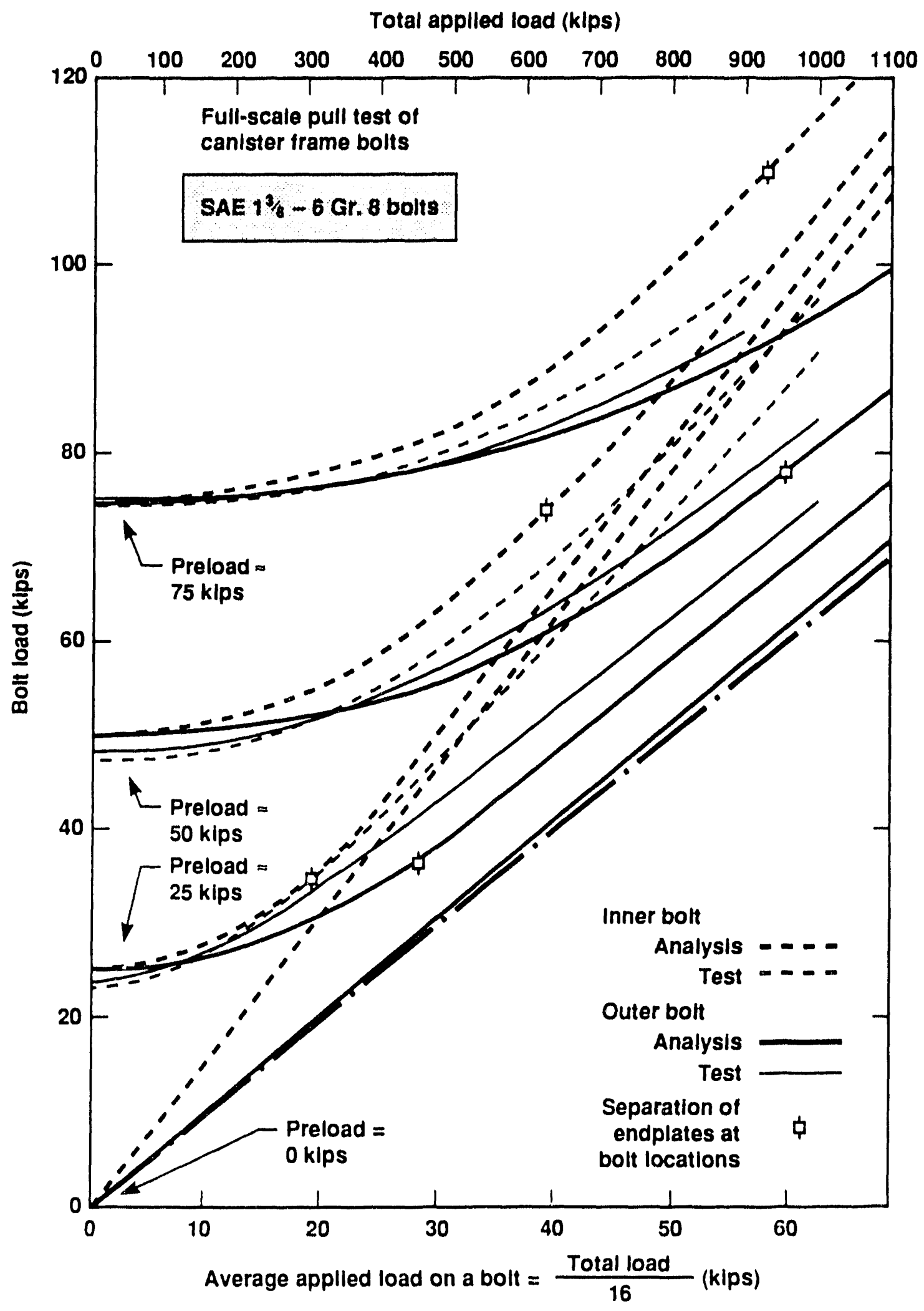

Figure 37. Comparison of test and analysis results. 
Total applled load (klps)

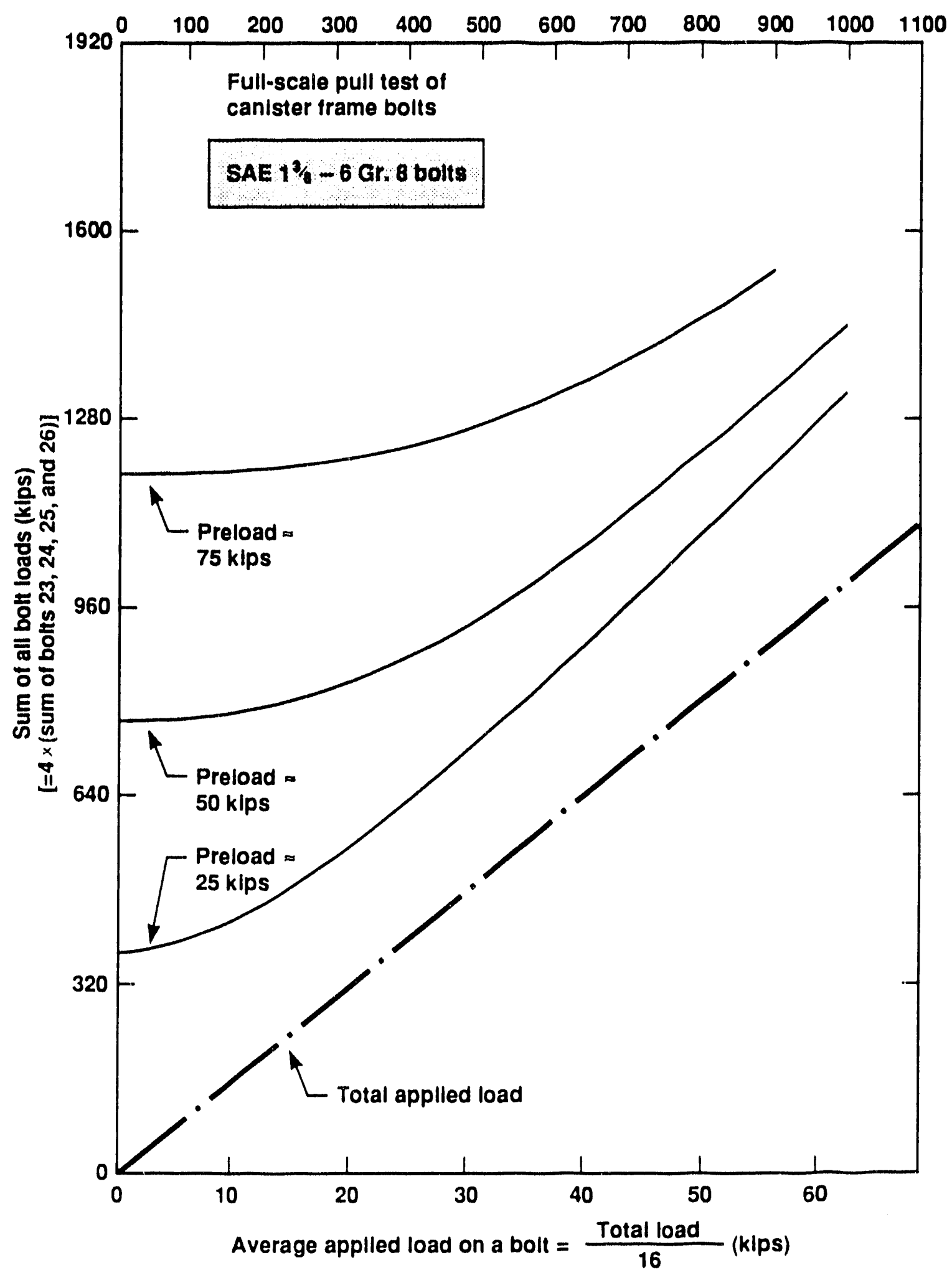

Figure 38. Sum of all bolt loads as functions 0 , the applied external axial load. 


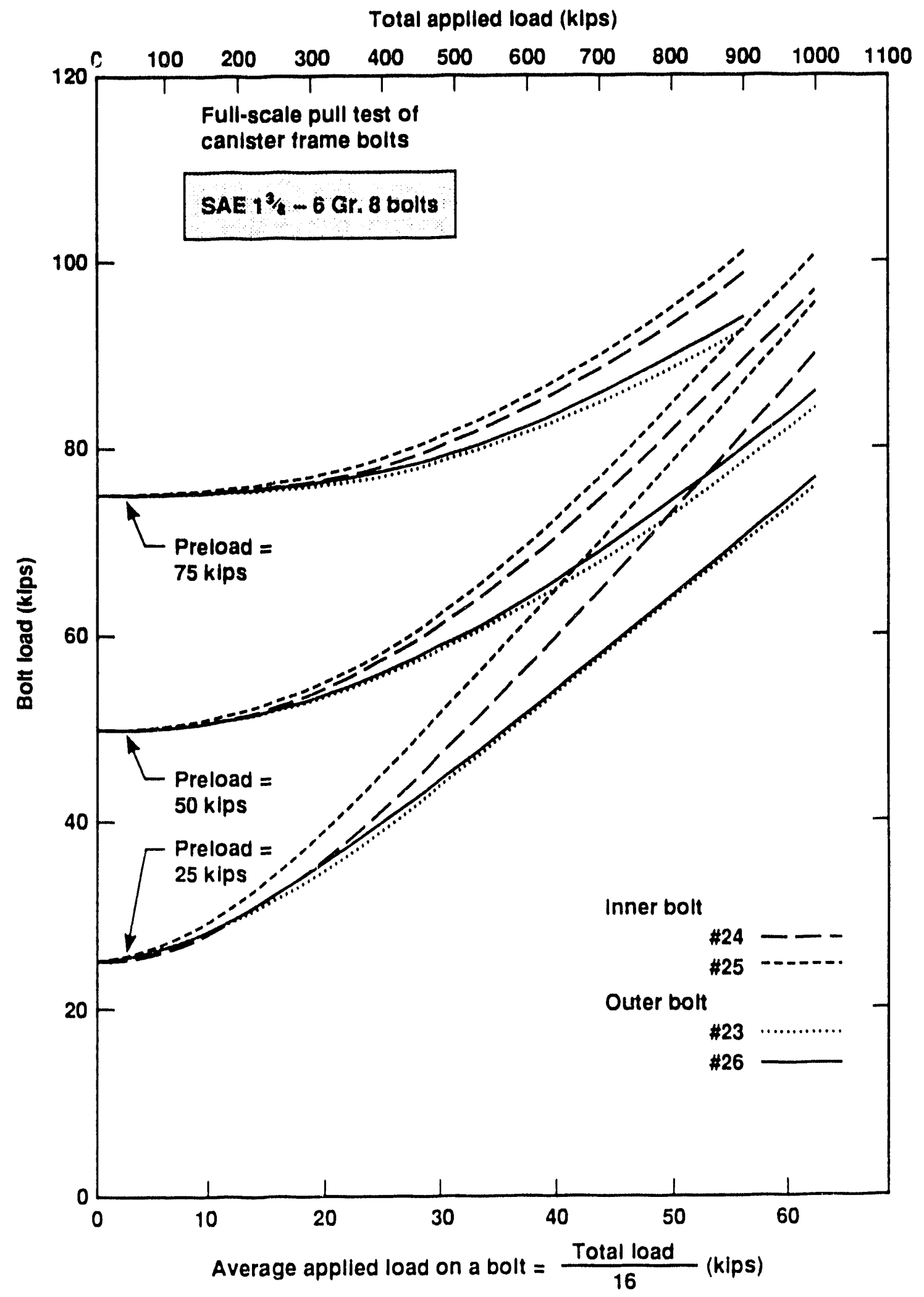

Figure 39. Bolt loads with adjustments in preload. 


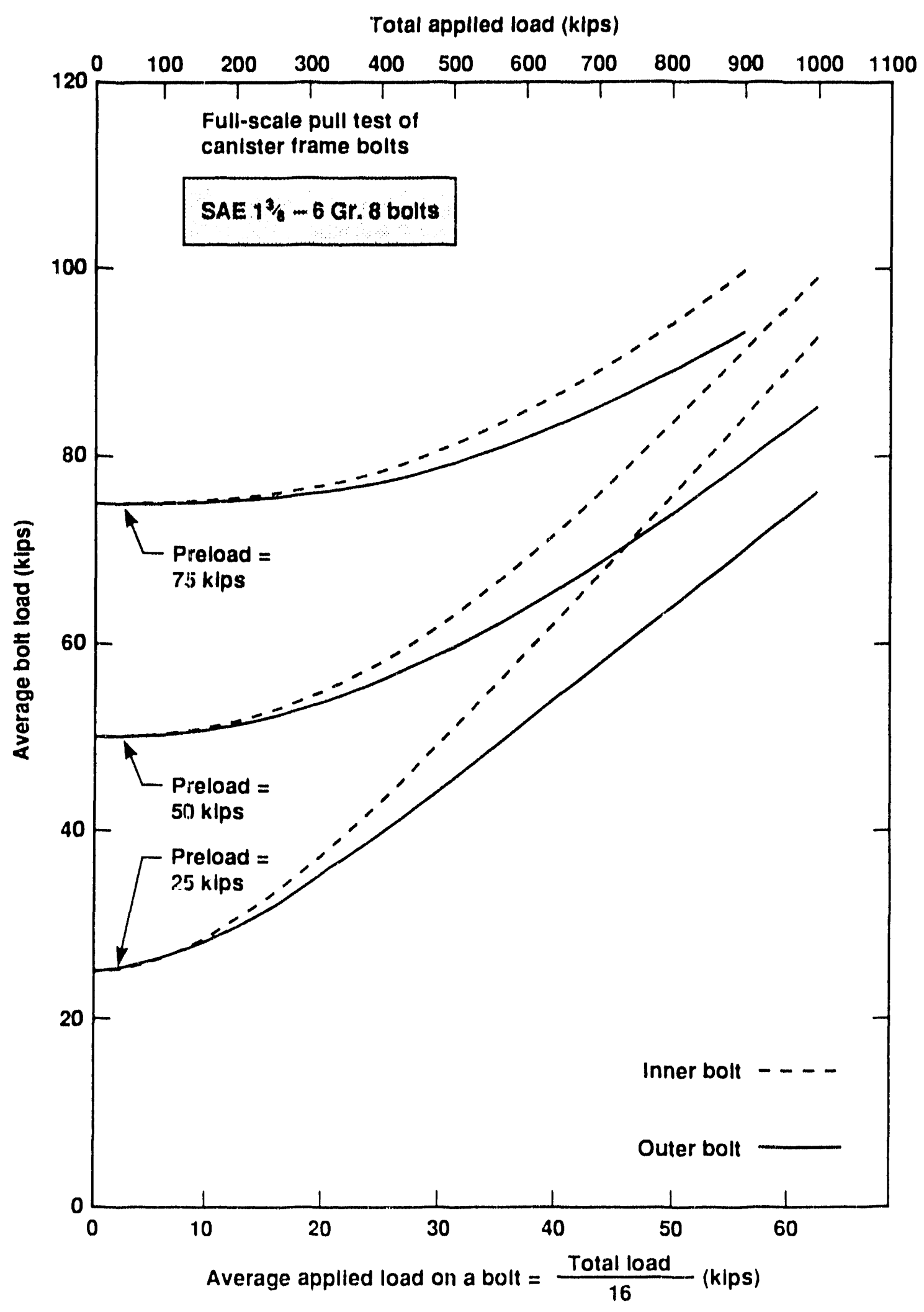

Figure 40. Average inner and outer bolt loads with adjustments in preload. 
Total applled load (kips)

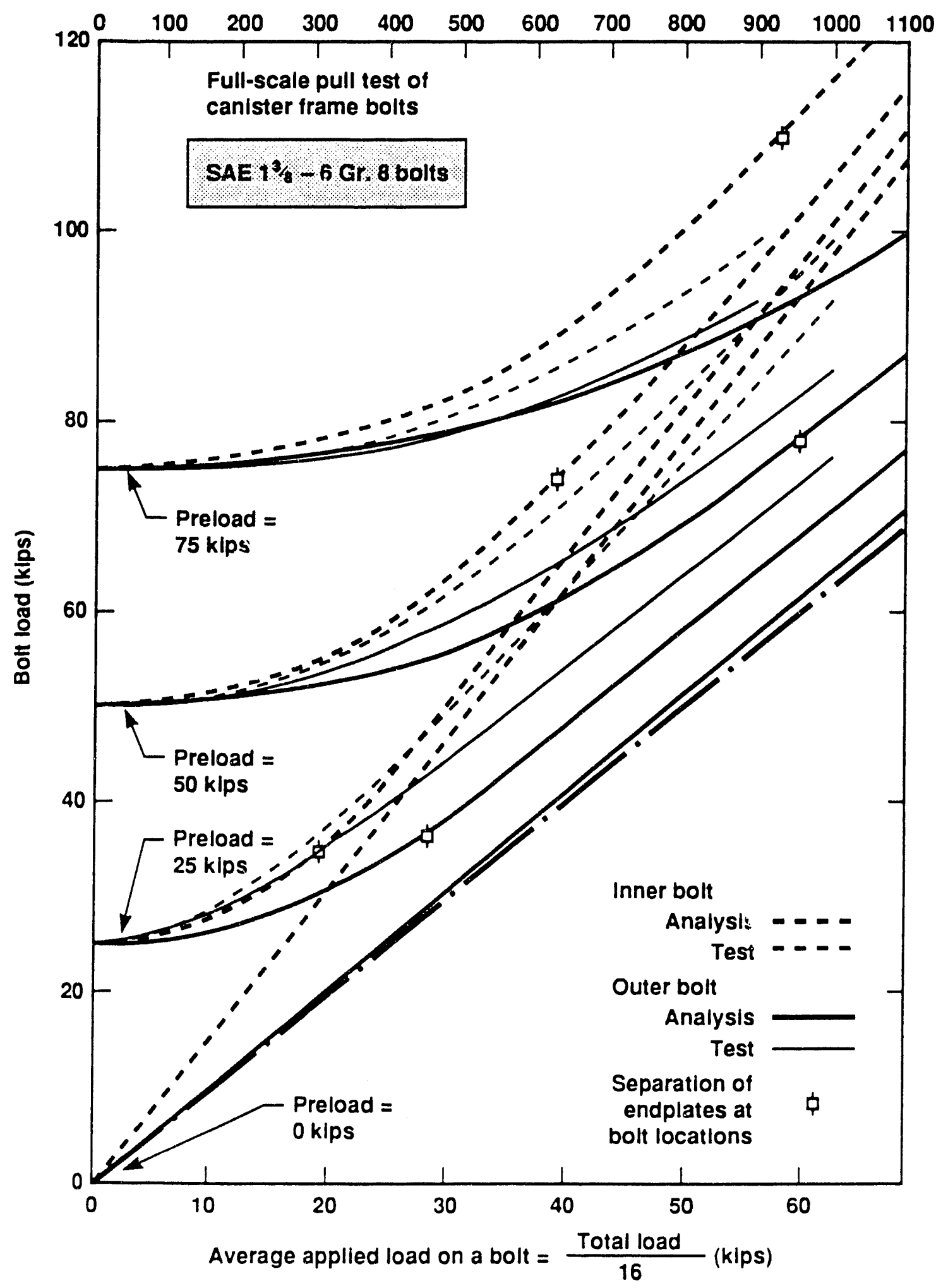

Figure 41. Comparison of test and analysis results (with adjustments in preload). 


\subsection{SUMMARY AND CONCLUSIONS}

This study provided needed insight into the bolt and canister frame design for the nuclear downhole emplacement assembly. Although the study was performed for 86-inch-diameter diagnostic canisters, the results are expected to be applicable to 68-inch-diameter canisters as well. The reason is that the results are mainly affected by the local geometries of the canister at the interface between the cable trays and the end plates including the connection bolts; and these local geometries are essentially the same for 86- and 68-inch-diameter canister frames. A few finite element analyses of a 68-inch-diameter canister frame are sufficient to provide needed validation.

The results of the finite element analysis indicated that the bolt load increases with the preload for any given external load. The results also showed that an uneven distribution of bolt loads exists between the inner and outer bolts due to the eccentricity in load path through the connections. The inner bolts carry more load than the outer bolts for the canisters included in this study. Preload generally does not improve the bolt loads and the cable tray stresses, but it does make the bolt loads between inner and outer bolts more equitable. However, operational considerations may require a certain amount of preload to prevent loosening of the bolts and excessive separation of the end plates. Readers are advised that the study documented in this report is for canister modules with cable tray thickness of 0.5 inches and end plate thickness of 2.25 inches. Although the overall behavior of canisters with different plate thicknesses is expected to be similar to the canister geometry studied, the actual stress values and local stress patterns may be significantly different. It is suggested that the effects of cable tray and end plate thickness be included in future studies.

Theoretically, different preloads can be applied to the inner and outer bolts to achieve equitable bolt loads. Applying different preloads is not needed if the door straps are included because the difference in bolt loads is rioi great in this case. This is especially true when some preload exists in the bolts. More equituble bolt loads can also be achieved if it is practical to move the bolt holes inward radially. 
Summation of all bolt loads at a canister interface is greater than the applied external load due to the combined effects of preload and prying. The prying is caused by the bolts being off-center from the cable tray flanges. As a result of the bending in the end plates, some bending moment also exists in the bolts due to the rotation of bolt heads.

Because the end plates are thick, they experience only low levels of stresses except in the regions between cable tray flanges and the bolt holes. There are two regions of high stresses in the cable trays. One is in the curved region between the flange and the web of the cable tray just above the end plate. The other is on the cable tray flange below the cut-off point of the door strap. This latter region of high stresses does not exist if door straps are not used. However, without the door straps, the stresses in the former region will be higher. The door straps also have the advantage of causing more even distribution in bolt loads by shifting the neutral axis of the cable tray radially outward.

Stress information for bolts, cable trays, and end plates is documented in this report. For a specific design, stresses such as primary membrane, primary bending, local membrane, local bending, or the combination of these stresses can be obtained. An evaluation of the design can be made in accordance with the NTED Design Guide or the existing codes such as the ASME B\&PV Code. The NTED Design Guide has the same design philosophy as the ASME Code in classifying stresses, such as primary vs. secondary stresses and membrane vs. bending stresses. The NTED Design Guide and the ASME B\&PV Code provide higher allowable values for the bending and secondary stresses than for the membrane and primary stresses, respectively.

The analytical study documented in this report is based on a finite element method using NIKE3D code. A full-scale test was carried out by a team of EG\&G personnel at a DOE facility in Las Vegas, Nevada to validate the analysis and the computer code used in the analysis. Two canister frames having the same end plate geometry and cable tray thickness were bolted together with sixteen bolts, four of which tray are load-sensing bolts around a single cable. Three levels of preload were tested. The applied axial load on the canister assembly and the bolt loads in these load-sensing bolts were monitored. There is a good agreement in 
bolt loads between the test and the finite element analysis. The maximum deviation is less than 10 percent for all preload levels tested. The agreement not only validated the analysis results presented in this report but also provided additional evidence about the validity of the LLNL computer code NIKE3D.

A couple of areas which were not included in this study but are important in the design of canister frames should be examined in the future. These areas are the weld integrity and the optimum type of canister-to-canister connection method. The current method of canister-to-canister connection produces high stresses in cable tray flanges and is not the optimum design. Other types of connections should be explored. Modifying current design, such as changing the locations and the number of bolts around the cable tray, provides a good starting point for this effort. 


\subsection{REFERENCES}

1. D.B. McCallen, "Stress Analys is of CONTACT Streak Camera Module/Upper Diagnostic Canister Connection," Lawrence Livermore National Laboratory, Livermore, CA, January, 1989.

2. J.0. Hallquist, "NIKE3D: An implicit, finite-deformation, finite element code for analyzing the static and dynamic response of three-dimensional sol ids," Lawrence Livermore National Laboratory, Livermore, CA, UCID-18822, July 1984.

3. M.A. Gerhard, "SLIC - the Interactive Graphic Mesh Generator," Lawrence Livermore National Laboratory, Livermore, CA, UCRL-52823, September 1985.

4. J.H. Bickford, An Introduction to the Design and Behavior of Bolted Joints, Marcel Dekker, Inc., New York, 1981.

5. N. Motosh, "Determination of Joint Stiffness in Bolted Connections," Journal of Engineering for Industry, Transactions of the ASME, August 1976.

6. G.H. Junker, "Rules for Design and Calculation of High-Duty Bolted Joints; Part 2: Determination of Facto:", in Main Design Formulae," SUB-ASSEMBLY Components - Fastening, England, Apri1, 1973.

7. Verein Deutscher Ingenieure (VDI, or Society of German Engineers), VDI Society for Design and Development, Committee on Bolted Joints, "VDI 2230: Systematic Calculation of High Duty Bolted Joints, "Translated by Language Services, Knoxville, Tennessee, ORNL-r-5055, October, 1977.

8. T. Lo and M.W. Schwartz, "Design and Analysis of the Closure Bolts of Shipping Casks," Lawrence Livermore National Laboratory, Livermore, CA, UCRL-ID-103851, May, 1990.

9. J.E. Shigley and L.D. Mitchell, Mechanical Engineering Design, 4th Edition, McGraw Hil1, 1983.

10. R.C. Juvinal1, Fundamentals of Machine Component Design, John Wiley \& Son, 1983.

11. NTED Design Guide," NTED89-119, Lawrence Livermore National Laboratory, Livermore, CA, Dated October 30, 1989. 


\section{Appendix A \\ Data Acquisition System}

Ful1-Scale Pull Tests of Canister Frame Connections 


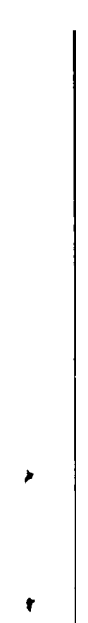




\section{¿ EGRG ENERGY MEASUREMENTS \\ Las Vegas Area Operations}

EG\&G ENERGY MEASUREMENTS, INC., P.O. BOX 1912, L.AS VEGAS, NEVADA 89125

TEL(702)

May 9, 1990

SM: $90 A-153$

Mr. Tony Davito

Lawrence Livermore National Laboratory

P.O. Box 808

Livermore, California 94550

SUBJECT: LOAD BOLT TEST DATA ACQUISITION SYSTEM

The following information is being provided, per the request of Ting Lo, for the Test Data Acquisition System used to record the load test performed on the load bolts at the ATLAS facility on 25 April 1990.

The data acquisition system consisted of an HP 3497A data acquisition unit, an HP 85 computer, and an HP 9895 floppy disk drive. The system was connected via an HPIB buss network. Gauge excitation was provided by two HP 6114A power supplies which were monitored by a Fluke 8860A DVM.

The 3497A was used as the input multiplexer and the system DVM. It was set to make five digit measurements with a resolution of one microvolt. The $3497 \mathrm{~A}$ monitored both the load bolt outputs and the bridge outputs of the Horizontal Load Test Facility. Once the measurements were made, the result.s were transferred to the HP 85 computer.

The computer stored the raw data trom the $3497 \mathrm{~A}$ on the disk. It also converted the raw data to engineering units and displayed the converted data on its CRT.

The software was developed by EG\&G Department 1262 for this test. It allowed for setting a tare on any and all data channels. The tare values once set were recorded on disk for use in data reduction. The software uses a value of $3 \mathrm{mV} / \mathrm{N}$ at $100 \mathrm{~K}$ lbs to convert from load bolt output to engineering units. This conversion factor was based on the manufacturer's calibration data.

The system was able to make one scan approximately every 1.5 seconds. One scan consisted of time and date, Bridge $A$ and Bridge B from the Horizontal Load Test Facility, and four load bolt channels. The data was recorded on floppy disk after each scan.

The data reduction software was also developed by EG\&G Department 1262 . It used an HP 7475A pen plotter to plot the results in a load vs load format. The plot routine has an autoscaling feature that will insure the data is displayed completely. It also has manual scaling capabilities so that a plot may be made with any scaling desired. 
Page /p

May 9, 1990

LOAD BOLT TEST DATA ACQUISITION SYSTEMY

If we can provide further assistance or additional information, please contact me at 702-295-2533.

Very truly yours, EG\&G Energy Measurements, Inc.

Daved Tammi

David C. Fannin, Tech. Supv.

Special Measurements

DCF : bae

Copies:

Ting Lo, L-197

G. Hill

L. Davies 

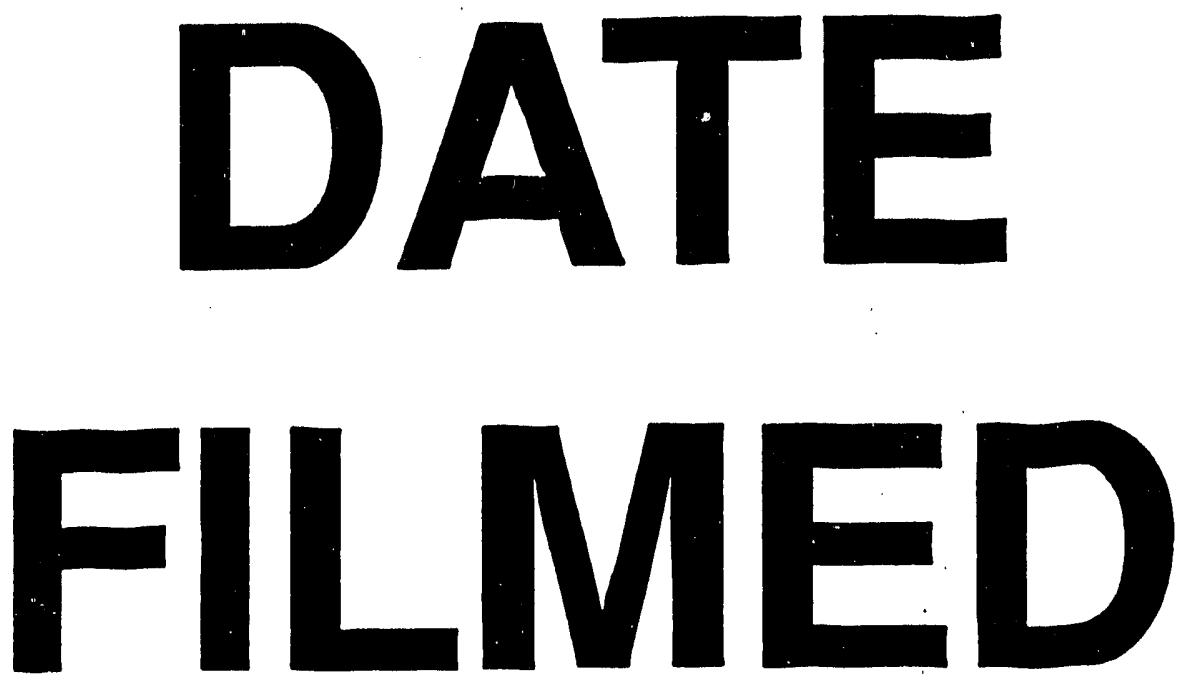

$12 / 22 / 93$
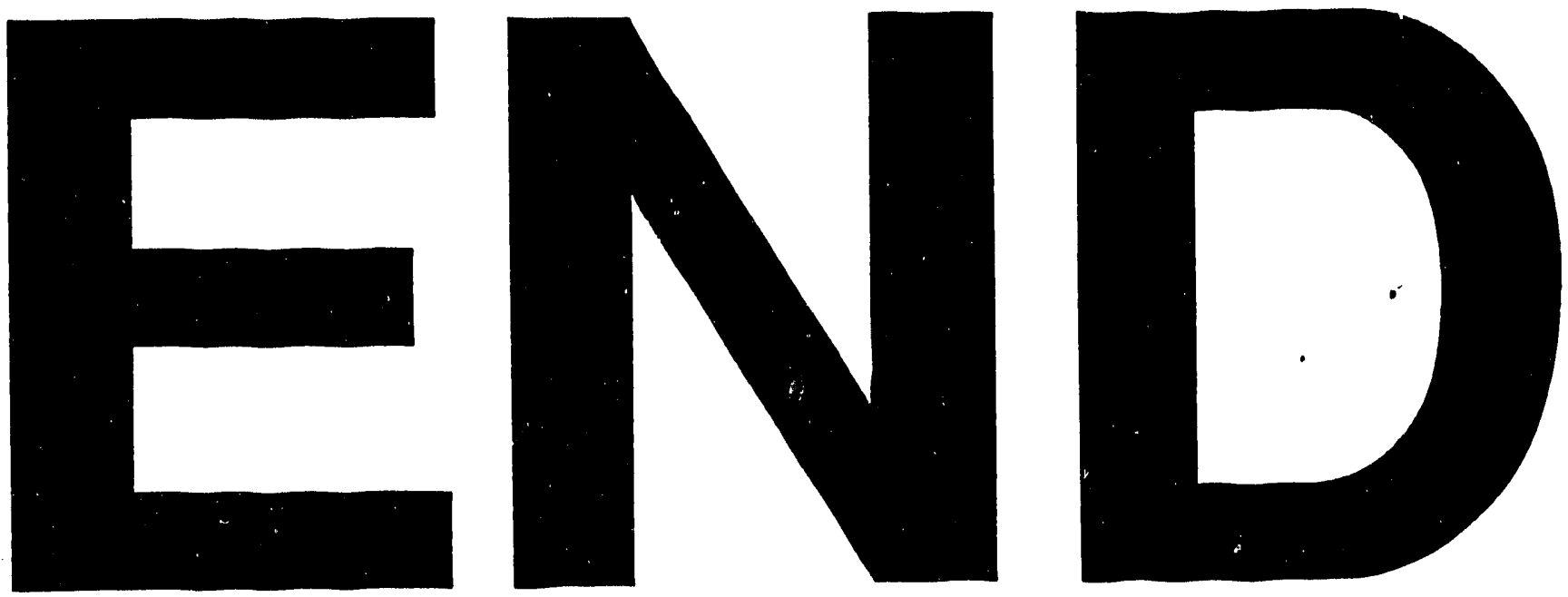
